This manuscript "The Effect of Ti on Ca-pv and Mg-pv phase stability" is a preprint manuscript uploaded to EarthArvix. It has been submitted to Physics of the Earth and Planetary Interiors and is under review. Subsequent versions may have different content. 


\title{
The Effect of Ti on Ca-pv and Mg-pv phase stability
}

\author{
Joshua M. R. Muir ${ }^{1}$, Feiwu Zhang ${ }^{2}$ \\ Institute of Geochemistry, Chinese Academy of Sciences, 99 West Lincheng Road, Guiyang, Guizhou 550081, \\ China
}

1 j.m.r.muir@mail.gyig.ac.cn

2 zhangfeiwu@mail.gyig.ac.cn (ORCID: 0000-0002-4979-0790)

\section{Abstract:}

Magnesium silicate perovskite in the form of bridgmanite (bdg) and Calcium silicate perovskite (Capv) have similar chemical structures and may mix into a single perovskite phase in the lower mantle which would have profound effects on many seismic properties. While we have previously found that this is unlikely to occur in pure bdg and ca-pv in this paper we examine whether phase mixing can be induced by Titanium.

We predict that even small amounts of Ti can cause significant increases in mixing of the two phases. Miscibility of the phases has a strong dependence upon how $\mathrm{Ti}$ is partitioned between the two phases before mixing and thus the source and history of introduced Ti is important in determining miscibility. We predict basalts, even those with heavy $\mathrm{Ti}$ enrichment (10\%), will not form a single phase in subducted slabs as their mixing temperatures remain above $2500 \mathrm{~K}$ for most compositions throughout lower mantle pressures. In pyrolytic mantle it is predicted that at shallow depths large amounts of $\mathrm{Ti}$ are needed to induce phase mixing ( $\sim 0 \% \mathrm{Ti}$ at $25 \mathrm{GPa}$ and geotherm temperatures) but less $\mathrm{Ti}$ is needed to induce mixing with depth ( $1 \%$ Ti at $125 \mathrm{GPa}$ and geotherm temperatures). Thus we predict that enriched Ti regions will see perovskite mixing near the bottom of the lower mantle. These mixed perovskite regions partition $\mathrm{Ti}$ out of unmixed regions and thus provide a mechanism for Ti enriched regions to form in the deep lower mantle. Both ferrous iron and the $\mathrm{Ca}: \mathrm{Mg}$ ratio are predicted to have 
a larger control on the mixing temperature of pyrolytic systems than $\mathrm{Ti}$, however. For $\mathrm{Ti}$ and $\mathrm{Ca}$ rich pyroxene megacrysts we find that they should become a single phase along a lower mantle geotherm at around 40-115 GPa depending heavily upon Ti and Ca concentration.

\section{Introduction:}

At depths beyond around $600-700 \mathrm{~km}$ perovskite $\left(\mathrm{ABO}_{3}\right)$ solutions will predominate in both ultra-mafic and mafic lithologies and control their physical attributes (O' Neill and Jeanloz, 1990, Irifune and Ringwood, 1993, Ono et al., 2004, Ono et al., 2005). In both typical lower mantle and in descending slabs this will predominately consist of two phases- bridgmanite (bdg) $\mathrm{MgSiO}_{3}$ and Calcium-Silicate Perovskite (Ca-pv) $\mathrm{CaSiO}_{3}$. Due to their similarity in chemical formula and structure at some point these two phases can dissolve into each other to form a single $\mathrm{Ca}_{x} \mathrm{Mg}_{1-\mathrm{x}} \mathrm{SiO}_{3}$ phase. Previous investigations (Armstrong et al., 2012, Fujino et al., 2004, Irifune et al., 2000, Vitos et al., 2006, Jung and Schmidt, 2011, Muir et al., 2020) have suggested that this is unlikely to happen with the pure phases but that the presence of other elements such as Fe and Ti may increase its likelihood.

One element that has been shown to instigate mixing is Ti (Armstrong et al., 2012). Various compositions of $\mathrm{CaSiO}_{3}, \mathrm{CaTiO}_{3}, \mathrm{MgSiO}_{3}$ and $\mathrm{MgTiO}_{3}$ were placed in laser-heated $\mathrm{DAC}$ and multianvils at pressures up $97 \mathrm{GPa}$ and temperatures up to $2400 \mathrm{~K}$ and then the phase determined with powder diffraction XRD. It was found that increasing the concentration of $\mathrm{Ti}$ and/or increasing the pressure increased the solubility of the two phases into one another. At $97 \mathrm{GPa}$ a 50:50 mixture of Ca-pv and bdg was found to be stable as a single phase at $2000 \mathrm{~K}$ with only $\sim 5 \% \mathrm{Ti}$, at $50 \mathrm{GPa}$ this single phase required $\sim 25 \% \mathrm{Ti}$ and at $25 \mathrm{GPa}$ single phases could be only formed with very high or low $\mathrm{Ca} \%$ values regardless of Ti content. With a 90:10 mixture of Ca-pv and bdg a single phase could be formed at $2000 \mathrm{~K}$ with $\sim 20 \% \mathrm{Ti}$ at $25 \mathrm{Gpa}, \sim 3 \% \mathrm{Ti}$ at $50 \mathrm{GPa}$ and $<1 \% \mathrm{Ti}$ at $97 \mathrm{GPa}$. These results suggest that regions of high Ti concentration in the low mantle are likely to possess a single Ca-pv + bdg phase and that as you descend into the mantle very little Ti\% is required to form a single phase. Pyroxene 
ilmenite megacrysts were found to be likely to exist as single phases below $45 \mathrm{GPa}$. Subducted Ocean Island Basalt (OIB) was predicted to convert into a single phase around 80-100 GPa whereas MORB and primitive mantle with lower Ti concentrations was predicted to remain as two phases all the way down to the D" layer.

This previous work does not explore the effect of temperature above or below $2000 \mathrm{~K}$ which is important in a thermally hetereogenous lower mantle and does not reach the pressures of the $D^{\prime \prime}$ layer. Thus in this work we shall seek to establish the miscibility of Ca-pv and bdg as a function of Ti concentration and temperature using Density Functional Theory (DFT). We shall examine two pressures- $25 \mathrm{GPa}$ as the top of the lower mantle and for comparison with Armstrong et al. (2012) and $125 \mathrm{GPa}$ as an extension of this work down to the $\mathrm{D}^{\prime \prime}$ layer. Once this has been established, we shall then use our results combined with a simple model to see how other non-Ti elements such as Al and Fe affect this miscibility and then speculate on the phase structure of Ti-rich parts of the lower mantle.

\section{Methods}

\subsection{General Method}

To determine whether two phases mix we simply need to determine the energy of the following reaction:

${ }_{z C a S i} \mathrm{Ti}_{1-x} \mathrm{O}_{3}+(1-z) M g S i_{y} \mathrm{Ti}_{1-y} \mathrm{O}_{3} \rightarrow \mathrm{Ca}_{z} M g_{1-z} \mathrm{Si}_{z x+(1-z) y} \mathrm{Ti}_{1-(z x+(1-z) y)} \mathrm{O}_{3}$ Reaction 1

3 different variables are present in the above reaction but $\mathrm{x}$ and $\mathrm{y}$ are related by the partitioning of $\mathrm{Ti}$ between the two initial phases. Thus we shall refer to two variables: Ca\% which is $[\mathrm{Ca}] /([\mathrm{Ca}]+[\mathrm{Mg}]) * 100$ and $\mathrm{Ti} \%$ which is $[\mathrm{Ti}] /([\mathrm{Ti}]+\mathrm{Si})) * 100$ and thus represent $\mathrm{z}$ and $1-(\mathrm{zx}+(1-\mathrm{z}) \mathrm{y})$ in

\section{Reaction 1.}

The energy of this mixing reaction can be represented by:

$G_{\text {Mix }}=H_{\text {Mix }}-T S_{\text {Mix }}$ Equation 1

where $H_{\text {mix }}$ is the enthalpy of mixing, $T$ is the temperature, $S_{\text {mix }}$ is the entropy of mixing and $G_{\text {mix }}$ is the free energy of mixing. Mixing will occur when $G_{\text {mix }}$ is negative. $S_{\text {Mix }}$ will be broken into two 
components- $\mathrm{S}_{\text {vib }}$ a component representing vibrational entropy and $\mathrm{S}_{\text {config }}$ a component representing configurational entropy. $G_{\text {mix }}$ will then be determined in two parts. $H_{\text {mix }}$ and $S_{\text {vib }}$ will be determined through molecular dynamics (MD) calculations and $\mathrm{S}_{\text {config }}$ will be determined through static calculations.

To determine mixing over an array of conditions we ran calculations at various points and extrapolated between them. For the molecular dynamics portions we ran calculations at 25 , and $125 \mathrm{GPa}$ and at 1000, 2000 and $3000 \mathrm{~K}$. All pressures are uncorrected. Energies were determined at $\mathrm{Ca} \%=0,25,50$ and 100 and $\mathrm{Ti} \%=0,25,50$ and 100 . To calculate $\mathrm{G}_{\text {mix }}$ at any arbitrary $\mathrm{T}, \mathrm{P}, \mathrm{Ti} \%$ and $\mathrm{Ca} \%$ we then used the following scheme. First at each pressure point ( 25 and $125 \mathrm{GPa}$ ) and each Ti\% and Ca\% we calculated $\mathrm{G}$ of the products and the reactants as a function of $\mathrm{T}$. We then fit polynomials as a function of $T$ and determined the $G$ of the products and the reactants at the $T$ of interest. We then fit polynomials as a function of $\mathrm{Ca} \%$ and then pressure and calculated $\mathrm{G}_{\text {mix }}$ at the appropriate $\mathrm{Ti} \%, \mathrm{Ca} \%$ and pressure in this order.

The fits across $\mathrm{P}$ and $\mathrm{T}$ are relatively linear and are likely reliable. As shown in Figure $\mathrm{S} 1$ fits across $\mathrm{Ca} \%$ are also likely reliable. As shown in Muir and Zhang 2020 fitting across Ca\% with a solid solution model does not vary results significantly and statistical errors in the molecular dynamics are more important. These calculations give us 2 pressure points which we use to calculate the effect of pressure at the top and bottom of our range. To explore a pressure range we use some assumptions which will be discussed in the results section of the manuscript.

\subsection{Computational Details}

For these calculations we used the VASP code (Version 5.4.4) (Kresse and Furthmuller, 1996b, Kresse and Furthmuller, 1996a). This is a density functional theory approach where planewave pseudopotentials are used to simulate supercells which represent infinite crystals. The PBE (Perdew et al., 1996) exchange correlation functional was used alongside the included VASP PAW potentials (Kresse and Joubert, 1999). The valence electron shells used were Ca: 3s, 3p, 4s; Mg 3s, 3p; Si 2s, 2p; 
O 2s, 2p; Ti 3p, 4s, 3d. Two different sets of calculations were performed, static and molecular dynamics. Static calculations had planewave cutoffs of $850 \mathrm{eV}$, k-point grids of $4 \times 4 \times 4$ in a Monkhorst Pack grid (Monkhorst and Pack, 1976). Energies were relaxed to within $10^{-5} \mathrm{eV}$ and forces between atoms were relaxed to below $10^{-4} \mathrm{eV} / \AA ̊ \AA$. For molecular dynamic runs the gamma point was used with cutoffs of $600 \mathrm{eV}$ and relaxed to within $10^{-4} \mathrm{eV} .80$ atom unit cells were used $(2 \times 2 \times 1)$ except for the configurational entropy as noted below. Vibrational entropy was determined by applying a VelocityAutocorrelation function to molecular dynamics runs while configurational entropy was calculated by determined the relative enthalpy of all arrangements of $\mathrm{Ca}$ and $\mathrm{Mg}$ (on the $\mathrm{A}$ site) and $\mathrm{Ti}$ and $\mathrm{Si}$ (on the B) in 40 atom unit cells and then calculating the Gibbs entropy. Further details on this are given in the supplementary methods.

\subsection{Phases:}

Multiple different structures are possible in this system. $\mathrm{MgSiO}_{3}$ is usually in the orthorhombic pbnm spacegroup (Zhang et al., 2013) while $\mathrm{CaSiO}_{3}$ is in the cubic pm3m or the tetragonal i4mcm spacegroup (Stixrude et al., 2007, Sun et al., 2014). All systems (end members and mixtures) were calculated in all 3 of these possible structures. All extrapolations across Ca\%, Ti\% and temperature were done for all 3 symmetry structures and then at any specific composition and temperature point the lowest energy structures was chosen. We find that $\mathrm{Ti}$ does not change the preferences seen for Ti-free systems (Muir et al., 2020)- ie Mg end members and mixed phases exist as pbnm structures, Ca end members as $14 \mathrm{mcm}$ and $\mathrm{pm} 3 \mathrm{~m}$ structures with $\mathrm{pm} 3 \mathrm{~m}$ structres favoured by high temperatures. To determine phase loops we plotted the energy of the unmixed and mixed phases as a function of $\mathrm{Ti}$ either between Ti\% 0-0.5 or between $0.5-1$, fit them to polynomials and then found the common tangent between them.

\section{3. $\quad$ Results}

\subsection{Compositions}


In this work we shall examine how varying the $\mathrm{Ca}$ and the Ti content of bridgmanite (bdg) and Calcium silicate perovskite (Ca-pv) mixtures varies their solubilities. We shall thus define two terms Ca\% which is $(\mathrm{Ca} /(\mathrm{Mg}+\mathrm{Ca})) * 100$ and $\mathrm{Ti} \%$ which is $(\mathrm{Ti} /(\mathrm{Ti}+\mathrm{Si})) * 100$. Both of these values can have a wide range in the lower mantle. Ca\% can vary for basaltic compositions between $40=60 \%$ (Hirose et al., 2005, Hirose and Fei, 2002, Irifune and Tsuchida, 2007, Ricolleau et al., 2010), for harzburgitic compositions between 1-3\% (Ringwood, 1991, Michael and Bonatti, 1985), for orthopyroxene ilmenite megacrysts (OMC) between $5-10 \%$, for clinopyroxene ilmenite megacrysts (CMC) between 20-40\% (Dawson and Reid, 1970, Ringwood and Lovering, 1970, Gurney et al., 1973, Frick, 1973, Rawlinson and Dawson, 1979, Williams, 1932) and for pyrolytic compositions between 6-12\% (Kesson et al., 1998, Irifune and Tsuchida, 2007, Mattern et al., 2005, Ringwood, 1991),. In this work we shall set $\mathrm{Ca} \%=50$ as an average basalt, $\mathrm{Ca} \%=10$ as an average pyrolite, $\mathrm{Ca} \%=5$ as an average $\mathrm{OMC}$ and $\mathrm{Ca} \%=30$ as an average $\mathrm{CMC}$ but shall discuss other possibilities.

Ti\% also has significant variation. Ti\% in the overall mantle is low ( 0.2\%) (McDonough and Sun, 1995) and is expected to be similar in the pyrolytic lower mantle (Harte, 2010). Regions of high Ti enrichment exist, however. Subducted slabs can in some cases descend to the CMB (Fukao et al., 2001) and basaltic compositions can contain considerable Ti. Mid Ocean Range Basalts (MORB) with Ti\% up to 3\% have been observed (Hirose and Fei, 2002, Gale et al., 2013) and in Ocean Island Basalt (OIB) Ti\% up to $1 \%$ have been observed (Armstrong et al. 2012, GEOROC database (http://georoc.mpchmainz.gwdg.de/georoc/)). While pyrolite is expected to have low Ti, the presence of subducted diamonds with high amounts of $\mathrm{Ti}(\mathrm{Ti} \% \sim 2-7 \%$ ) has been interpreted as the products of retrograde unmixing of former bridgmanite (Thomson et al., 2014, Walter et al., 2011, Zedgenizov et al., 2015). Thus we shall consider Ti\%=10 as a possible upper end of pyrolytic composition. Pyroxene megacrysts from kimberlites can have Ti\% between 0.1-0.4 (Dawson and Reid, 1970, Ringwood and Lovering, 1970, Gurney et al., 1973, Frick, 1973, Rawlinson and Dawson, 1979, Williams, 1932). 


\subsection{Ti partitioning}

When mixing two phases that have a defect element it is important to know how that defect element is distributed in the two phases before mixing. We first consider the thermodynamic partitioning of Ti between our two separate phases of Calcium Silicate perovskite (Ca-pv) and bridgmanite (bdg) as shown in Figure S2-S3. This can be defined by a partitioning coefficient which we shall define as: $K=$ $\frac{{ }^{T i \#_{C a}-p v}}{T i \#_{B d g}}$.

At low pressure ( $25 \mathrm{GPa}$ ) Ti is preferentially partitioned into Ca-pv when the Ti\% is below $\sim 40 \%$ with lower temperatures favouring this sense of partitioning more. At higher pressure (125 GPa) the reverse is the case with $\mathrm{Ti}$ favoured very strongly in the bdg phase. This makes sense as $\mathrm{CaTiO}_{3}$ is a low pressure phase but at lower mantle pressures small amounts of $\mathrm{MgTiO}_{3}$ tend to stabilise bridgmanite (Matrosova et al., 2020). Thus with increasing pressure Ti moves from Ca-pv to bdg. We shall refer to these distributions as the "equilibrated" cases as $\mathrm{Ti}$ is spread into its thermodynamic equilibrium before mixing is attempted. It should be noted that we do not consider the solubility of $\mathrm{Ti}$ as a whole and thus in some of our cases a separate $\mathrm{TiO}_{2}$ phase is likely stable and this is an important future step to consider.

There is another possibility however. If Ti diffusion is very slow then chemical mixing may occur at substantially faster timescales than Ti partitioning. This would have the effect of kinetically promoting the mixed phase as once it forms it is unlikely to convert to two heavily partitioned separate phases even if these are thermodynamically more stable. This case will have quite different mixing dynamics to the equilibrated case and will always have higher miscibility. We are not aware of any studies on Ti diffusion in bdg or Ca-pv but Si diffusion is very slow $\left(10^{-19}\right.$ to $10^{-20} \mathrm{~m} / \mathrm{s}$ (Xu et al., 2011)). Ti exists on the Si site and thus likely diffuses via a similar mechanism and at a similar rate to the Si. In the case of a Si vacancy mechanism unless $\mathrm{Ti}$ diffuses considerably faster than $\mathrm{Si}$, Ti diffusion will be slower as it relies upon the product of Ti and Si vacancy concentrations. This is seen in olivine where Ti diffusion is around an order of magnitude slower than Si diffusion (Cherniak and Liang, 2014). In Armstrong 
et al. (2012) the two perovskite phases were mixed in 1 hour with grains that were ground to mostly sub-micro sizes during which time Ti would diffuse a maximum of a few femtometres using bdg Si diffusion rates from Xu et al (2011). Such a number suggests that chemical mixing is likely much faster than Mg or Ti diffusion in bridgmanite leading to the possibility of non-equilibrium kinetics.

In this "non-equilibrated" case the distribution of Ti depends upon the source and initial distribution of Ti. There are multiple possible cases and we shall consider a few of them to establish the range of such an effect. We shall consider $\mathrm{a} \mathrm{CaTiO}_{3}$ source (all the Ti resides initially in Ca-pv, $\mathrm{K}>1000$ ), a $\mathrm{MgTiO}_{3}$ source (all the Ti resides in bdg $\mathrm{K}<0.0001$ ) and a source that places an equal concentration of $\mathrm{Ti}$ in each phase before mixing such as when a large quantity of Titanium is introduced simultaneously to a Capv and bdg interface $(\mathrm{K}=1)$. This last case shall be referred to as the "distributed" case as Ti is equally distributed across two phases.

\subsection{Enthalpy and Entropy}

There are 3 key terms to mixing, $\mathrm{H}_{\text {mix }}, \mathrm{S}_{\text {config }}$ and $\mathrm{S}_{\text {vib. }}$. For a review of these values in a Ti free systems see Muir et al. (2020). The effect of Ti on $\mathrm{H}_{\text {mix }}$ is presented in Figure $\mathrm{S} 4$ and on $\mathrm{S}_{\text {vib }}$ in Table $\mathrm{S} 1$ and $\mathrm{S}_{\text {config }}$ in Table S2-S3.

On the addition of $\mathrm{Ti}, \mathrm{S}_{\text {config }}$ increases significantly peaking at $\mathrm{Ti} \%=50$ while $\mathrm{S}_{\text {vib }}$ and $\mathrm{H}_{\text {mix }}$ have more complex effects. $\mathrm{H}_{\text {mix }}$ decreases significantly when $\mathrm{Ti}$ is distributed equally to the two phases but can both increase and decrease when partitioning is considered premixing. The former effect is because the mixed phase is less dense than a mixture of the two unmixed phases (Table 1 ) and is thus able to incorporate larger Ti atoms more effectively. Svib typically decreases slightly with Ti concentration but this is a small effect and can typically be ignored. Unlike in the pure case of $\mathrm{MgSiO}_{3}-\mathrm{CaSiO}_{3}$ (Muir et al., 2020) where the $S_{\text {config }}$ term can be reasonably approximated with that derived from perfect mixing, in the Ti-containing case $\mathrm{S}_{\text {config }}$ is significantly non-perfect. In some cases $\mathrm{S}_{\text {config }}$ being non-perfect raises 
$\mathrm{T}_{\text {mix }}$ by $>200 \mathrm{~K}$ when compared to its perfect equivalent. Overall, the addition of Ti causes a significant decrease in $\mathrm{T}_{\text {mix }}$ and this decrease is primarily driven by the increase in $\mathrm{S}_{\text {config }}$ from adding in Ti with a small secondary effect coming from changes to $\mathrm{H}_{\text {mix. }}$.

\subsection{Mixing of $\mathrm{CaTi}_{x} \mathrm{Si}_{1-x} \mathrm{O}_{3}$ and $\mathrm{MgTi}_{x} \mathrm{Si}_{1-x} \mathrm{O}_{3 s}$}

We shall consider mixing at two pressures, $25 \mathrm{GPa}$ and $125 \mathrm{GPa}$. These represent roughly the top of the lower mantle and the top of the $D^{\prime \prime}$ layer. While not a full sampling of pressure this shall allow us to examine the maximum effect that pressure can have on this system.

\section{$25 \mathrm{GPa}$}

The solubility of $\mathrm{Ca}$ in bdg is shown in Figure 1 and for $\mathrm{Mg}$ in Ca-pv in Figure S5 but as the mantle has more Mg than Ca we shall focus on the former case. As shown in Figure 1 adding Ti substantially reduces $T_{\text {mix }}$ for the reasons discussed above. This can clearly be seen at high solubilities where the $T_{\text {mix }}$ value plateaus (as configurational entropy dominates the system) and this plateau temperature changes from $\sim 3200 \mathrm{~K}$ with no Ti to $\sim 2750 \mathrm{~K}$ with Ti\%=10. With no Ti a pyrolytic mixture of $\mathrm{Ca}$ and $\mathrm{Mg}(\mathrm{Ca} \%=10)$ mixes at $\sim 3100 \mathrm{~K}$, with $\mathrm{Ti} \%=1$ this drops to $\sim 3000 \mathrm{~K}$ and with $\mathrm{Ti} \%=10$ this drops to $\sim 2500$ K. For a more MORB like composition with $\mathrm{Ca} \%=50$ the relative values are $\sim 3160, \sim 3120$ and $2780 \mathrm{~K}$ respectively.

As also shown in Figure 1 in general the solubility at this pressure has little dependence on the partitioning of Ti before mixing. An equilibrated and distributed sample have very similar $T_{\text {mix }}$ values with maximum differences in $T_{\text {mix }}$ of $<50 \mathrm{~K}$ or $\sim 4 \%$ of $T_{\text {mix }}$. Significant differences to solubility are only found with a $\mathrm{CaTiO}_{3}$ source of $\mathrm{Ti}$. With a $\mathrm{CaTiO}_{3}$ source the solubility of $\mathrm{Mg}$ in $\mathrm{Ca}$-pv is essentially unchanged from the equilibrated sample but the solubility of Ca in bdg is substantially increased. 
The addition of Ti allows a phase loop to form. This is pictured in Figure 2. As shown the phase loop causes the onset of mixing to drop by up to $200 \mathrm{~K}$ compared to the univariant case for both pyrolytic (Figure 2) and basaltic (Figure S6) compositions and causes a maximum phase loop width of around $400 \mathrm{~K}$. These values are small when considering the changes to mixing temperature induced by geological variability in Ca\%, Ti\% and other elements (see for example Figures 7-9). In the real mantle the phase widths will be even smaller than calculated here. Our calculated values are for the thermodynamic maximum width of the phase loop but various kinetic effects will likely narrow the phase loop in a real system. We consider two cases.

First we consider a case where Ti diffusion is fast enough that equilibration of Ti occurs. In this case the generally large value of the partitioning coefficient between the two phase and one phase system means that the effective width of the phase transition seen by seismic waves is likely considerably smaller (Stixrude, 1997).

Second we consider a case where Ti diffusion is sluggish. In the limit of very slow Ti diffusion a univariant phase transition would be obtained. As Ti diffusion becomes slower the phase transition thus narrows towards the univariant. As explained above Ti diffusion is likely slow and thus trends towards the univariant case. Thus we shall present univariant results from now on but the phase loop could lower the onset of mixing by up to $400 \mathrm{~K}$ across the Ti\% range.

Figure 3 shows a comparison between our calculated data and points determined in Armstrong et al. (2012) for pressures 21-30 GPa and temperatures 1800-2200 K. In this we plot both the equilibrated case and the distributed case which are near identical as was also seen in Figure 1. It is difficult to know the exact dynamics of the experiment but due to its short nature (by mantle timescales) it is possible $\mathrm{Ti}$ was not fully equilibrated before mixing occured. If the $\mathrm{Ti}$ was primarily in $\mathrm{MgTiO}_{3}$ then it would have essentially the same trace as our equilibrated case. The $\mathrm{CaTiO}_{3}$ source case is also plotted but has very substantial differences to the experiment and so is unlikely to have occurred. 
The majority of the phase determinations in Armstrong et al. (2012) fit our phase boundary with some notable exceptions. At high Ca\% one composition that was observed to be 1 phase is inside our 2 phase region but is within the error caused by temperature fluctuations. At Ca\%=60 and Ti\%=50 a 2 phase mixture was observed in the experiment at $26 \mathrm{GPa}$ and $2000-2100 \mathrm{~K}$. Our calculations predict that a single phase should form above $1955 \mathrm{~K}$ at $25 \mathrm{GPa}$. This difference could be related to errors in our projection across $\mathrm{Ca} \%$ where we only have points at $0,25,50$ and 100 . Alternatively the mixed phase could be somewhat sluggish in forming at such middling values of Ti\% and thus was not formed in the experimental timeframe or exsolution of $\mathrm{TiO}_{2}$ could cause the $\mathrm{Ti} \%$ value in the mixture to be lower that predicted here.

Our calculated phase boundary in Figure 3 at $2000 \mathrm{~K}$ is similar to that determined experimentally by Armstrong et al. (2012) at low Ti\% but varies significantly with high Ti\%. We find that mixing/solubility increases rapidly as Ti\% approaches 50 due to $S_{\text {Config }}$ which leads to our different high Ti\% behaviour. It is possible that exsolution of $\mathrm{TiO}_{2}$ - which is not considered in our model-causes some raising of the phase boundary curve at high $\mathrm{Ti} \%$ in real samples as exsolution of $\mathrm{TiO}_{2}$ must necessarily raise $\mathrm{T}_{\text {mix }}$. Alternatively the high Ti\% trend speculated in Armstrong is between our predicted high Ti\% trends predicted for 1600 and $2000 \mathrm{~K}$ and thus the Armstrong phase relations being near the lower end of their temperature range ( $1800 \mathrm{~K})$ may also explain these results.

Figure 4 shows a plot of mixing temperature of the $\mathrm{MgSiO}_{3}-\mathrm{MgTiO}_{3}-\mathrm{CaTiO}_{3}-\mathrm{CaSiO}_{3}$ plane in the equilibrated case at $25 \mathrm{GPa}$. Other partitioning cases are shown in Figure S7-S9 but are fairly similar.

This plot has a few interesting features. On the low Ti\% side there is a large patch of high $\mathrm{T}_{\text {mix }}(>3000$ K) stretching across the entire Ca\% range. This shows that regardless of composition very large amounts of $\mathrm{Ti}$ are required to drop $\mathrm{T}_{\text {mix }}$ to $\sim 2000 \mathrm{~K}$, around $30 \%$ at a pyrolytic composition ( $\mathrm{Ca} \%=10$ ) and above $45 \%$ with a basaltic composition $(\mathrm{Ca} \%=50)$. It also shows that thermal fluctuations are relatively unimportant at this pressure. At $\sim 60 \% \mathrm{Ti}$ there is a band of extremely low $\mathrm{T}_{\mathrm{mix}}$ across all Ca\% 
values which relates to the maximum of the $S_{\text {config }}$ and $S_{\text {mix }}$ terms. Compositions with high Ti\% behave similarly to those with low Ti\% but we have no measure of Ti solubility in these calculations and so these structures likely break down at some point.

\section{$125 \mathrm{GPa}$}

Figure 5 shows the Ca solubility in bdg at 125 GPa with different partitioning values (Figure S10 shows the Mg solubility in Ca-pv). We find that partitioning of the Ti before mixing leads to larger differences in $\mathrm{T}_{\text {mix }}$ than was seen for $25 \mathrm{GPa}$ due to the larger difference in enthalpy between $\mathrm{CaTiO}_{3}$ and $\mathrm{MgTiO}_{3}$ at this pressure. The equilibrated and $\mathrm{MgTiO}_{3}$ cases are near identical and are the two most likely possibilities in the lower mantle. The distributed case is less likely and has $T_{\text {mix }}$ values that are somewhat lower (up to $200 \mathrm{~K}$ lower at $50 \% \mathrm{Ca}$ ). $\mathrm{A} \mathrm{CaTiO}_{3}$ source has much lower $\mathrm{T}_{\text {mix }}$ values but is unlikely to occur.

As shown in Figure 2 the phase loop is similar at $125 \mathrm{GPa}$ as at $25 \mathrm{GPa}$ but less wide due to the large energy differences between the phases. Similar arguments regarding the phase width and the relevance of this phase loop apply at these pressures as at $25 \mathrm{GPa}$.

Figure 6 shows a plot of mixing temperature of the $\mathrm{MgSiO}_{3}-\mathrm{MgTiO}_{3}-\mathrm{CaTiO}_{3}-\mathrm{CaSiO}_{3}$ plane in the equilibrated case at $125 \mathrm{GPa}$. Figure S11-13 show the other partitioning cases.

$T_{\text {mix }}$ values are universally lower at $125 \mathrm{GPa}$ than they are at $25 \mathrm{GPa}$, a fact also observed in absence of Ti (Muir et al., 2020). This, combined with the higher temperature at these pressures in the Earth, means mixing is more likely deep in the mantle. At the low Ti\% region of the diagram large patches of relatively high $T_{\text {mix }}$ remain and show that with low Ti concentrations mixing does not occur except with large thermal fluctuations. While at $25 \mathrm{GPa}$ there is a large patch of very low $\mathrm{T}_{\text {mix }}$ values at around $\mathrm{Ti} \%=50-60$ this does not occur as prominently at $125 \mathrm{GPa}$. While there remains a large increase in Sconfig at middling Ti\% values at $125 \mathrm{GPa}$ the increases in $\mathrm{H}_{\text {mix }}$ are also larger at $125 \mathrm{GPa}$ than $25 \mathrm{GPa}$. This is due to the stability of Ti in the bdg phase at this pressure and this somewhat cancels out the 
large increase in $\mathrm{S}_{\text {config }}$ seen with $~ 50 \%$ Ti. Thus $\mathrm{T}_{\text {mix }}$ does decrease with increasing Ti\% at $125 \mathrm{GPa}$ but this decrease is much smaller than is seen at $25 \mathrm{GPa}$ and mixing at this pressure is more robust to varying Ti concentrations.

\subsection{Mixing as a function of pressure}

Table 2 compares Ca solubility as a function of pressure and $\mathrm{K}$. We find that increasing pressure increases solubility in both Ti-free (Muir et al., 2020) and Ti containing samples. With an equilibrated distribution or with $\mathrm{MgTiO}_{3}$ distributions where $\mathrm{K}$ is nearly 0 there is only a mild increase in solubility on increasing the pressure by $100 \mathrm{GPa}$ as the effect of Ti\% on $\mathrm{T}_{\text {mix }}$ decreases with pressure. This is in stark contrast to Armstrong et al. (2012) where it was found that pressure causes very large increases in mixing for Ti-containing samples. To mix a sample containing around $50 \% \mathrm{Ca}$ at $\sim 2000 \mathrm{~K}$ they found that around $25 \% \mathrm{Ti}$ was required at $55 \mathrm{GPa}, \sim 8 \%$ at $85 \mathrm{GPa}$ and $<5 \%$ at $100 \mathrm{GPa}$ with no mixing observed at 25 and $35 \mathrm{GPa}$. This can be compared to our data where we find that $50 \%$ Ca mixtures do not mix at $125 \mathrm{GPa}$ and $2000 \mathrm{~K}$ until very extreme Ti\% values (>47\%). With increasing $\mathrm{K}$ (premixing partitioning of Ti to Ca-pv), however, larger increases in solubility with pressure are seen. With a distributed sample $(\mathrm{K}=1)$ and Ti\% $=20$, solubility is $5 \%$ at $25 \mathrm{GPa}$ and $24 \%$ at $125 \mathrm{GPa}$ and $2000 \mathrm{~K}$ though these values are still smaller than seen in experiment. $\mathrm{K}$ values approaching the $\mathrm{CaTiO}_{3}$ source are required to match experimental pressure derivatives but these high $\mathrm{K}$ values means that we cannot reproduce experimental results at $25 \mathrm{GPa}$ (see Figure 3). We also never approach the maximum solubility seen in Armstrong et al. (2012) even with a $\mathrm{CaTiO}_{3}$ source- at $97 \mathrm{GPa}$ they observed solubility of $45 \%$ (Ca-pv into bdg) with only $5 \% \mathrm{Ti}$ and this solubility should be even larger at $125 \mathrm{GPa}$ ). Thus the differences between our theoretical results and those measured by Armstrong et al (2012) is some fundamental difference in how pressure derivatives are calculated and are not simply related to how Ti is distributed in the sample before mixing. In Ti-free samples we also predicted a smaller pressure derivative of solubility than was observed experimentally (Muir et al., 2020). 
There are a few possible causes of this discrepancy. The most likely reason for the discrepancy is that our model fails to capture some aspect of the dissolution. Our model does not include $\mathrm{TiO}_{2}$ exsolution but this can only lower solubility and so it cannot increase our agreement with experimental data which predict higher solubilities than we obtain.

One possible aspect that we do not calculate in our model is pressure non-linearity. We consider only the points 25 and $125 \mathrm{GPa}$ whereas the experimental data runs from 20-96 GPa. If pressure varied highly non-linearly between 25 and $125 \mathrm{GPa}$ this would explain these differences. We consider this to be unlikely as the component energies of the phases have near-linear relationships with pressure. There are two major components to the mixing energies: $\mathrm{S}_{\text {config }}$ and $\mathrm{H}_{\text {mix. }}$. $\mathrm{S}_{\text {config }}$ has only a small dependence on pressure (see Table S2 and S3). $\mathrm{H}_{\text {mix }}$ has a strong non-linear dependence on pressure but this pressure dependence is related to partitioning- if we remove the partitioning component $\mathrm{H}_{\text {mix }}$ is largely linear with only some small deviations near $125 \mathrm{GPa}$ (Figure S4). We can enforce near linear behaviour in $\mathrm{H}_{\text {mix }}$ therefore by fixing both 25 and $125 \mathrm{GPa}$ samples to the same partitioning regime of $\mathrm{a} \mathrm{CaTiO}_{3}$ source $(\mathrm{K}>1000)$. By doing so we have a regime that should be highly linear with pressure and as shown in Table 2 this still does not reproduce the experimental results and predicts lower solubility at high pressures than Armstrong et al. (2012). Thus this is highly unlikely to be the source of our discrepancy.

Contamination of the experiment is unlikely to be important as we find in the next section that very large concentrations of defects are required to shift $T_{\text {mix }}$ values. To shift $T_{\text {mix }}$ by a few hundred degrees as would be required to explain our observed discrepancies would require defects with a concentration on the order of $10 \%$ which is far higher than experimental contamination levels.

The most likely explanation is that we do not consider in our model the kinetics of dissolution, we only consider thermodynamics and how to minimise the overall energy. There may be macroscopic kinetic effects which increase the propensity for either global or local mixing. Regions with heterogeneously high concentrations of Ti may induce local and then global mixing which would explain why solubilities 
are higher in experiment than in our theoretical prediction. Alternatively there may be some other aspect of pressure which our model does not consider. Regardless our results predict the thermodynamic minimum and thus are possibly more robust in the long-time scales of the mantle where thermodynamic equilibriums should be obtained.

\section{Discussion}

\subsection{Partitioning}

In the lower mantle the equilibrated case is much more likely to occur. Bdg and Ca-pv are produced as two separate phases in different transitions in the mantle and at the top of the lower mantle (when bdg is first produced) we predict them to exist as two unmixed phases (Fig 5 and Muir et al. (2020)). While Ti diffusion is likely slow, over the long timescales of the mantle this should not matter and Ti could equilibrate across the two phases before conditions which induce mixing are reached. Nonequilibrated mixing would only occur if large amounts of Ti were introduced suddenly deep in the mantle where mixing is more favoured (Fig 7). Non-equilibrated mixing is likely, however, to be extremely important in experimental measurements over short timescales and thus should inform experimental design. We shall only discuss equilibrated cases for the rest of this paper however as those the most likely to be relevant in the Earth.

\section{Mixing in the Lower mantle}

To examine mixing in the lower mantle we built a small model. Ti-free values at 25,75 and 125 were taken from Muir et al. (2020) and Ti values at 25 and 125 GPa. These were then extrapolated over pressure to predict the mixing of different compositions in the lower mantle.

\subsection{Basalts}

First we will consider basaltic mixtures. Basalt was previously found not to mix in the absence of $\mathrm{Ti}$ (Muir et al., 2020)in geotherm conditions. Figure 7 show the mixing of a basalt enriched in $10 \% \mathrm{Ti}$ as is possible in OIB compositions, a more MORB like basalt with $1 \% \mathrm{Ti}$ is shown in Figure $\mathrm{S} 14$ but $\mathrm{T}_{\text {mix }}$ 
values are $\sim 400 \mathrm{~K}$ larger in the $1 \%$ MORB compared to the $10 \%$ OIB. We find that even with the maximum amount of $\mathrm{Ti}$ the mixing temperature of basalt remains far above likely slab temperatures thus ruling out perovskite phase mixing in descending slabs. At $115 \mathrm{GPa}$ highly enriched OIB basalts reach the temperature of the geotherm and thus mixing could occur at the outer edge of descending slabs or in basaltic regions of the lower mantle. Lesser enriched MORB basalts never reach such temperatures and thus never mix in descending slabs.

In Figure 7 we show the effect of a plausible range of Ca\% (30-60\%) values but this has very low effect on $T_{\text {mix }}$ as these values are all in the plateau region of solubility (Figure 1 ) and have similar solubilities (variations in Tmix $<100 \mathrm{~K}$ ). Thus variation in Ca\% is not a significant factor for basalts.

Other elements are present in basalts and we address these using a simple model described in Muir et al. (2020) and shown in Table S5-S6. We find extremely similar results to the Ti-free system-notably that large amounts of any defect ( $\sim \%)$ are needed to make substantial changes to $T_{\text {mix }}$ and that of the likely elements in these concentrations $\mathrm{Fe}(\mathrm{II})$ decreases $\mathrm{T}_{\text {mix }}$ and $\mathrm{Al}$ and $\mathrm{Fe}(\mathrm{III})$ increase it. These are plotted in Table 3 and visualised for basalts in Figure 8 (other compositions are shown in Figure S16S19 but defect elements have similar effects on all compositions in this model). While large amounts of iron can induce mixing in basaltic compositions basaltic compositions have high amounts of Al which would increase $T_{\text {mix. }}$. Thus miscibility of basaltic compositions should be even lower than is predicted in Figure 8 with a real Al containing basalt.

Thus we conclude that basaltic compositions in descending slabs will remain as two phases even if they descend right to the $D^{\prime \prime}$ layer and even if they have the maximum amount of Ti (10\%) speculated to be in basaltic compositions. Small amounts of mixing will be possible on the edges of slabs as they approach lower mantle temperatures but this will be limited only to extreme depths and small portions of the slab. No seismic anomalies should thus occur from this phase change in descending slabs. Basalt that is present at lower mantle temperatures, from unmixed pyrolite for example, will mix but only in the deep lower mantle (> 115 GPa) and with high concentrations of Ti ( $\sim 10 \%)$. 


\subsection{Pyrolytic Mantle}

Finally we shall consider the effect of Ti on pyrolytic mantle (Figure 7). Increasing the amount of Ti in pyrolytic mantle decreases the pressure at which it reaches the geotherm (Figure S19). With no Ti the pressure at which phase mixing is seen along the geotherm is $\sim 126 \mathrm{GPa}$ and drops to $104 \mathrm{GPa}$ with 10\% Ti. At $25 \mathrm{GPa} \sim 40 \% \mathrm{Ti}$ induces mixing at the geotherm. At $125 \mathrm{GPa} \sim 1 \% \mathrm{Ti}$ induces mixing at the geotherm. Temperature fluctuations will only have small effects on these numbers. Thus in regions enriched in Ti pyrolytic mantle will undergo mixing near the bottom of the lower mantle.

Phase mixing also provides a method for producing Ti rich regions in the lower mantle. As shown in Figure 2 the mixed perovskite phase have a strong preference for $\mathrm{Ti}$ compared to the unmixed perovskite phases. If a mixed phase region forms in the lower mantle it will partition Ti out of regular unmixed pyrolite thus providing a chemical and physically separated region that naturally enriches in Titanium.

While the concentration of Ti may reach up to $10 \%$ in enriched sections of the lower mantle other elements will likely have larger effects on perovskite miscibility. As shown in Figure $7 \mathrm{Ca} \%$ has a large effect on pyrolytic miscibility in the presence of $\mathrm{Ti}$ and thus is a stronger control than Ti. As shown in Figure $\mathrm{S} 20$ adding in $10 \% \mathrm{Fe}(\mathrm{II})$ instead of $10 \%$ Ti drops the pressure at which the geotherm is met to $\sim 76 \mathrm{GPa}$. While $\mathrm{Fe}$ (II) concentrations in perovskite are likely very low as $\mathrm{Fe}(\mathrm{II})$ partitions to ferropericlase at the bottom of the mantle (Muir and Brodholt, 2016, Xu et al., 2017) such conclusions may not hold in highly heterogenous regions of the lower mantle such as those that contain Ti. In the presence of both Fe and Ti fluctuations of concentration Fe will be a stronger control on perovskite miscibility.

\subsection{Megacrysts}

Next we shall consider the case of megacrysts. The phase of megacrysts is important as to determining their origin. One suggested origin is that they began as single phase perovskites under lower mantle 
conditions (Collerson 2004, 2005). Iron and aluminium free clinopyroxene megacrysts ( $\sim \mathrm{Ca} \% 15-35 \%$ Ti\% 15-40\%) were found by Armstrong et al. (2012) to convert to a single phase around 50-80 GPa and around $\sim 65 \mathrm{GPa}$ for an average composition. We show a sample CMC (Ca\% $30 \mathrm{Ti} \% 25)$ in Figure 9 and find that in the absence of other elements it mixes at around $85 \mathrm{GPa}$ along a geotherm. This is higher than the value derived in Armstrong et al. (2012) due to our different pressure derivatives. Within the geological variation of $\mathrm{CMC}(\mathrm{Ca} \%=20-40, \mathrm{Ti} \%=15-30)$ we find that this value can vary between 65-115 GPa with Ti\% being the strongest control on this depth. OMC have lower levels of Ca\% than $\mathrm{CMC}$ and thus have higher miscibility and are observed to mix (in the absence of other elements) at around 30-65 GPa along a geotherm. Moderate amounts of iron increase mixing even more (Figure S19-S20). Thus single phase ilmenite pyroxene megacrysts can be found at depths $\sim 1000$ $\mathrm{km}$ with the actual depth depending upon the exact composition which can cause large variations in $\mathrm{T}_{\text {mix }}(\sim 700 \mathrm{~K})$ and the depth at which single phase perovskites are favoured.

\section{Conclusion}

We find that while Ti has large effects on miscibility of bdg and Ca-pv it should not induce mixing in basalts in descending slabs and thus there should no seismic signals from phase mixing in these slabs. While Ti can induce mixing in pyrolytic compositions this will only occur near the bottom of the lower mantle where seismic signals are complicated by the presence of the $D^{\prime \prime}$ layer and the CMB. Additionally $\mathrm{Ca} \%$ is likely to be a stronger control on the miscibility. The main effect of $\mathrm{Ti}$ is converting pyroxene ilmenite megacrysts into single phases at depths of greater than $1000 \mathrm{~km}$ with strong variability dependent upon $\mathrm{Ca} \%$ and Ti\% ratios. This is evidence promoting the single phase origin hypothesis in the literature.

These speculations all assume equilibrium chemistry. In non-equilibrium chemistry as may occur in experiments or dynamic parts of the mantle the effect of Ti on inducing mixing can be much larger. Thus it is important to constrain the dynamics of this mixing and of cationic diffusion in bdg and Ca-pv in future works to fully account for this effect. 
Acknowledgments:

The research in this proposal was supported by National Natural Science Foundation of China (41773057). JM is highly thankful to Chinese Academy of Sciences (CAS) for PIFI. Calculations were run on the TH-2 High supercomputer centre in Lvliang, China.

ARMSTRONG, L. S., WALTER, M. J., TUFF, J. R., LORD, O. T., LENNIE, A. R., KLEPPE, A. K. \& CLARK, S. M. 2012. Perovskite Phase Relations in the System CaO-MgO-TiO2-SiO2 and Implications for Deep Mantle Lithologies. Journal of Petrology, 53, 611-635.

CHERNIAK, D. J. \& LIANG, Y. 2014. Titanium diffusion in olivine. Geochimica Et Cosmochimica Acta, $147,43-57$

DAWSON, J. B. \& REID, A. M. 1970. A PYROXENE-ILMENITE INTERGROWTH FROM MONASTERY MINE, SOUTH-AFRICA. Contributions to Mineralogy and Petrology, 26, 296-\&.

FRICK, C. 1973. Intergrowths of orthopyroxene and ilmenite from Frank Smith mine near Barkly West, South Africa. Transactions of the Geological Society of South Africa, 76, 195-200.

FUJINO, K., SASAKI, Y., KOMORI, T., OGAWA, H., MIYAJIMA, N., SATA, N. \& YAGI, T. 2004. Approach to the mineralogy of the lower mantle by a combined method of a laser-heated diamond anvil cell experiment and analytical electron microscopy. Physics of the Earth and Planetary Interiors, 143, 215-221.

FUKAO, Y., WIDIYANTORO, S. \& OBAYASHI, M. 2001. Stagnant slabs in the upper and lower mantle transition region. Reviews of Geophysics, 39, 291-323.

GALE, A., DALTON, C. A., LANGMUIR, C. H., SU, Y. J. \& SCHILLING, J. G. 2013. The mean composition of ocean ridge basalts. Geochemistry Geophysics Geosystems, 14, 489-518.

GURNEY, J. J., FESQ, H. W. \& KABLE, E. J. D. 1973. Clinopyroxene-ilmenite intergrowths from Lesotho kimberlites: a reappraisal. In: NIXON, P. (ed.) Lesotho Kimberlites. Cape Town. 
HARTE, B. 2010. Diamond formation in the deep mantle: the record of mineral inclusions and their distribution in relation to mantle dehydration zones. Mineralogical Magazine, 74, 189-215.

HIROSE, K. \& FEI, Y. W. 2002. Subsolidus and melting phase relations of basaltic composition in the uppermost lower mantle. Geochimica Et Cosmochimica Acta, 66, 2099-2108.

HIROSE, K., TAKAFUJI, N., SATA, N. \& OHISHI, Y. 2005. Phase transition and density of subducted MORB crust in the lower mantle. Earth and Planetary Science Letters, 237, 239-251.

IRIFUNE, T., MIYASHITA, M., INOUE, T., ANDO, J., FUNAKOSHI, K. \& UTSUMI, W. 2000. High-pressure phase transformation in CaMgSi2O6 and implications for origin of ultra-deep diamond inclusions. Geophysical Research Letters, 27, 3541-3544.

IRIFUNE, T. \& RINGWOOD, A. E. 1993. PHASE-TRANSFORMATIONS IN SUBDUCTED OCEANIC-CRUST AND BUOYANCY RELATIONSHIPS AT DEPTHS OF 600-800 KM IN THE MANTLE. Earth and Planetary Science Letters, 117, 101-110.

IRIFUNE, T. \& TSUCHIDA, Y. 2007. Mineralogy of the Earth-Phase transitions and mineralogy of the lower mantle. In: GD, P. \& G, S. (eds.) Treatise on Geophysics, Vol 2 Mineral Physics.

JUNG, D. Y. \& SCHMIDT, M. W. 2011. Solid solution behaviour of CaSiO3 and MgSiO3 perovskites. Physics and Chemistry of Minerals, 38, 311-319.

KESSON, S. E., FITZ GERALD, J. D. \& SHELLEY, J. M. 1998. Mineralogy and dynamics of a pyrolite lower mantle. Nature, 393, 252-255.

KRESSE, G. \& FURTHMULLER, J. 1996a. Efficiency of ab-initio total energy calculations for metals and semiconductors using a plane-wave basis set. Computational Materials Science, 6, 15-50.

KRESSE, G. \& FURTHMULLER, J. 1996b. Efficient iterative schemes for ab initio total-energy calculations using a plane-wave basis set. Physical Review B, 54, 11169-11186.

KRESSE, G. \& JOUBERT, D. 1999. From ultrasoft pseudopotentials to the projector augmented-wave method. Physical Review B, 59, 1758-1775. 
MATROSOVA, E. A., BOBROV, A. V., BINDI, L., PUSHCHAROVSKY, D. Y. \& IRIFUNE, T. 2020. Titaniumrich phases in the Earth's transition zone and lower mantle: Evidence from experiments in the system MgO-SiO2-TiO2(+/- Al2O3) at 10-24 GPa and 1600 degrees C. Lithos, 366.

MATTERN, E., MATAS, J., RICARD, Y. \& BASS, J. 2005. Lower mantle composition and temperature from mineral physics and thermodynamic modelling. Geophysical Journal International, 160, $973-$ 990.

MCDONOUGH, W. F. \& SUN, S. S. 1995. THE COMPOSITION OF THE EARTH. Chemical Geology, 120, 223-253.

MICHAEL, P. J. \& BONATTI, E. 1985. PERIDOTITE COMPOSITION FROM THE NORTH-ATLANTIC REGIONAL AND TECTONIC VARIATIONS AND IMPLICATIONS FOR PARTIAL MELTING. Earth and Planetary Science Letters, 73, 91-104.

MUIR, J. M. R. \& BRODHOLT, J. P. 2016. Ferrous iron partitioning in the lower mantle. Physics of the Earth and Planetary Interiors, 257, 12-17.

MUIR, J. M. R., THOMSON, A. R. \& ZHANG, F. 2020. The miscibility of Calcium Silicate Perovskite and Bridgmanite: A single phase perovskite in hot, iron-rich regions. Submitted Preprint, https://doi.org/10.31223/X56309.

O' NEILL, B. \& JEANLOZ, R. 1990. EXPERIMENTAL PETROLOGY OF THE LOWER MANTLE - A NATURAL PERIDOTITE TAKEN TO 54 GPA. Geophysical Research Letters, 17, 1477-1480.

ONO, S., KIKEGAWA, T. \& IIZUKA, T. 2004. The equation of state of orthorhombic perovskite in a peridotitic mantle composition to $80 \mathrm{GPa}$ : implications for chemical composition of the lower mantle. Physics of the Earth and Planetary Interiors, 145, 9-17.

ONO, S., OHISHI, Y., ISSHIKI, M. \& WATANUKI, T. 2005. In situ X-ray observations of phase assemblages in peridotite and basalt compositions at lower mantle conditions: Implications for density of subducted oceanic plate. Journal of Geophysical Research-Solid Earth, 110. 
RAWLINSON, P. J. \& DAWSON, J. B. 1979. A quench pyroxene-ilmenite xenolith from kimberlite: implications for pyroxene-ilmenite intergrowths. In: BOYD, F. R. \& MEYER, H. O. A. (eds.) The Mantle Sample: Inclusions in Kimberlites and other Volcanics, Vol. 2. Washington DC: AGU.

RICOLLEAU, A., PERRILLAT, J.-P., FIQUET, G., DANIEL, I., MATAS, J., ADDAD, A., MENGUY, N., CARDON, H., MEZOUAR, M. \& GUIGNOT, N. 2010. Phase relations and equation of state of a natural MORB: Implications for the density profile of subducted oceanic crust in the Earth's lower mantle. Journal of Geophysical Research-Solid Earth, 115.

RINGWOOD, A. E. 1991. PHASE-TRANSFORMATIONS AND THEIR BEARING ON THE CONSTITUTION AND DYNAMICS OF THE MANTLE. Geochimica Et Cosmochimica Acta, 55, 2083-2110.

RINGWOOD, A. E. \& LOVERING, J. F. 1970. SIGNIFICANCE OF PYROXENE-ILMENITE INTERGROWTHS AMONG KIMBERLITE XENOLITHS. Earth and Planetary Science Letters, 7, 371-\&.

STIXRUDE, L. 1997. Structure and sharpness of phase transitions and mantle discontinuities. Journal of Geophysical Research-Solid Earth, 102, 14835-14852.

STIXRUDE, L., LITHGOW-BERTELLONI, C., KIEFER, B. \& FUMAGALLI, P. 2007. Phase stability and shear softening in CaSiO3 perovskite at high pressure. Physical Review B, 75.

SUN, T., ZHANG, D. B. \& WENTZCOVITCH, R. M. 2014. Dynamic stabilization of cubic CaSiO3 perovskite at high temperatures and pressures from ab initio molecular dynamics. Physical Review B, 89, 094109-1.

THOMSON, A. R., KOHN, S. C., BULANOVA, G. P., SMITH, C. B., ARAUJO, D., WALTER, M. J. \& EIMF 2014. Origin of sub-lithospheric diamonds from the Juina-5 kimberlite (Brazil): constraints from carbon isotopes and inclusion compositions. Contributions to Mineralogy and Petrology, 168. VITOS, L., MAGYARI-KOPE, B., AHUJA, R., KOLLAR, J., GRIMVALL, G. \& JOHANSSON, B. 2006. Phase transformations between garnet and perovskite phases in the Earth's mantle: A theoretical study. Physics of the Earth and Planetary Interiors, 156, 108-116. 
WALTER, M. J., KOHN, S. C., ARAUJO, D., BULANOVA, G. P., SMITH, C. B., GAILLOU, E., WANG, J., STEELE, A. \& SHIREY, S. B. 2011. Deep Mantle Cycling of Oceanic Crust: Evidence from Diamonds and Their Mineral Inclusions. Science, 334, 54-57.

WILLIAMS, A. F. 1932. The Genesis of Diamond, London, Ernest Benn.

XU, J., YAMAZAKI, D., KATSURA, T., WU, X., REMMERT, P., YURIMOTO, H. \& CHAKRABORTY, S. 2011. Silicon and magnesium diffusion in a single crystal of $\mathrm{MgSiO3}$ perovskite. Journal of Geophysical Research-Solid Earth, 116.

XU, S. Z., LIN, J. F. \& MORGAN, D. 2017. Iron partitioning between ferropericlase and bridgmanite in the Earth's lower mantle. Journal of Geophysical Research-Solid Earth, 122, 1074-1087.

ZEDGENIZOV, D. A., SHATSKY, V. S., PANIN, A. V., EVTUSHENKO, O. V., RAGOZIN, A. L. \& KAGI, H. 2015. Evidence for phase transitions in mineral inclusions in superdeep diamonds of the Sao Luiz deposit (Brazil). Russian Geology and Geophysics, 56, 296-305.

ZHANG, Z., STIXRUDE, L. \& BRODHOLT, J. 2013. Elastic properties of MgSiO3-perovskite under lower mantle conditions and the composition of the deep Earth. Earth and Planetary Science Letters, $379,1-12$. 
Figure Captions:

Figure 1 Univariant solubility of $\mathrm{Ca}$ in bdg at $25 \mathrm{GPa}$ with different values of Ti\% (0, 5 and 10 with different colours) as a function of temperature (Mg in Ca-pv is shown in Figure S5). Solid lines are for equilibrated case, dashed lines for the distributed case $\mathrm{K}=1$ and dotted lines for the $\mathrm{CaTiO}_{3}$ source case $\mathrm{K}=1000$.

Figure 2: Phase loops determined at fixed pressure ( $25 \mathrm{GPa}$ blue, $125 \mathrm{GPa}$ red) at $\mathrm{Ca} \%=10$ as a function of Ti with the univariant transition plotted as a dotted line. Phase loops with basaltic $\mathrm{Ca} \%$ have much narrower phase loops- see Figure S6. At low concentrations of Ti the band broadens extremely quickly from the Ti\%=0 point.

Figure 3: Plot of the univariant mixing temperature ( $\mathrm{red}=2400 \mathrm{~K}$, black= $2000 \mathrm{~K}$, blue $=1600 \mathrm{~K}$ ) as a function of Ca\% and Ti\%. Solid lines are the equilibrated case. At $2000 \mathrm{~K}$ we also plot the distributed case $(K=1)$ as a dashed line and the $\mathrm{CaTiO}_{3}$ source $(\mathrm{K}=1000)$ case as a dotted line. There is no high $\mathrm{Ti} \%$ line for the $\mathrm{CaTiO}_{3}$ source case as all compositions are 1 phase when $\mathrm{Ti} \%=50$ for this case. $\mathrm{An} \mathrm{MgTiO}_{3}$ case $(K=0.0001)$ would be essentially identical to the equilibrated case. Grey boundaries show the predicted phase loop at $2000 \mathrm{~K}$ as outlined in the methods. Squares represent experimental data from Armstrong et al. (2012) obtained between 21-30 GPa and 1800-2200 K with black squares representing points where 2 phases were observed and white squares where 1 phase was observed. The orange line is the phase boundary obtained in Armstrong et al. (2012). 
Figure 4: Heatmap of univariant $\mathrm{T}_{\text {mix }}$ as a function of Ti\% and Ca\% at $25 \mathrm{GPa}$ with thermodynamic equilibrium of the Ti before mixing (Figure S7-S9 show non-equilibrium cases). Values below $1000 \mathrm{~K}$ and above $3000 \mathrm{~K}$ were truncated to these values respectively.

Figure 5 Univariant solubility of $\mathrm{Ca}$ in bdg with Ti\%=10 at $125 \mathrm{GPa}$ as a function of $\mathrm{T}$ and with different distribution of Ti premixing (in $\mathrm{K}$, different coloured dotted lines). The case where Ti is equilibrated before mixing is shown as a black solid line and has the lowest miscibility. For solubility of $\mathrm{Mg}$ in Capv see Figure S10.

Figure 6 Heatmap of univariant $\mathrm{T}_{\text {mix }}$ as a function of Ti\% and Ca\% at $125 \mathrm{GPa}$ with thermodynamic equilibrium of the Ti before mixing (Figure S11-S13 show non-equilibrium cases). Values below 1000 $\mathrm{K}$ and above $3000 \mathrm{~K}$ were truncated to these values respectively.

Fig $7 \mathrm{~T}_{\text {mix }}$ as a function of pressure for 2 compositions (basaltic $\mathrm{Ca}=50 \%$ and pyrolytic $\mathrm{Ca} \%=10$ ) with Ti\%=10- for these samples without Ti see Muir et al. (Submitted, 2020). The dashed line represents the univariant case, the shaded areas the phase loop. The dotted lines represent the bounds of the phase loop including geological variations of $\mathrm{Ca} \%$ - for the pyrolytic composition these are $\mathrm{Ca} \%=7-12$ and for basaltic compositions these are $\mathrm{C} a \%=30-60$.

Figure 8 Depth at which $T_{\text {mix }}$ crosses the geotherm for a sample OIB composition ( $\mathrm{Ca} \%=50 \mathrm{Ti} \%=10$ ) mixture with various amounts of Fe and Al as determined via the model outlined in the text. For this model the formation of Fe-Al was prioritised such that Fe-Al forms first and then leftover Fe or Al 
forms Ferrous iron or Al-Al pairs. Mixing depths above $1800 \mathrm{~km}$ and below $2800 \mathrm{~km}$ have been truncated to these values to follow the stability field of bdg. $T_{\text {mix }}$ always remains well above the coldest slab adiabat (see Figure S15).

Fig $9 \mathrm{~T}_{\text {mix }}$ as a function of pressure for 2 compositions- red clinopyroxene ilmenite megacryst (Ca\%=30 Ti\%=25) and blue orthopyroxene ilmenite megacryst $(\mathrm{C} a \%=5 \mathrm{Ti} \%=20)$. The dashed line represents the univariant case, the shaded areas the phase loop. The dotted lines represent the bounds of the phase loop including geological variations of $\mathrm{Ca} \%(20-40)$ and Ti\% (15-30) for the clinopyroxene ilmenite megacryst.

Table 1: Change in density (\%) upon mixing of $\mathrm{Ca}-\mathrm{pv}$ and bdg with $\mathrm{Ti} \%=0$ and $10, \mathrm{Ca}=10$ and 50 and at 25 and $125 \mathrm{GPa}$. This data was projected from runs at $\mathrm{Ca} \%=0,25,50$ and 100 and $\mathrm{Ti} \%=0,25,50$ and 100.

Table 2: Ca solubility (\%) in bdg as a function of pressure, Ti\% and $\mathrm{K}$ at $2000 \mathrm{~K}$. Mg solubility in Ca-pv is shown in Table S4. 
Table 3: $\Delta \mathrm{T}_{\text {mixdefect }}$ at $125 \mathrm{GPa}$ induced by different elements as a function of their concentration and the background $\mathrm{Ca}$ and Ti concentration constructed using our defect model. $25 \mathrm{GPa}$ values are listed in Table S7 and have the similar values. 


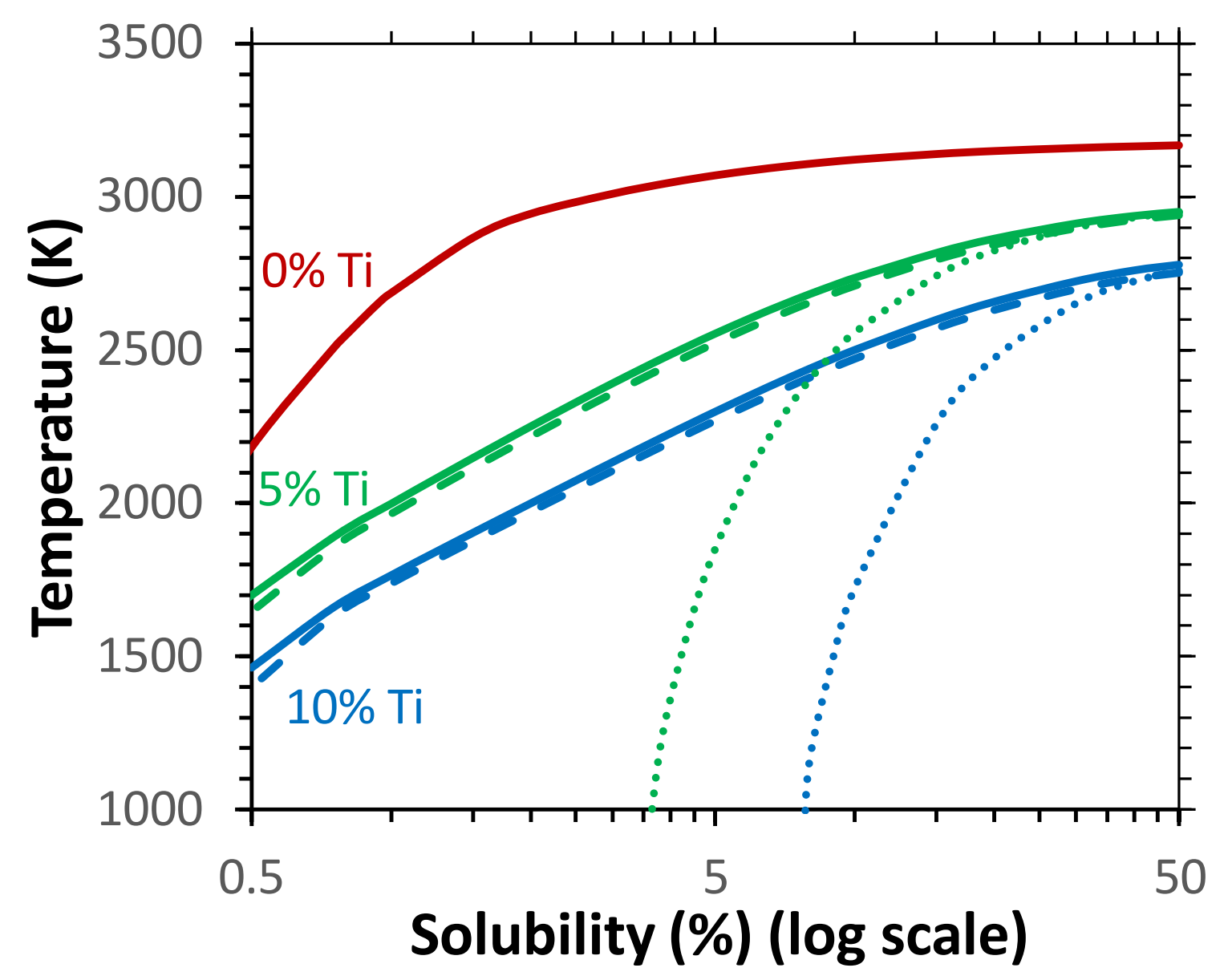

Figure 1 Univariant solubility of $\mathrm{Ca}$ in bdg at $25 \mathrm{GPa}$ with different values of Ti\% (0, 5 and 10 with different colours) as a function of temperature (Mg in Ca-pv is shown in Figure S5). Solid lines are for equilibrated case, dashed lines for the distributed case $\mathrm{K}=1$ and dotted lines for the $\mathrm{CaTiO}_{3}$ source case $K=1000$. 


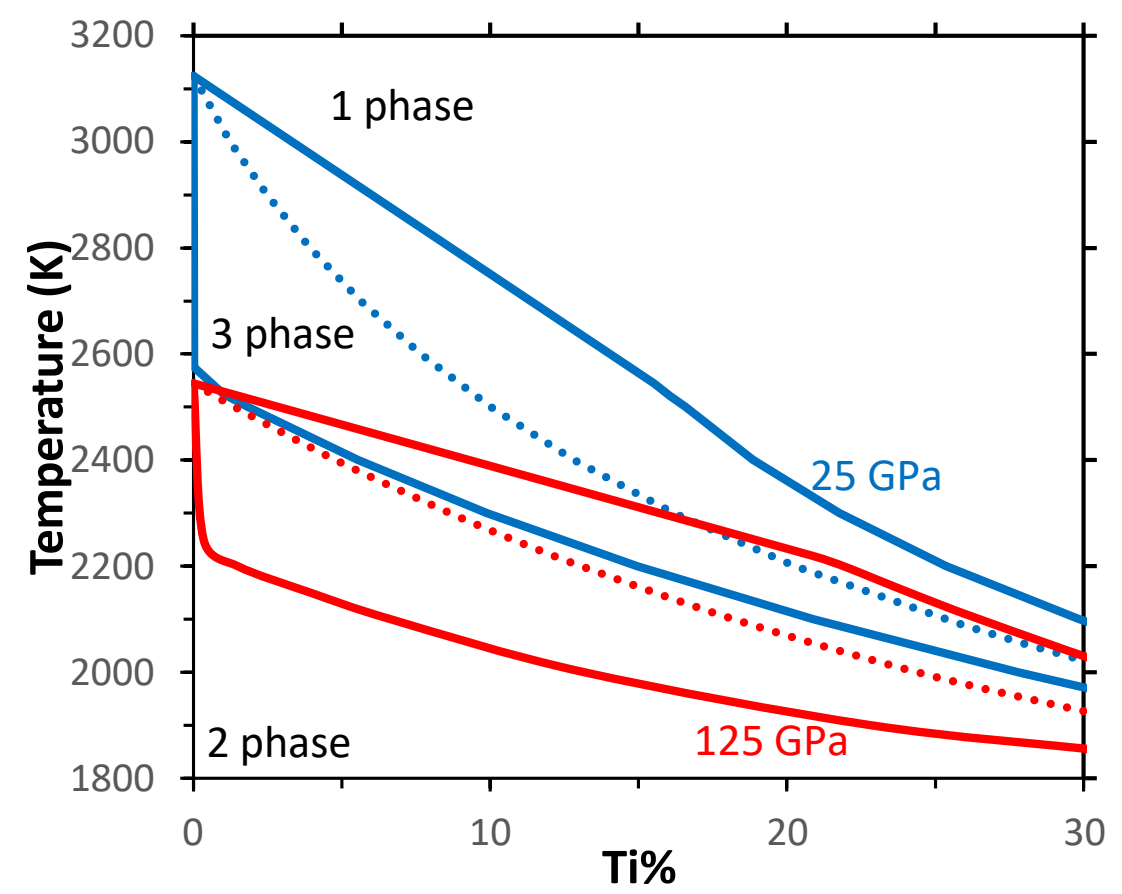

Figure 2: Phase loops determined at fixed pressure (25 GPa blue, $125 \mathrm{GPa}$ red) at $\mathrm{Ca} \%=10$ as a function of $\mathrm{Ti}$ with the univariant transition plotted as a dotted line. Phase loops with basaltic $\mathrm{Ca} \%$ have much narrower phase loops- see Figure S6. At low concentrations of Ti the band broadens extremely quickly from the Ti\%=0 point. 


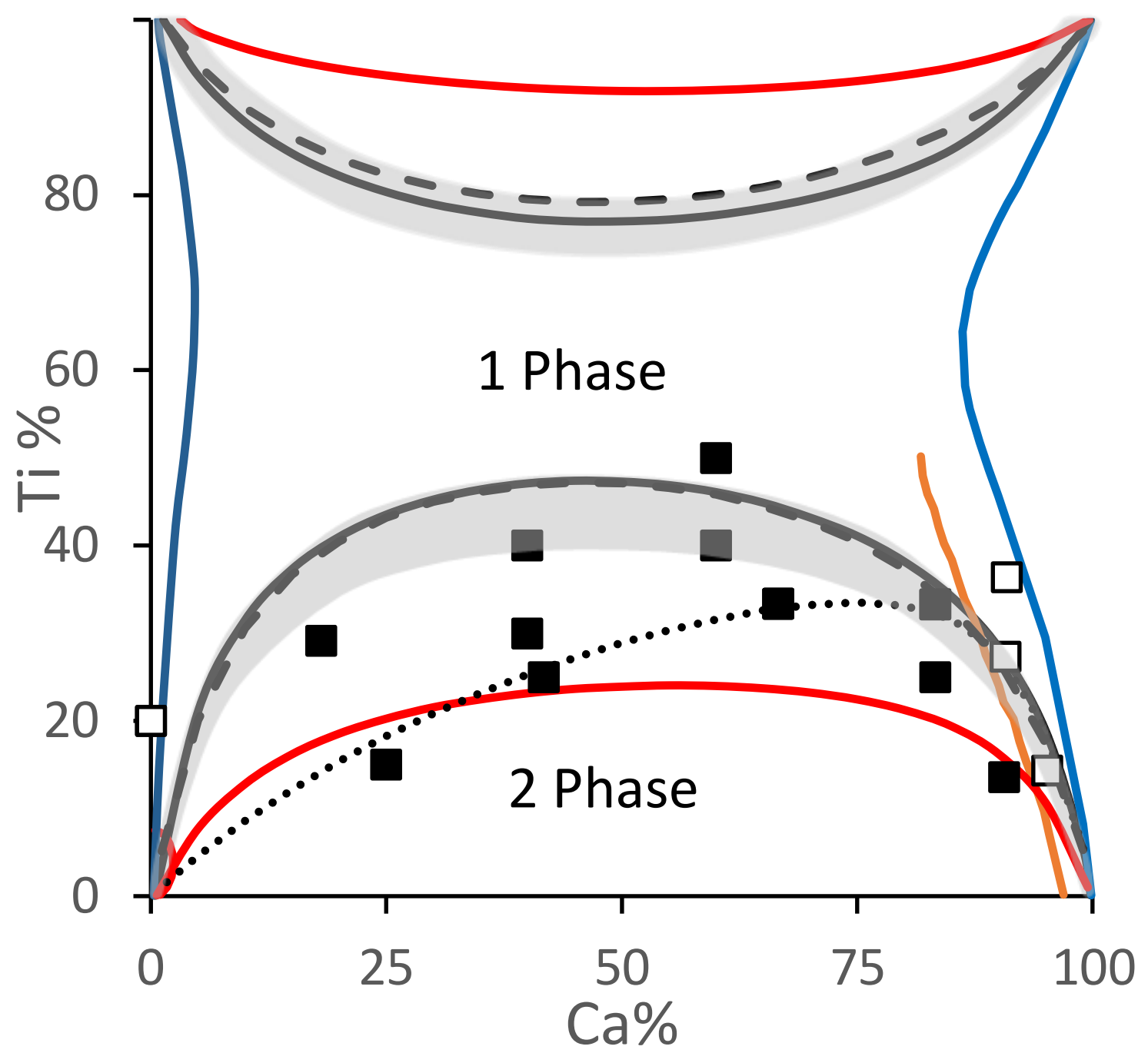

Figure 3: Plot of the univariant mixing temperature ( $\mathrm{red}=2400 \mathrm{~K}$, black= $2000 \mathrm{~K}$, blue=1600 K) as a function of $\mathrm{Ca} \%$ and Ti\%. Solid lines are the equilibrated case. At $2000 \mathrm{~K}$ we also plot the distributed case $(\mathrm{K}=1)$ as a dashed line and the $\mathrm{CaTiO}_{3}$ source $(\mathrm{K}=1000)$ case as a dotted line. There is no high $\mathrm{Ti} \%$ line for the $\mathrm{CaTiO}_{3}$ source case as all compositions are 1 phase when $\mathrm{Ti} \%=50$ for this case. $\mathrm{An} \mathrm{MgTiO}_{3}$ case $(K=0.0001)$ would be essentially identical to the equilibrated case. Grey boundaries show the predicted phase loop at $2000 \mathrm{~K}$ as outlined in the methods. Squares represent experimental data from Armstrong et al. (2012) obtained between 21-30 GPa and 1800-2200 K with black squares representing points where 2 phases were observed and white squares where 1 phase was observed. The orange line is the phase boundary obtained in Armstrong et al. (2012). 



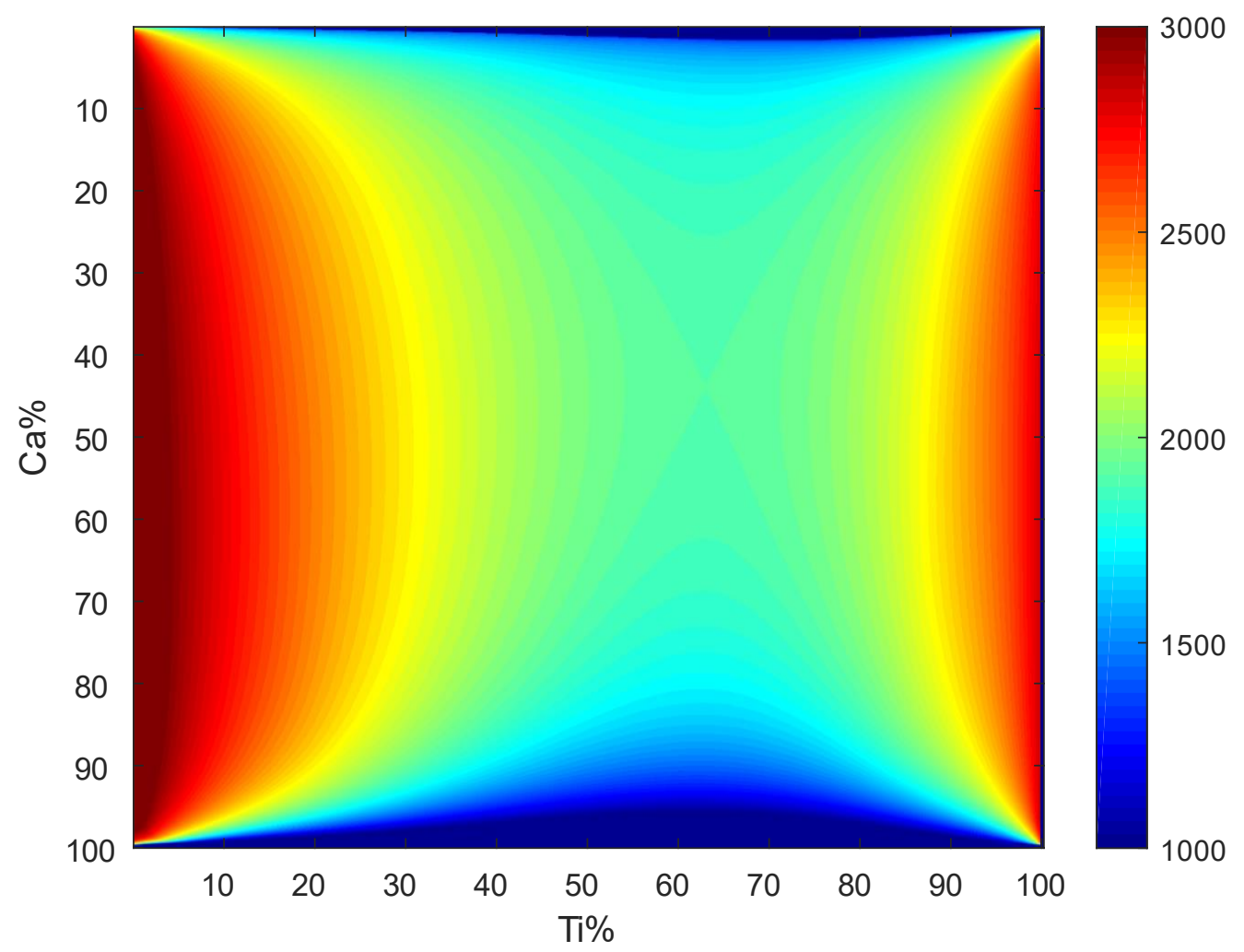

Figure 4: Heatmap of univariant $\mathrm{T}_{\text {mix }}$ as a function of Ti\% and Ca\% at 25 GPa with thermodynamic equilibrium of the Ti before mixing (Figure S7-S9 show non-equilibrium cases). Values below $1000 \mathrm{~K}$ and above $3000 \mathrm{~K}$ were truncated to these values respectively. 


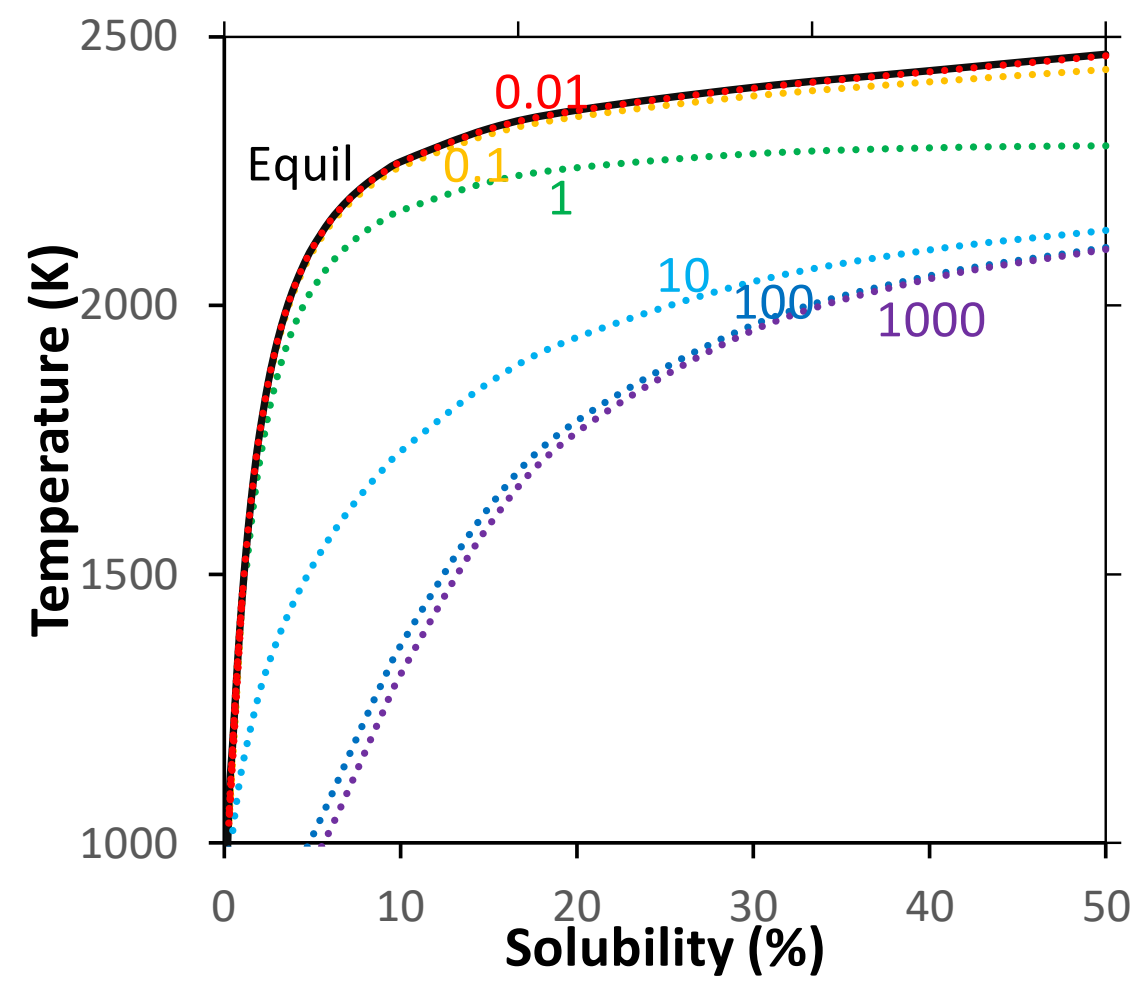

Figure 5 Univariant solubility of $\mathrm{Ca}$ in bdg with Ti\%=10 at $125 \mathrm{GPa}$ as a function of $\mathrm{T}$ and with different distribution of Ti premixing (in K, different coloured dotted lines). The case where Ti is equilibrated before mixing is shown as a black solid line and has the lowest miscibility. For solubility of $\mathrm{Mg}$ in $\mathrm{Ca}$ pv see Figure S10. 


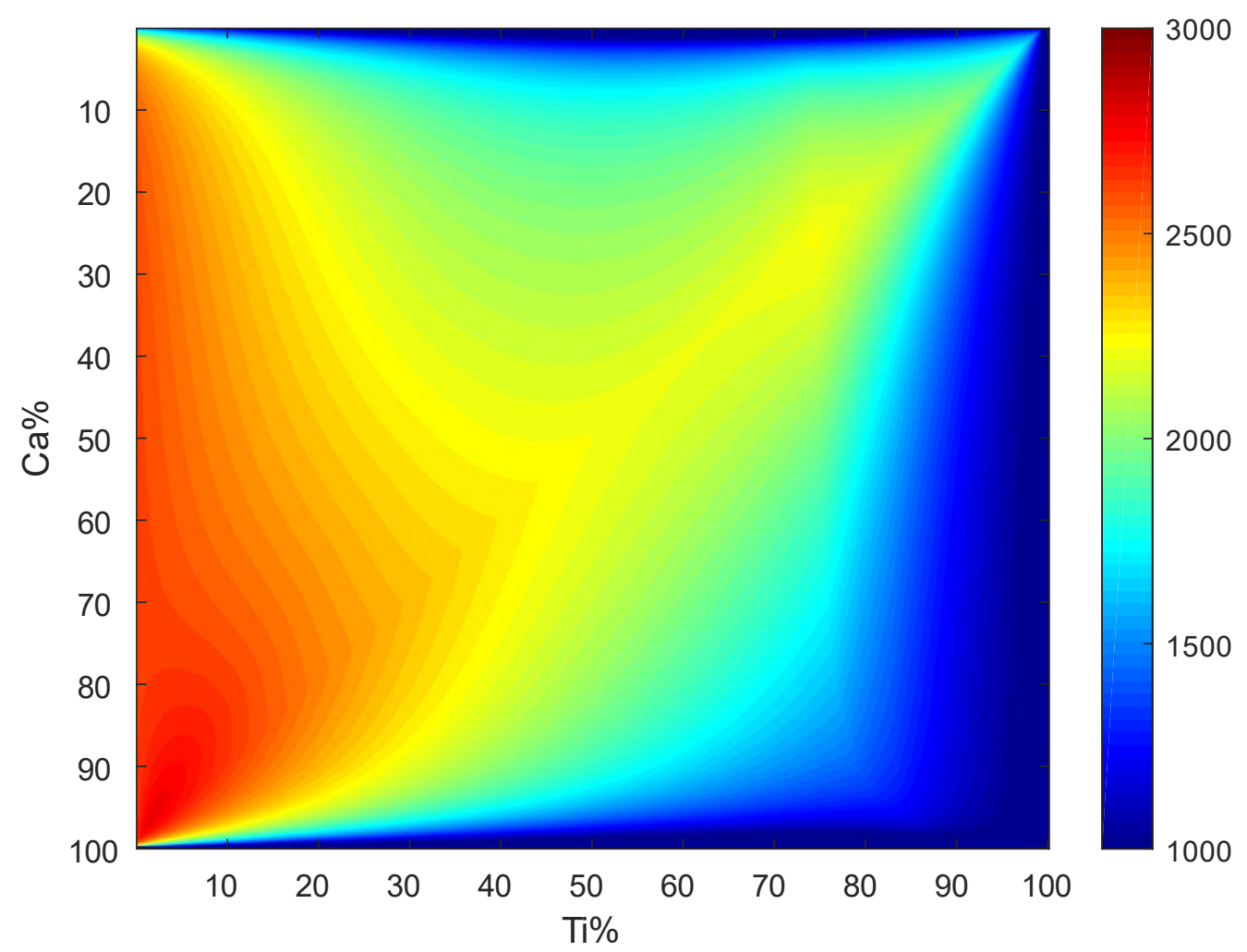

Figure 6 Heatmap of univariant $\mathrm{T}_{\text {mix }}$ as a function of Ti\% and Ca\% at $125 \mathrm{GPa}$ with thermodynamic equilibrium of the Ti before mixing (Figure S11-S13 show non-equilibrium cases). Values below 1000 $\mathrm{K}$ and above $3000 \mathrm{~K}$ were truncated to these values respectively. 


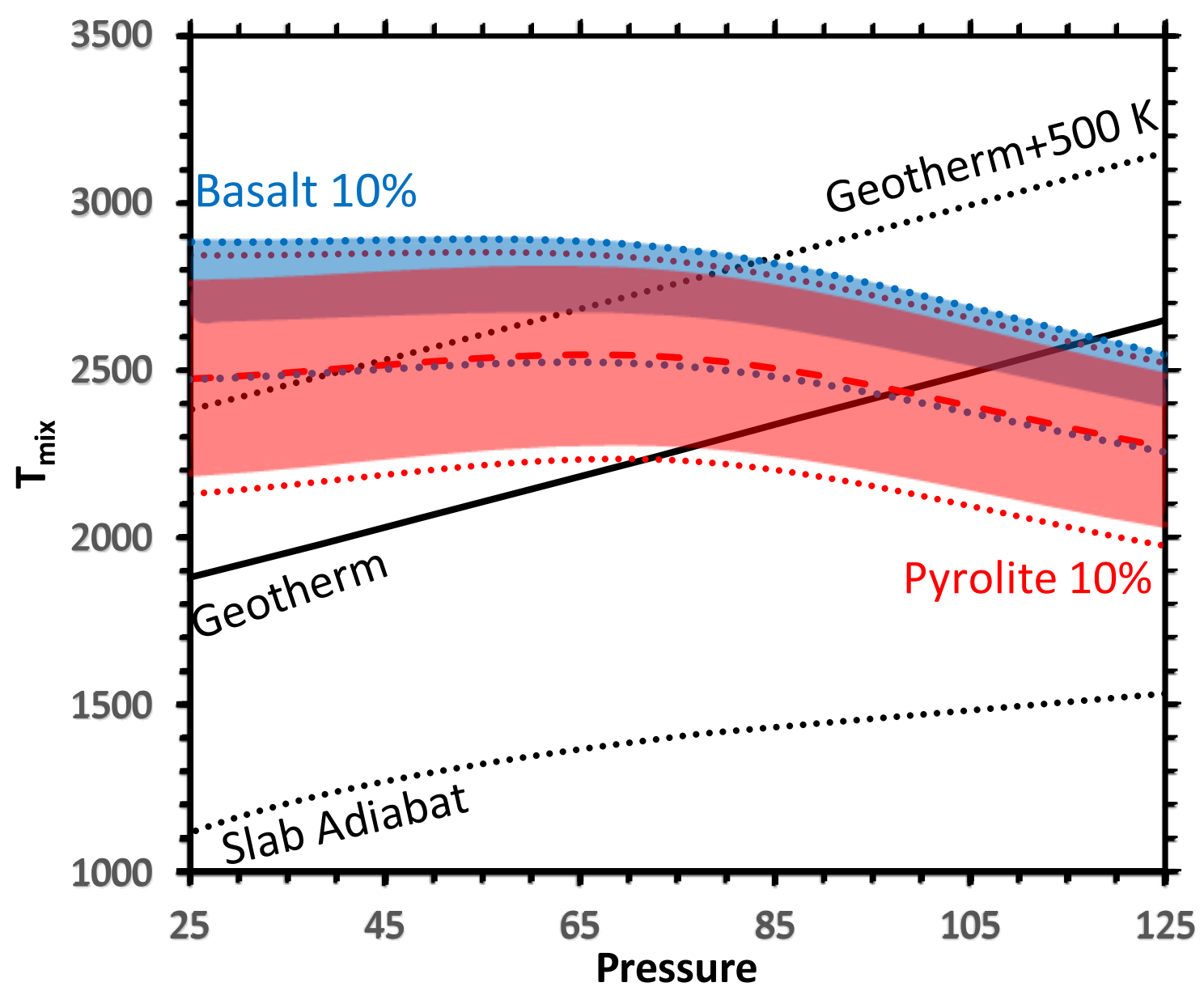

Fig $7 \mathrm{~T}_{\text {mix }}$ as a function of pressure for 2 compositions (basaltic $\mathrm{Ca}=50 \%$ and pyrolytic $\mathrm{Ca} \%=10$ ) with Ti\%=10- for these samples without Ti see Muir et al. (Submitted, 2020). The dashed line represents the univariant case, the shaded areas the phase loop. The dotted lines represent the bounds of the phase loop including geological variations of $\mathrm{Ca} \%$ - for the pyrolytic composition these are $\mathrm{Ca} \%=7-12$ and for basaltic compositions these are $\mathrm{C} a \%=30-60$. 


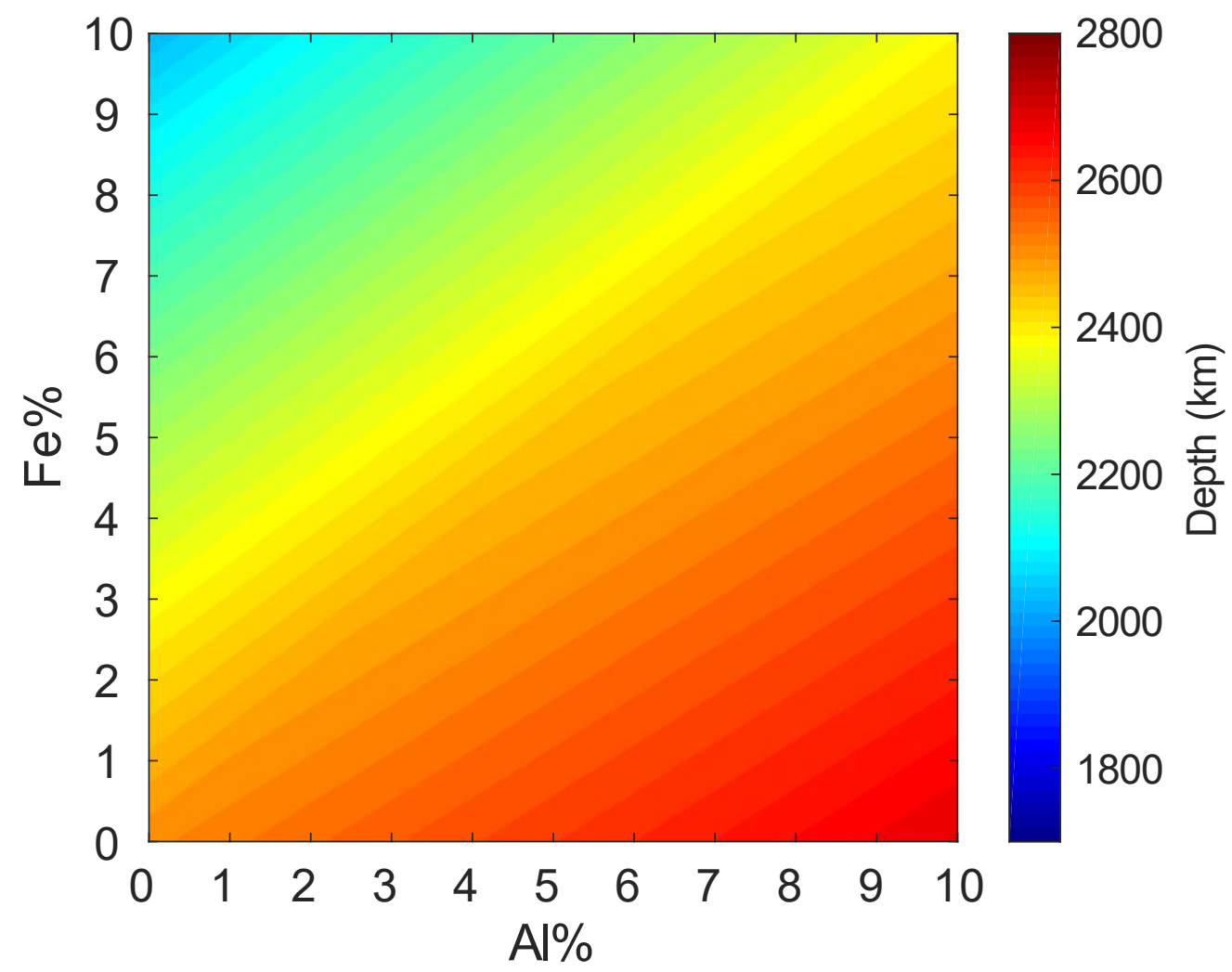

Figure 8 Depth at which $\mathrm{T}_{\text {mix }}$ crosses the geotherm for a sample OIB composition ( $\mathrm{Ca} \%=50 \mathrm{Ti} \%=10$ ) mixture with various amounts of $\mathrm{Fe}$ and $\mathrm{Al}$ as determined via the model outlined in the text. For this model the formation of Fe-Al was prioritised such that Fe-Al forms first and then leftover Fe or Al forms Ferrous iron or Al-Al pairs. Mixing depths above $1800 \mathrm{~km}$ and below $2800 \mathrm{~km}$ have been truncated to these values to follow the stability field of bdg. $T_{\text {mix }}$ always remains well above the coldest slab adiabat (see Figure S15). 


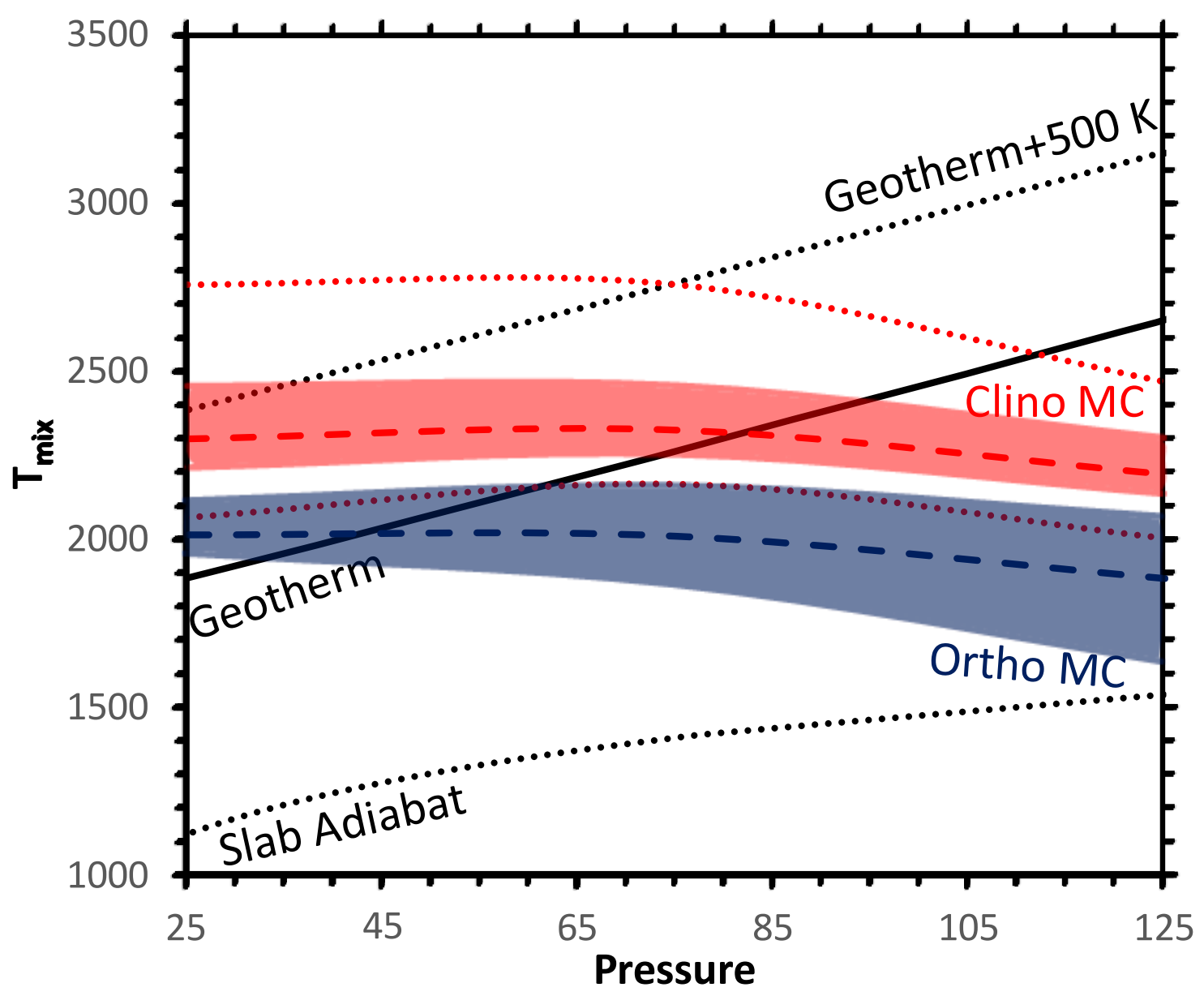

Fig $9 \mathrm{~T}_{\text {mix }}$ as a function of pressure for 2 compositions- red clinopyroxene ilmenite megacryst (Ca\%=30 $\mathrm{Ti} \%=25)$ and blue orthopyroxene ilmenite megacryst $(\mathrm{Ca} \%=5 \mathrm{Ti} \%=20)$. The dashed line represents the univariant case, the shaded areas the phase loop. The dotted lines represent the bounds of the phase loop including geological variations of Ca\% (20-40) and Ti\% (15-30) for the clinopyroxene ilmenite megacryst. 


\begin{tabular}{|r|r|r|r|r|r|r|r|r|}
\hline & \multicolumn{3}{|c|}{ Ti\%=0 } & \multicolumn{3}{c|}{ Ti\%=10 } \\
\hline & $25 \mathrm{GPa}$ & 25 & 125 & 125 & $25 \mathrm{GPa}$ & 25 & 125 & 125 \\
\hline & $\mathrm{Ca} \%=10$ & $\mathrm{Ca} \%=50$ & $\mathrm{Ca} \%=10$ & $\mathrm{Ca} \%=50$ & $\mathrm{Ca} \%=10$ & $\mathrm{Ca} \%=50$ & $\mathrm{Ca} \%=10$ & $\mathrm{Ca} \%=50$ \\
\hline $1000 \mathrm{~K}$ & -0.63 & -0.59 & -0.89 & -0.73 & -0.24 & -0.63 & -0.34 & -0.89 \\
\hline $2000 \mathrm{~K}$ & -0.86 & -0.76 & -0.97 & -0.75 & -0.32 & -0.86 & -0.36 & -0.97 \\
\hline $3000 \mathrm{~K}$ & -0.85 & -0.98 & -1.06 & -0.76 & -0.32 & -0.85 & -0.40 & -1.06 \\
\hline
\end{tabular}

Table 1: Change in density (\%) upon mixing of Ca-pv and bdg with $\mathrm{Ti} \%=0$ and $10, \mathrm{Ca}=10$ and 50 and at 25 and $125 \mathrm{GPa}$. This data was projected from runs at $\mathrm{Ca} \%=0,25,50$ and 100 and $\mathrm{Ti} \%=0,25,50$ and 100. 


\begin{tabular}{|c|c|c|c|c|c|c|c|}
\hline & & $\mathrm{Ti} \%=0$ & 5 & 10 & 15 & 20 & 30 \\
\hline \multirow{2}{*}{ Equilibrated } & $25 \mathrm{GPa}$ & 0.4 & 1.0 & 2.0 & 3.1 & 4.6 & 9.1 \\
\hline & $125 \mathrm{GPa}$ & 1.1 & 2.2 & 3.6 & 5.3 & 7.6 & 13.7 \\
\hline \multirow{2}{*}{$\begin{array}{l}\text { Distributed } \\
(\mathrm{K}=1)\end{array}$} & $25 \mathrm{GPa}$ & 0.4 & 1.1 & 2.1 & 3.5 & 5.0 & 9.6 \\
\hline & $125 \mathrm{GPa}$ & 1.1 & 2.4 & 4.5 & 8.6 & 23.9 & 50.0 \\
\hline \multirow{3}{*}{$\begin{array}{l}\mathrm{CaTiO}_{3} \\
\text { source } \\
(\mathrm{K}=1000)\end{array}$} & $25 \mathrm{GPa}$ & 0.4 & 5.5 & 11.9 & 19.4 & 28.3 & 50.0 \\
\hline & & & & & & & \\
\hline & $125 \mathrm{GPa}$ & 1.1 & 12.9 & 34.1 & 50.0 & 50.0 & 50.0 \\
\hline \multirow{3}{*}{$\begin{array}{l}\mathrm{MgTiO}_{3} \\
\text { source } \\
(\mathrm{K}=0.00001)\end{array}$} & $25 \mathrm{GPa}$ & 0.4 & 1.1 & 2.5 & 4.3 & 7.9 & 50.0 \\
\hline & & & & & & & \\
\hline & $125 \mathrm{GPa}$ & 1.1 & 2.2 & 3.6 & 5.3 & 7.6 & 13.8 \\
\hline \multirow{2}{*}{$K=2$} & $25 \mathrm{GPa}$ & 0.4 & 1 & 2.05 & 3.19 & 4.68 & 10.57 \\
\hline & $125 \mathrm{GPa}$ & 0.9 & 2.65 & 6.05 & 21 & 50.0 & 50.0 \\
\hline \multirow{2}{*}{$K=5$} & $25 \mathrm{GPa}$ & 0.4 & 1 & 2.14 & 4.55 & 10.28 & 33.9 \\
\hline & $125 \mathrm{GPa}$ & 0.9 & 3.63 & 15.8 & 50.0 & 50.0 & 50.0 \\
\hline
\end{tabular}

Table 2: Ca solubility (\%) in bdg as a function of pressure, Ti\% and $\mathrm{K}$ at $2000 \mathrm{~K}$. Mg solubility in Ca-pv is shown in Table $\mathrm{S} 4$. 


\begin{tabular}{|l|r|r|r|r|r|r|r|r|r|r|r|r|}
\hline & \multicolumn{5}{|c|}{ Pyrolytic Ca\%=10 } & \multicolumn{5}{c|}{ Basaltic Ca\%=50 } \\
\cline { 2 - 13 } & \multicolumn{3}{|c|}{ Ti\%=1 } & \multicolumn{3}{c|}{ Ti\%=10 } & \multicolumn{3}{c|}{ Ti\%=1 } & \multicolumn{3}{c|}{ Ti\%=10 } \\
\cline { 2 - 12 } & $0.1 \%$ & 1 & 10 & 0.1 & 1 & 10 & 0.1 & 1 & 10 & 0.1 & 1 & 10 \\
\hline $\mathrm{Fe}^{2+}$ & -8 & -77 & -793 & -8 & -78 & -809 & -3 & -34 & -344 & -3 & -35 & -353 \\
\hline $\mathrm{Fe}^{3+}-\mathrm{Fe}^{3+}$ & 2 & 20 & 195 & 2 & 21 & 202 & 7 & 50 & 276 & 7 & 50 & 270 \\
\hline $\mathrm{Fe}^{3+}-\mathrm{Al}^{3+}$ & -1 & -7 & -68 & -1 & -6 & -63 & 6 & 41 & 175 & 6 & 39 & 166 \\
\hline $\mathrm{Al}^{3+}-\mathrm{Al}^{3+}$ & 6 & 59 & 561 & 6 & 60 & 566 & 9 & 65 & 418 & 9 & 64 & 415 \\
\hline
\end{tabular}

Table 3: $\Delta \mathrm{T}_{\text {mixdefect }}$ at $125 \mathrm{GPa}$ induced by different elements as a function of their concentration and the background $\mathrm{Ca}$ and Ti concentration constructed using our defect model. $25 \mathrm{GPa}$ values are listed in Table S7 and have the similar values. 


\section{Supplementary Information}

This document contains supplementary figures and tables for the manuscript "The Effect of Ti on Capv and Mg-pv phase stability". Presented within are additional details of our method and additional graphs mostly plotting data for different Ca\% and Ti\% values.

\section{Supplementary Methods:}

\section{Molecular Dynamics:}

To determine the vibrational entropy we used a Velocity-Autocorrelation Function (VACF) method. More accurate methods such as thermodynamic integration are possible but as $G_{\text {mix }}$ values are fairly large the extreme accuracy of these methods is likely unnecessary.

Vibrational entropy determination requires the vibrational density of states function, $S(v)$, which represents the distribution of normal modes $(v)$ in the system. This can be represented as:

$S(v)=\frac{2}{k_{b} T} \sum_{i=1}^{N} \sum_{k=1}^{3} m_{i} s_{i}^{k}$ Equation $\mathrm{S} 1$

where $\mathrm{N}$ is the total number of atoms in the system, $m_{i}$ is the mass of atom $i, s_{i}^{k}$ is the spectral density of atom $i$ in the direction $k(x=1, y=2, z=3), T$ is the temperature and $k_{b}$ is the Boltzmann constant. In our case $s_{i}^{k}$ is obtained by taking the fourier transform of the VACF. Entropy is then obtained by

$$
S_{v i b}=k_{b} \int_{0}^{\infty} S(v) d V \text { Equation S2 }
$$

Entropies and enthalpies were determined from molecular dynamics runs with a length of $2.5 \mathrm{ps.}$

The error of the energies obtained from molecular dynamics were calculated for each individual run using the method of Flyvbjerg and Petersen (Flyvbjerg and Petersen, 1989) and were less than 1.5 $\mathrm{meV} /$ atom in all cases. Propagating these errors leads to the error in mixing temperatures $<50 \mathrm{~K}(2 \sigma)$ for all mixtures. As shown in Figure 7-9 compositional variation causes larger changes than our likely errors.

\section{Configurational Entropy:}

To determine the configurational entropy of mixed phases we calculated the enthalpy of different configurations of $\mathrm{Mg}$ and $\mathrm{Ca}$ on the $\mathrm{Mg}$ site and $\mathrm{Ti}$ and $\mathrm{Si}$ on the Si site in the unit cell. For $\mathrm{Ca}_{\times} \mathrm{Mg}_{1-}$ 
${ }_{x} \mathrm{Si}_{y} \mathrm{Ti}_{1-y} \mathrm{O}_{3}$ we calculated the configurational entropy for all combinations of $x$ and $y=0$, $0.125,0.25,0.375,0.5,0.75,0.875,1$ at 25 and $125 \mathrm{GPa}$.

As the number of configurations increase with $\mathrm{N}$ factorial, 80 atom unit cells proved too large to obtain a workable number of configurations. The energy difference of different configurations is independent of unit cell size, however, and the disadvantage of using a small unit cell in these calculations is simply that some configurations may not be appropriately sampled. To this end for $\mathrm{Ca}_{x} \mathrm{Mg}_{1-x} \mathrm{Si}_{y} \mathrm{Ti}_{1-y} \mathrm{O}_{3}$ we determined configurational entropy in a 40 atom unit cell $(2 \times 1 \times 1)$ when either $\mathrm{x}$ or $\mathrm{y}$ were between 0.25 and 0.75 or they were both $0.125 / 0.875$ and we used 80 atoms when $\mathrm{x}$ or $y=0.125$ or 0.875 and the other value was 0 or 1 . For each of these systems we determined all unique configurations of Ca, Mg, Si and Ti and calculated their static enthalpy. To determine $S_{\text {config }}$ we then used the Gibbs entropy formulation:

$$
\begin{aligned}
& Z=\sum_{i} e^{\frac{-E_{i}}{k b T}} \text { Equation S3 } \\
& P_{i}=\frac{1}{Z} e^{\frac{-E_{i}}{k b T}} \text { Equation S4 } \\
& S_{\text {config }}=-k_{b} \sum_{i} p_{i} \ln p_{i} \text { Equation S5 }
\end{aligned}
$$

where $Z$ is the partition function, $i$ is each configuration including degenerate copies of each configuration, $E_{i}$ is the energy of that configuration (in this case we used the enthalpy) and $p_{i}$ is the probability that it occurs. If every configuration has equivalent energy these calculations reduce to the Boltzmann entropy formula:

$$
S_{\text {config }}=k_{b} \ln W \text { Equation S6 }
$$

where $\mathrm{W}$ is the number of possible configurations. This is equivalent to ideal mixing of $\mathrm{Mg}, \mathrm{Ca}, \mathrm{Si}$ and Ti provides the maximum possible configurational entropy in this system. $S_{\text {config }}$ was interpolated across $\mathrm{Ca} \%$ and $\mathrm{Ti} \%$ using a polynomial and incorporated in the equation for $\Delta G_{m i x}$ (Equation 1). As all possible configurations (in 40 or 80 atom simulation cells) were evaluated the uncertainties in these estimates of $S_{\text {config }}$ are limited to missed configurations that may occur at high temperature or in simulation cells with an increased number of atoms that are more like infinite crystals. 


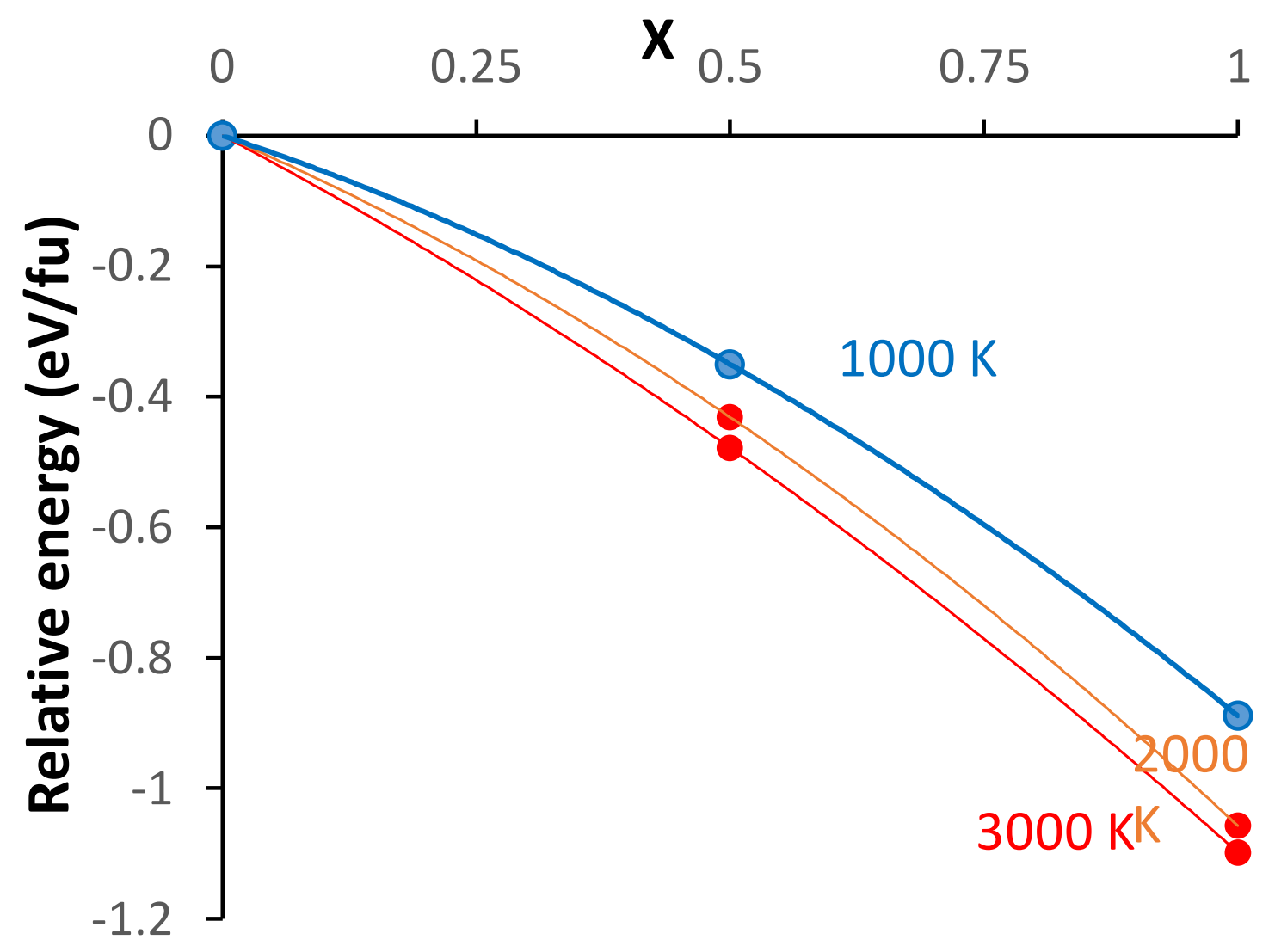

Figure S1: Plot of the energy of different compositions of $\mathrm{Ca}_{x} \mathrm{Mg}_{1-x} \mathrm{Si}_{0.5} \mathrm{Ti}_{0.5} \mathrm{O}_{3}$ relative to the energy of $\mathrm{MgSi}_{0.5} \mathrm{Ti}_{0.5} \mathrm{O}_{3}$ at $25 \mathrm{GPa}$. The plotted line was drawn with $\mathrm{x}=0,0.5$ and 1 and $\mathrm{x}=0.25$ was determined independently. This shows that a polynomial fit is appropriate for these phases except maybe at extreme values of $x$. Similar behaviour was observed at $125 \mathrm{GPa}$ and with different Ti values. 


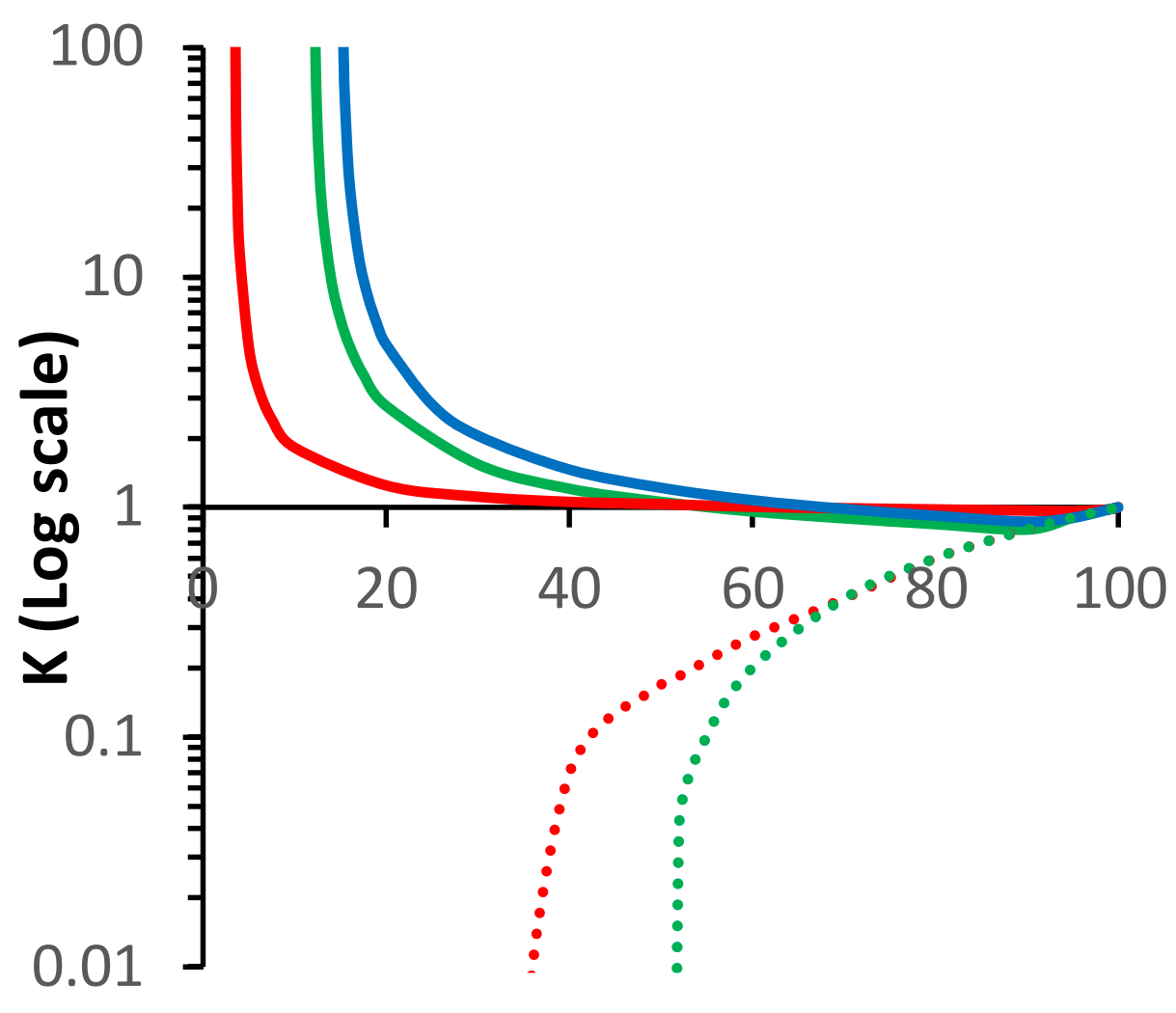

$\mathrm{Ti} \%$

Figure S2 Partitioning of Ti ( $\mathrm{K}$ see text) as a function of temperature (red $=3000$, green $=2000$ blue $=1000 \mathrm{~K}$ ) and pressure (solid lines=25 GPa, dashed lines=125 GPa) for a Ca-pv and bdg mixture with $\mathrm{Ca} \%=50$ and various total Ti\% values. For $125 \mathrm{GPa}$ the 1000 and $2000 \mathrm{~K}$ lines overlap at this scale. At $25 \mathrm{GPa}$ Ti increasingly partitions to Ca-pv with a lower Ti\% and lower T. At $125 \mathrm{GPa} \mathrm{Ti}$ overwhelmingly partitions to bdg and particularly below Ti\%=30. A mixture with $\mathrm{Ca} \%$ of 10 is shown in Figure S3. 


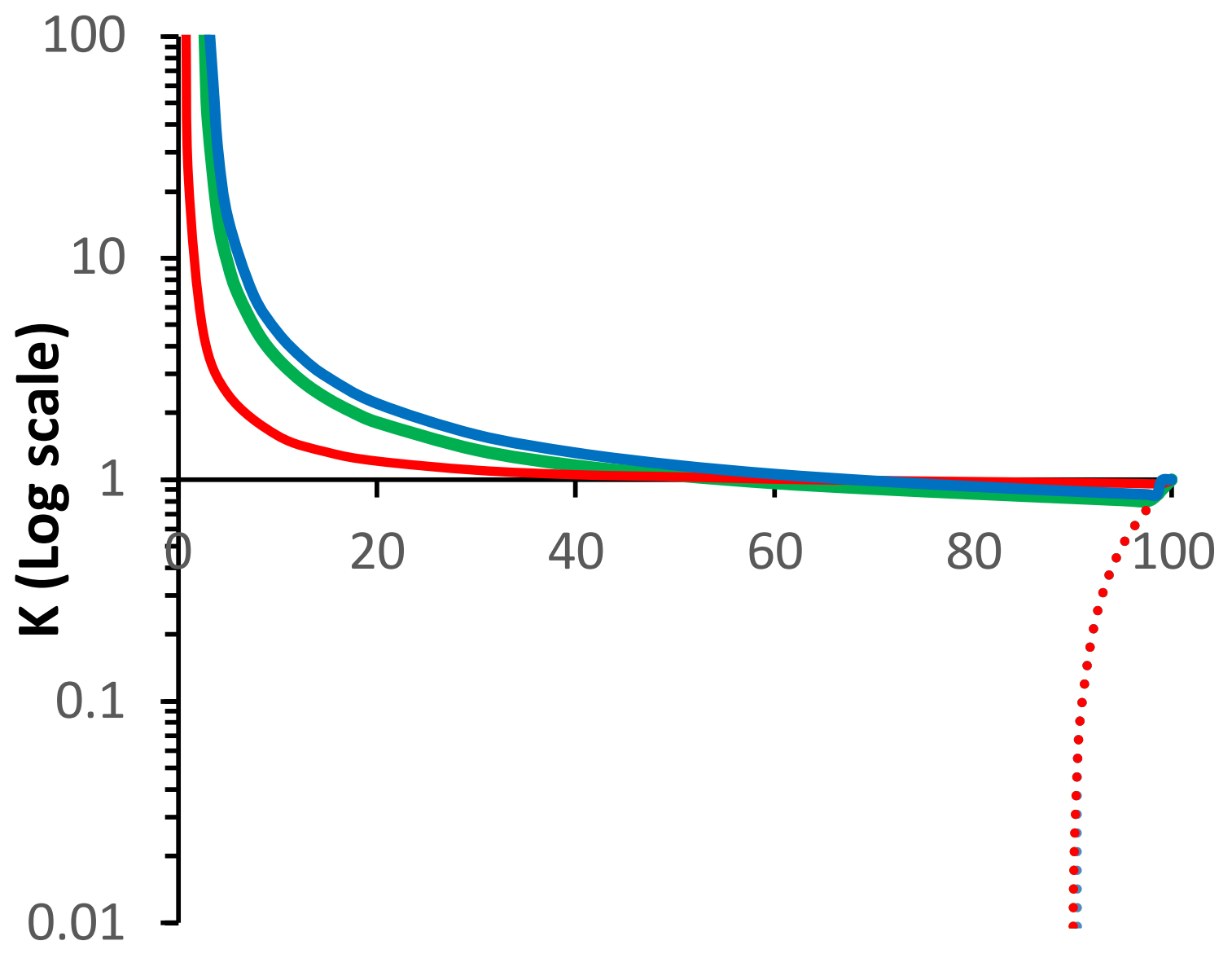

\section{$\mathrm{Ti} \%$}

Figure S3 Partitioning of $\mathrm{Ti}$ (K see text) as a function of temperature (red $=3000$, green $=2000$ blue $=1000 \mathrm{~K}$ ) and pressure (solid lines=25 GPa, dashed lines=125 GPa) for a Ca-pv and bdg mixture with $\mathrm{Ca} \%=10$ and various total Ti\% values. For $125 \mathrm{GPa}$ all lines overlap at this scale. At $25 \mathrm{GPa} \mathrm{Ti}$ increasingly partitions to Ca-pv with a lower Ti\% and lower T. At $125 \mathrm{GPa}$ Ti overwhelmingly partitions to bdg. 


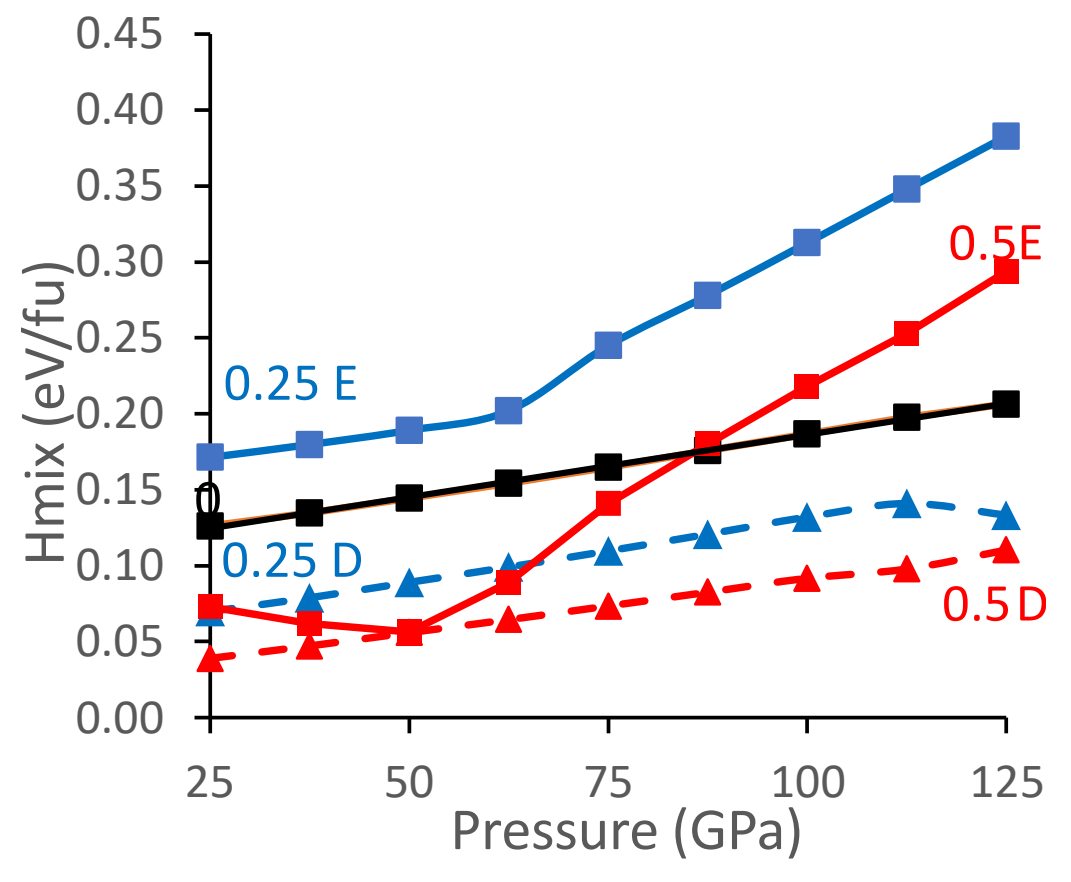

Figure S4: $\mathrm{H}_{\text {mix }}$ (eV/f.u) as a function of pressure for a mixture of Ca-pv and bdg with $\mathrm{Ca} \%=050$ with Ti\% set to 0,25 and 50 (black, blue and red) and with Ti distributed premixing either equally between the two components ( $d$, distributed $K=1$, dotted line) or distributed according to its energy entirely to one phase (e, equilibrated, solid line) 


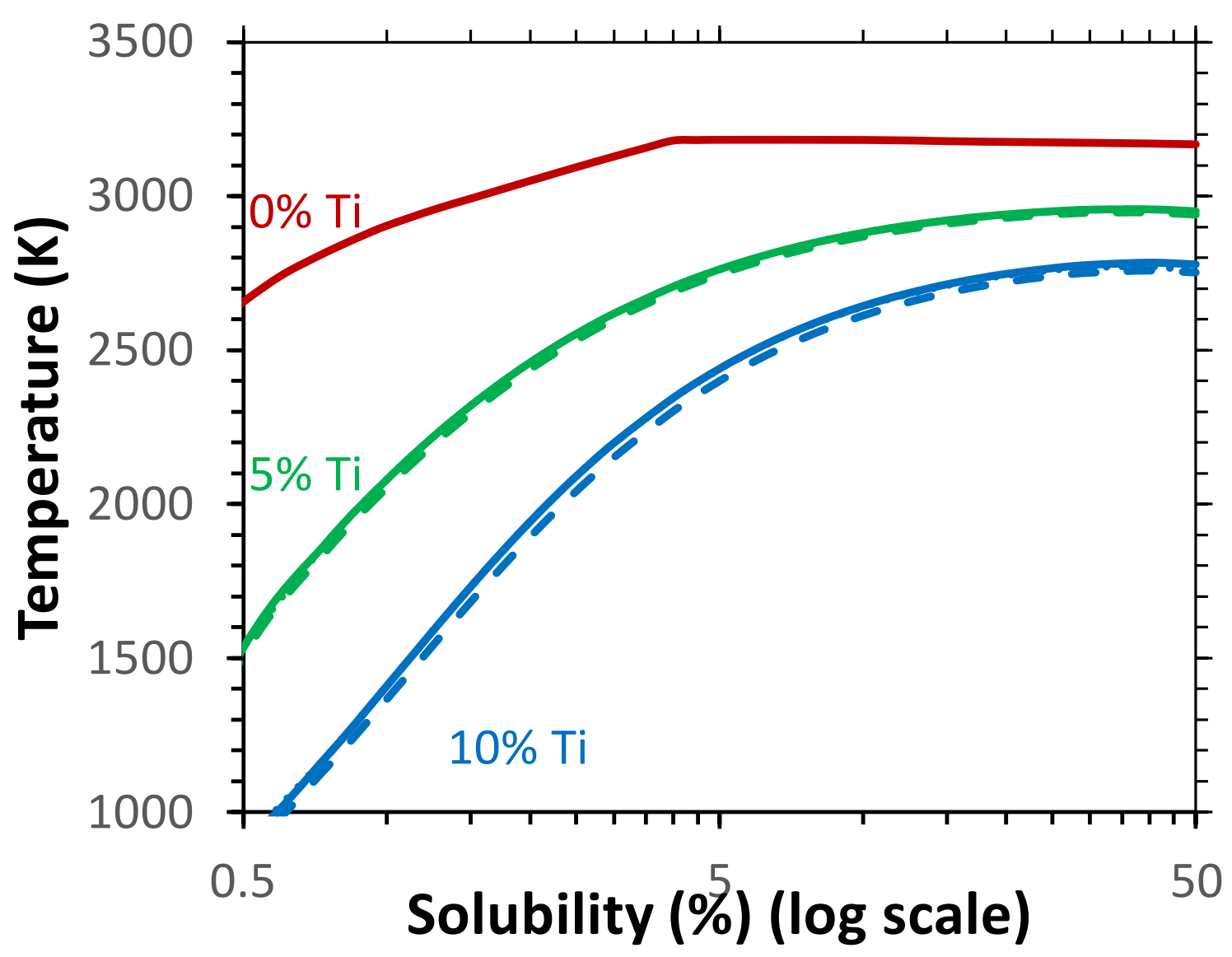

Figure S5 Univariant solubility of Mg in Ca-pv at $25 \mathrm{GPa}$ with different amounts of Ti\% (0, 5 and 10\% with different colours) as a function of temperature. Solid lines are for the equilibrated case, dashed lines for the distributed case $\mathrm{K}=1$ and dotted lines for the $\mathrm{CaTiO}_{3}$ source case $\mathrm{K}=1000$. The $\mathrm{K}=1000$ case is not visible for $\mathrm{Ti}=5 \%$ and $\mathrm{Ti}=10 \%$ but is near identical to the equilibrated case. 


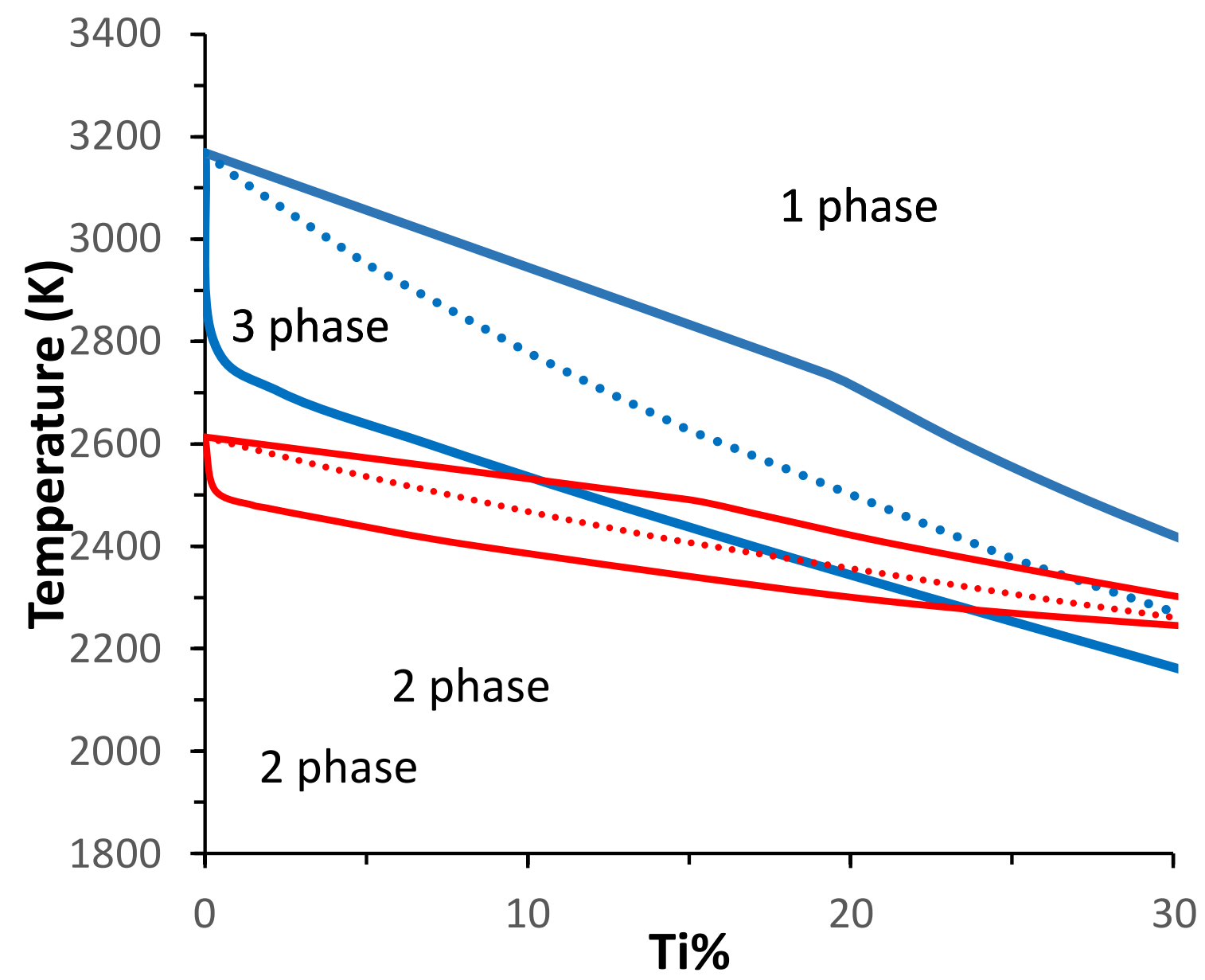

Figure $\mathrm{S} 6$ Phase loops (as outlined in the method) determined with fixed pressure ( $25 \mathrm{GPa}$ blue, 125 $\mathrm{GPa}$ red) at $\mathrm{Ca} \%=50$ as a function of $\mathrm{Ti}$ with the univariant transition plotted as a dotted line. At low concentrations of $\mathrm{Ti}$ the band broadens extremely quickly from the $\mathrm{Ti} \%=0$ point. 


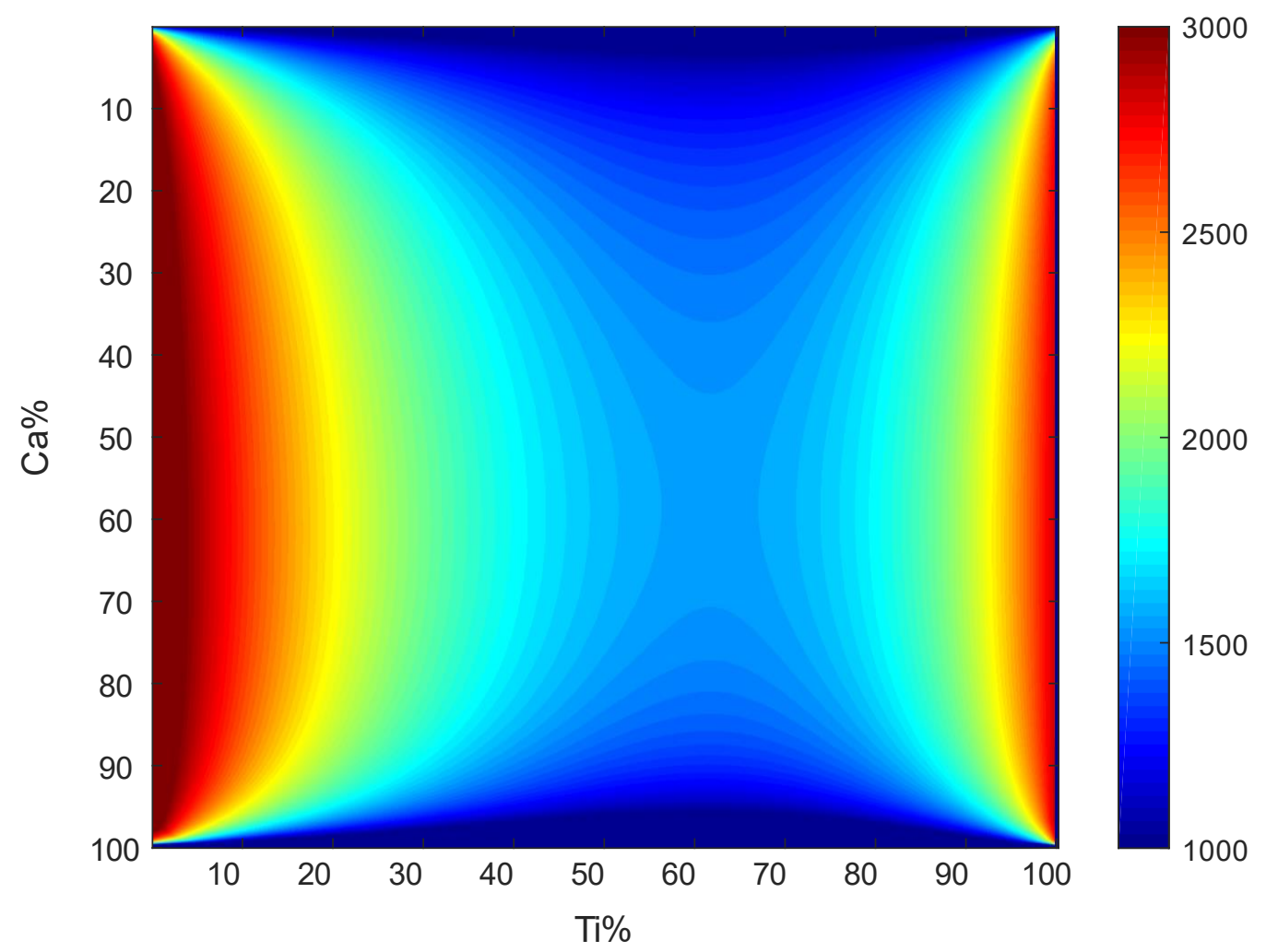

Figure S7 Heatmap of univariant $\mathrm{T}_{\text {mix }}$ as a function of Ti\% and Ca\% at $25 \mathrm{GPa}$ with the distributed case $\mathrm{K}=1$. Values below $1000 \mathrm{~K}$ and above $3000 \mathrm{~K}$ were truncated to these values respectively. 


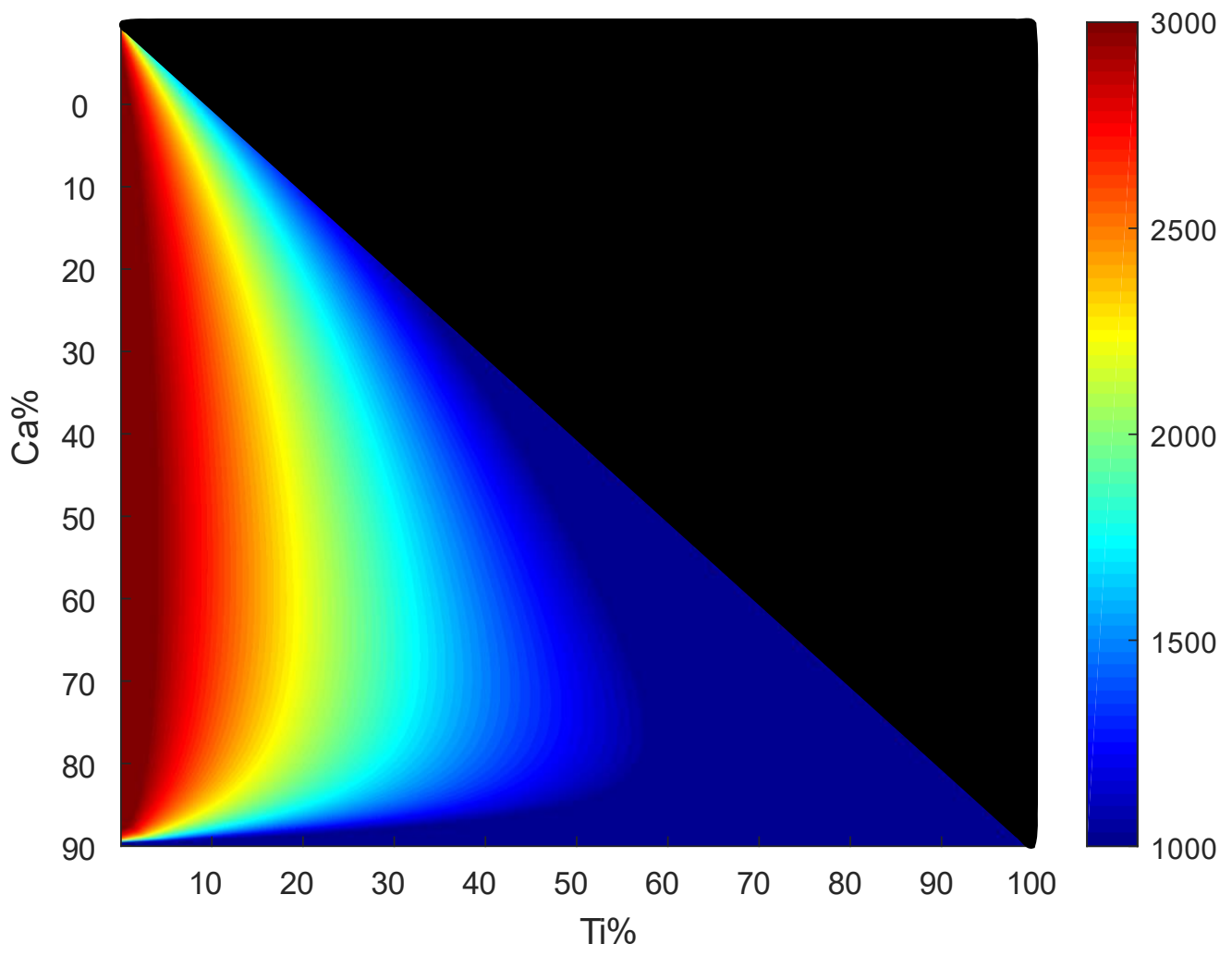

Figure S8: As Figure $\mathrm{S} 7$ but with the $\mathrm{CaTiO}_{3}$ source case $(\mathrm{K}=1000)$. The black region requires an additional source of $\mathrm{Ti}$ and thus cannot be properly shown in this case. This is similar to the equilibrated case in Figure 4 but with slightly lower mixing temperatures. 


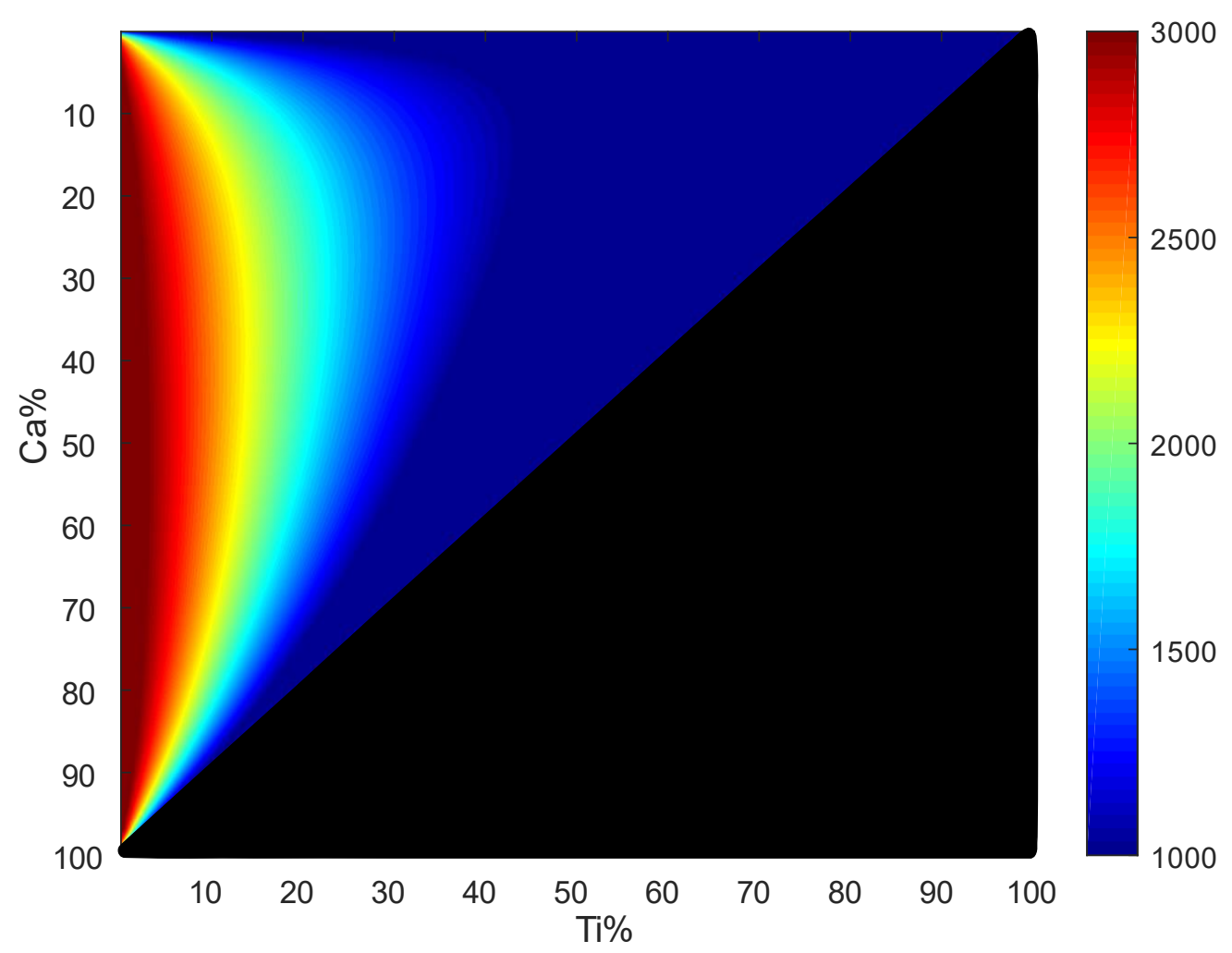

Figure S9: As Figure S7 but with the with $\mathrm{MgTiO}_{3}$ source case $(\mathrm{K}=0.001)$. This is very similar to the equilibrated case in Figure 4. 


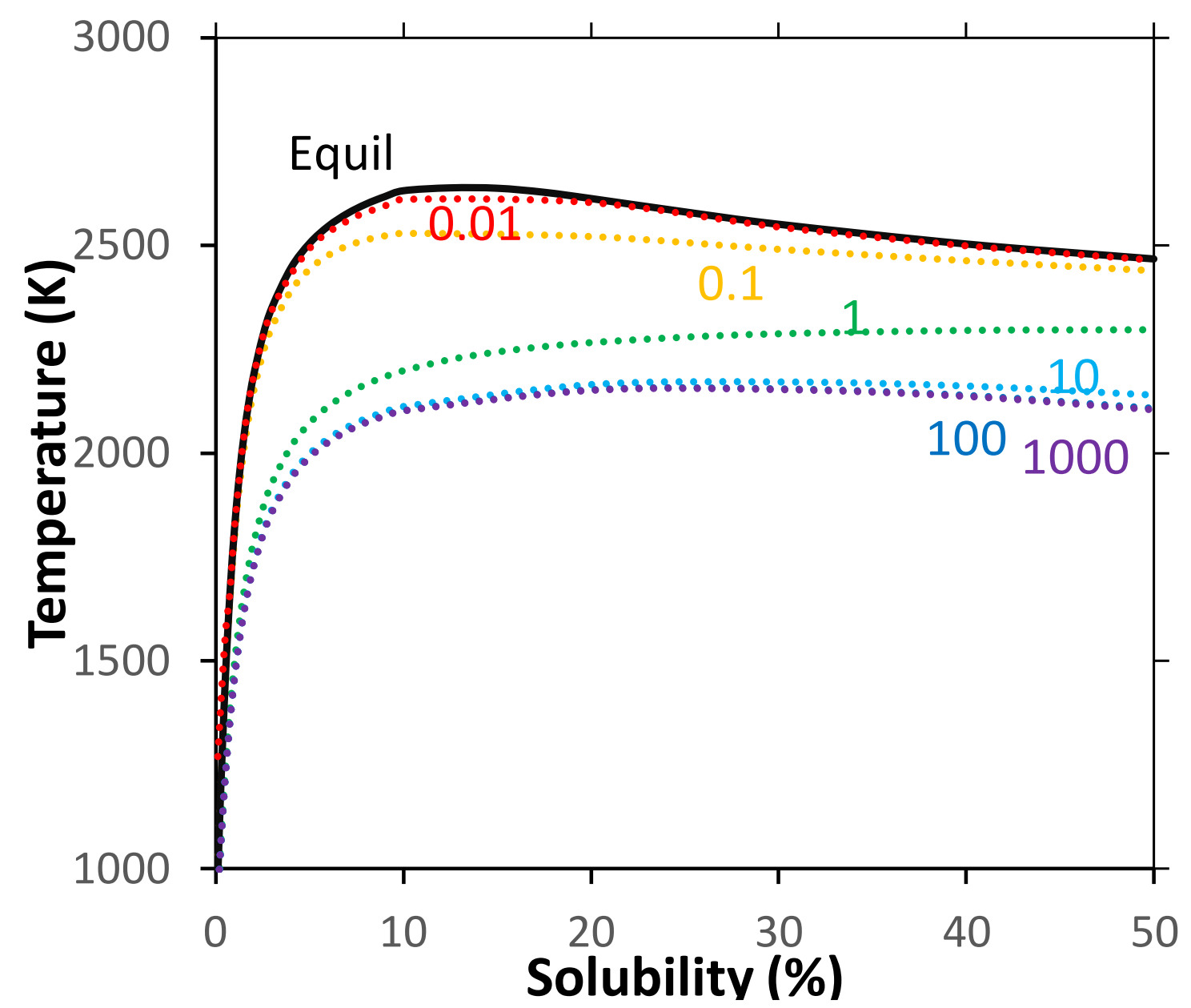

Figure S10: Solubility of $\mathrm{Mg}$ in Ca-pv at $125 \mathrm{GPa}$ as a function of $\mathrm{T}$ and with different distribution of $\mathrm{Ti}$ premixing (in $\mathrm{K}$, different coloured dotted lines). The case where Ti is equilibrated before mixing is shown as a black solid line and has the lowest mixing. 


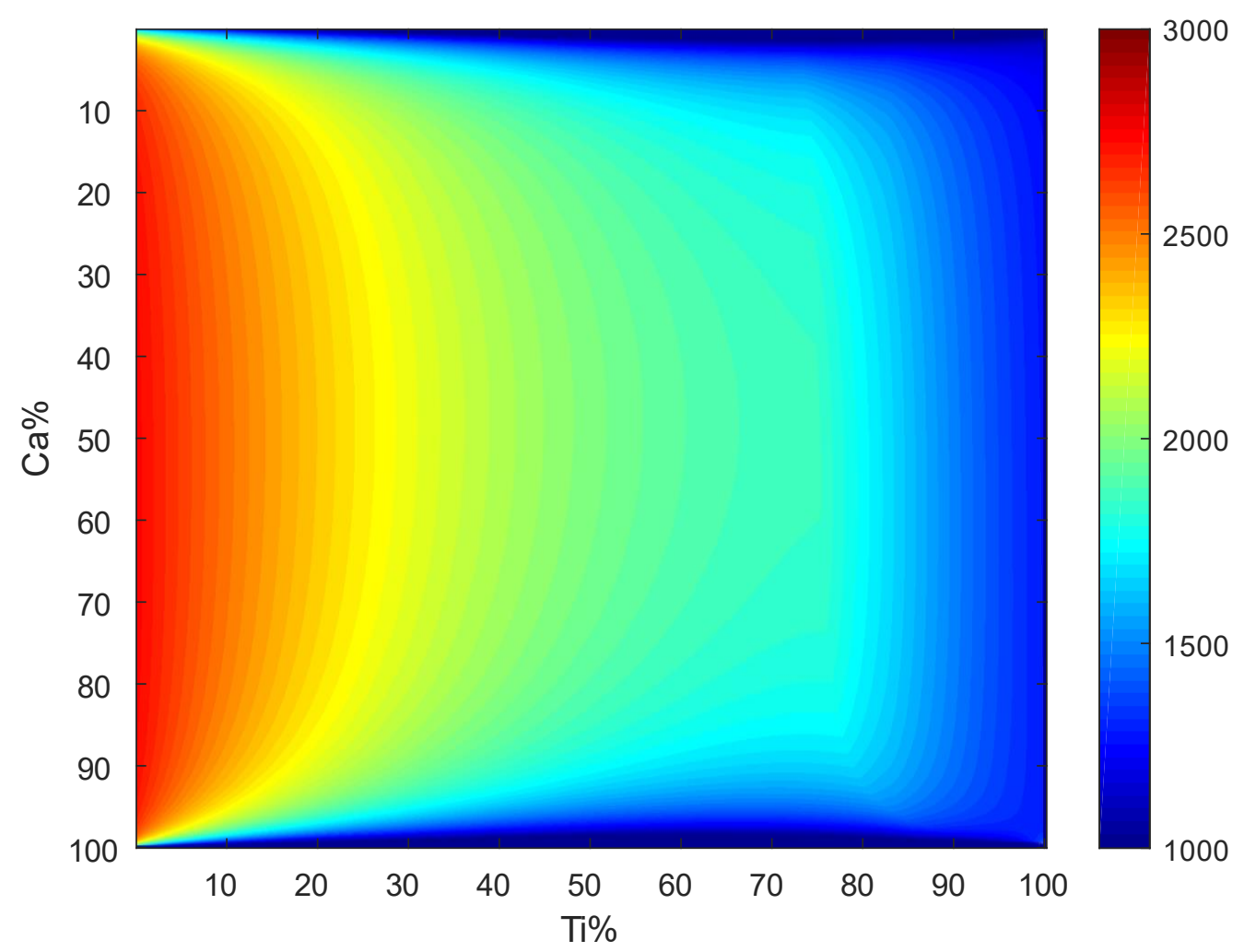

Figure S11 Heatmap of univariant $\mathrm{T}_{\text {mix }}$ as a function of Ti\% and Ca\% at $125 \mathrm{GPa}$ with the distributed case $\mathrm{K}=1$. Values below $1000 \mathrm{~K}$ and above $3000 \mathrm{~K}$ were truncated to these values respectively. This has a much smoother distribution than the equilibrated case which has large distortions due to the partitioning of $\mathrm{Ti}$. At low Ti\% a large band of high $\mathrm{T}_{\text {mix }}$ stretches across the Ca\% range. There is no decrease of $\mathrm{T}_{\text {mix }}$ at $50 \%$ and instead it steadily decreases across the $\mathrm{T}_{\text {mix }}$ range due to the nature of $\mathrm{H}_{\text {mix }}$ at this pressure. 


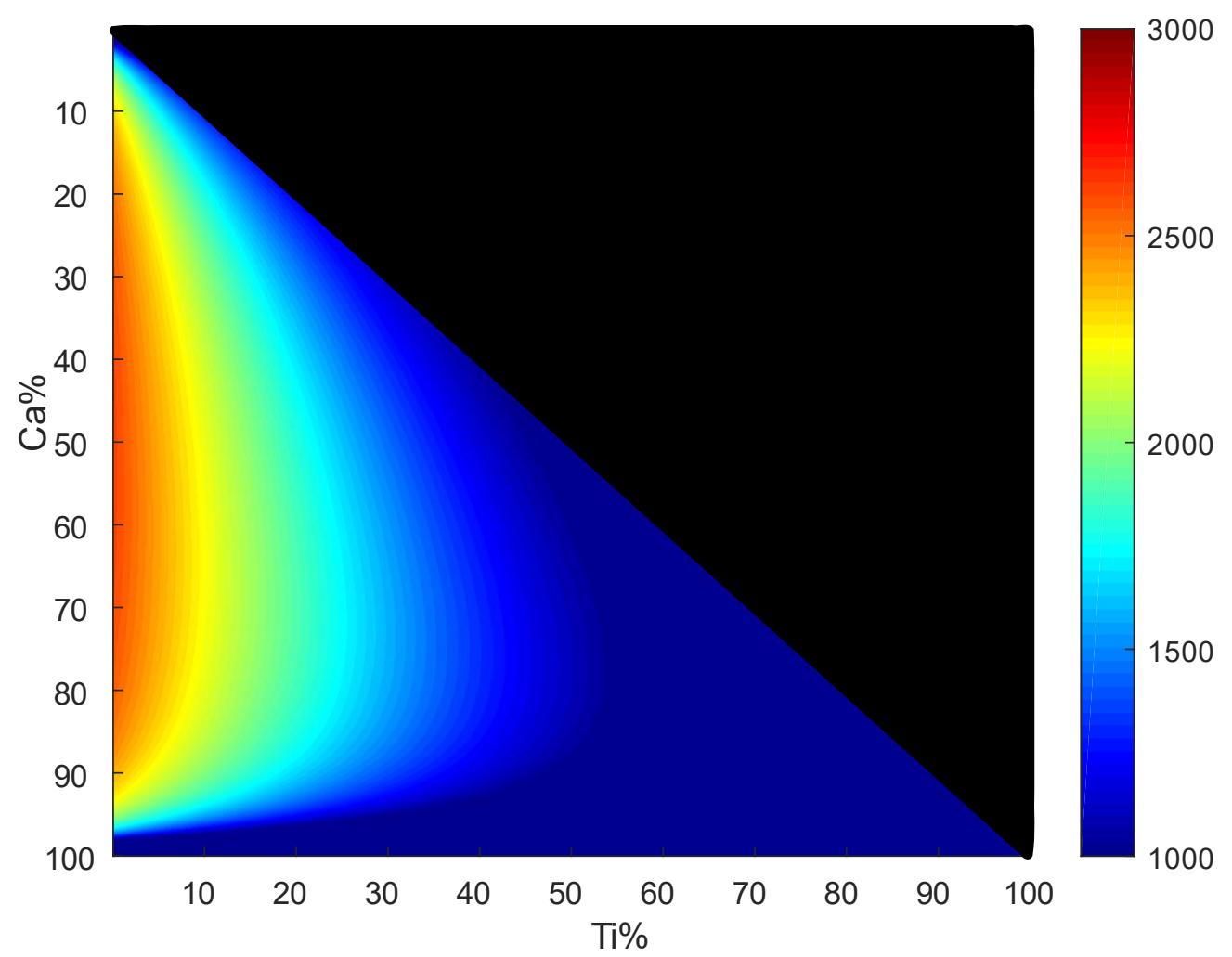

Figure S12: As Figure $\mathrm{S} 11$ but the $\mathrm{CaTiO}_{3}$ source case $(\mathrm{K}=1000)$. The black region requires an additional source of Ti and thus cannot be properly shown in this case. This is similar to the distributed case in Figure $\mathrm{S} 11$ but with much lower $\mathrm{T}_{\text {mix }}$ values due to the instability of $\mathrm{CaTiO}_{3}$ at this pressure. 


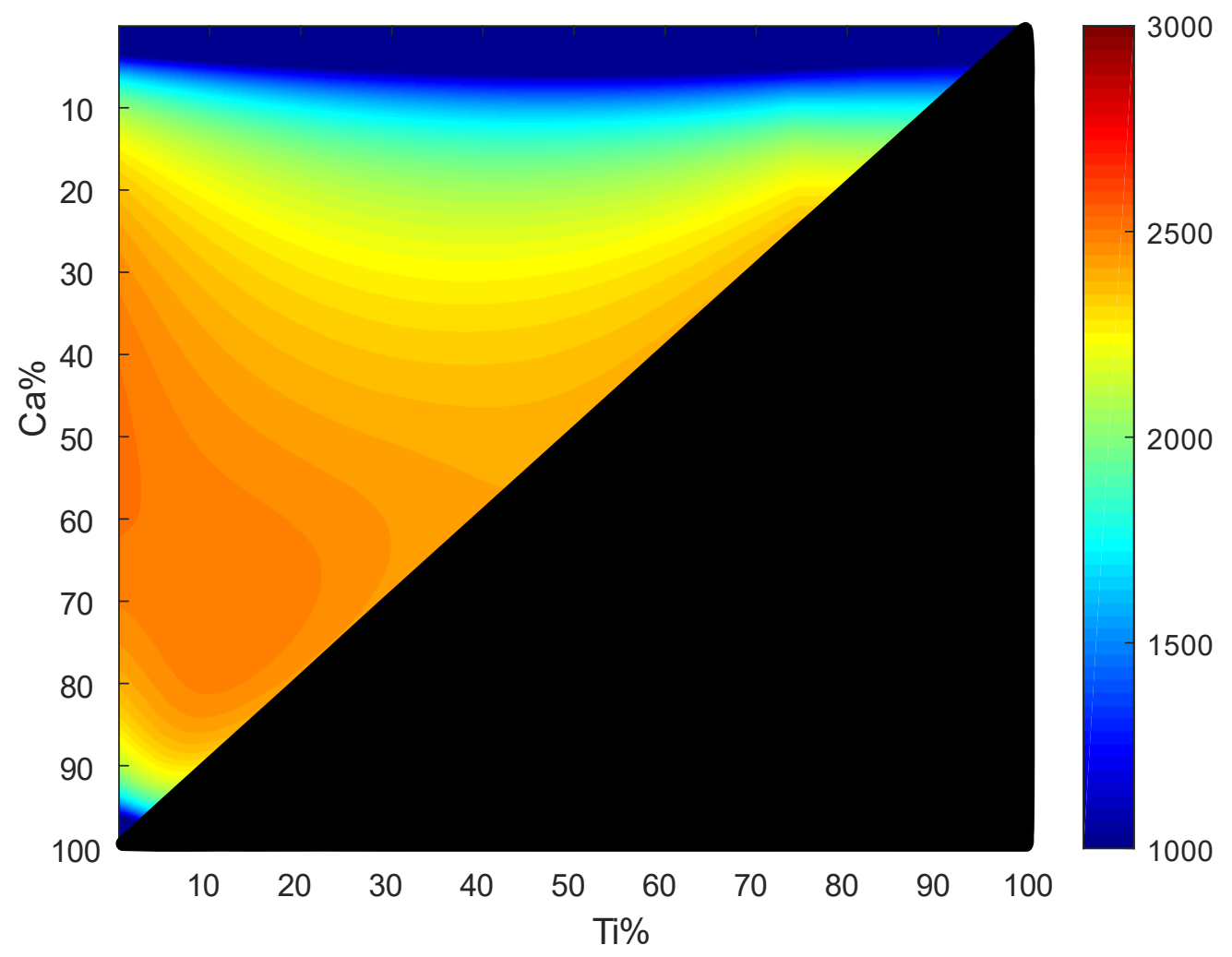

Figure S13: As Figure $\mathrm{S} 11$ but the $\mathrm{MgTiO}_{3}$ source case $(\mathrm{K}=0.001)$. The black region requires an additional source of $\mathrm{Ti}$ and thus cannot be properly shown in this case. This is similar to the equilibrated case in Figure 6 but with lower $T_{\text {mix }}$ values. 


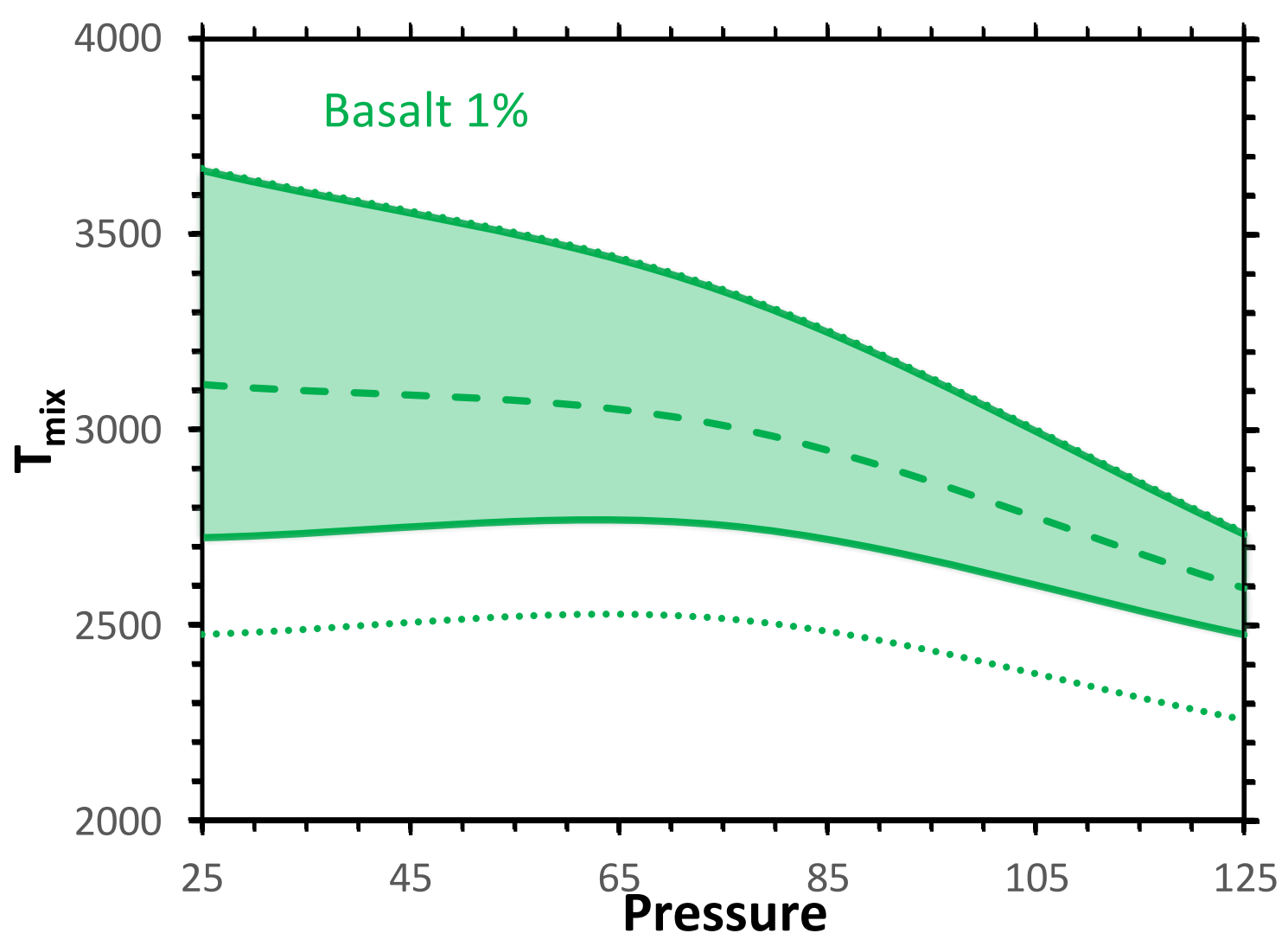

Figure $\mathrm{S} 14 \mathrm{~T}_{\text {mix }}$ as a function of pressure for basalt $(\mathrm{Ca}=50 \%)$ with $\mathrm{Ti} \%=1$. The dashed line represents the univariant case, the shaded areas the phase loop. The dotted line represent the bounds of the phase loop including geological variations of $\mathrm{Ca} \%=30-60$. The variation of $\mathrm{Ca} \%$ does not affect the bottommost boundary (and so is not pictured) but it increases the topmost boundary. 


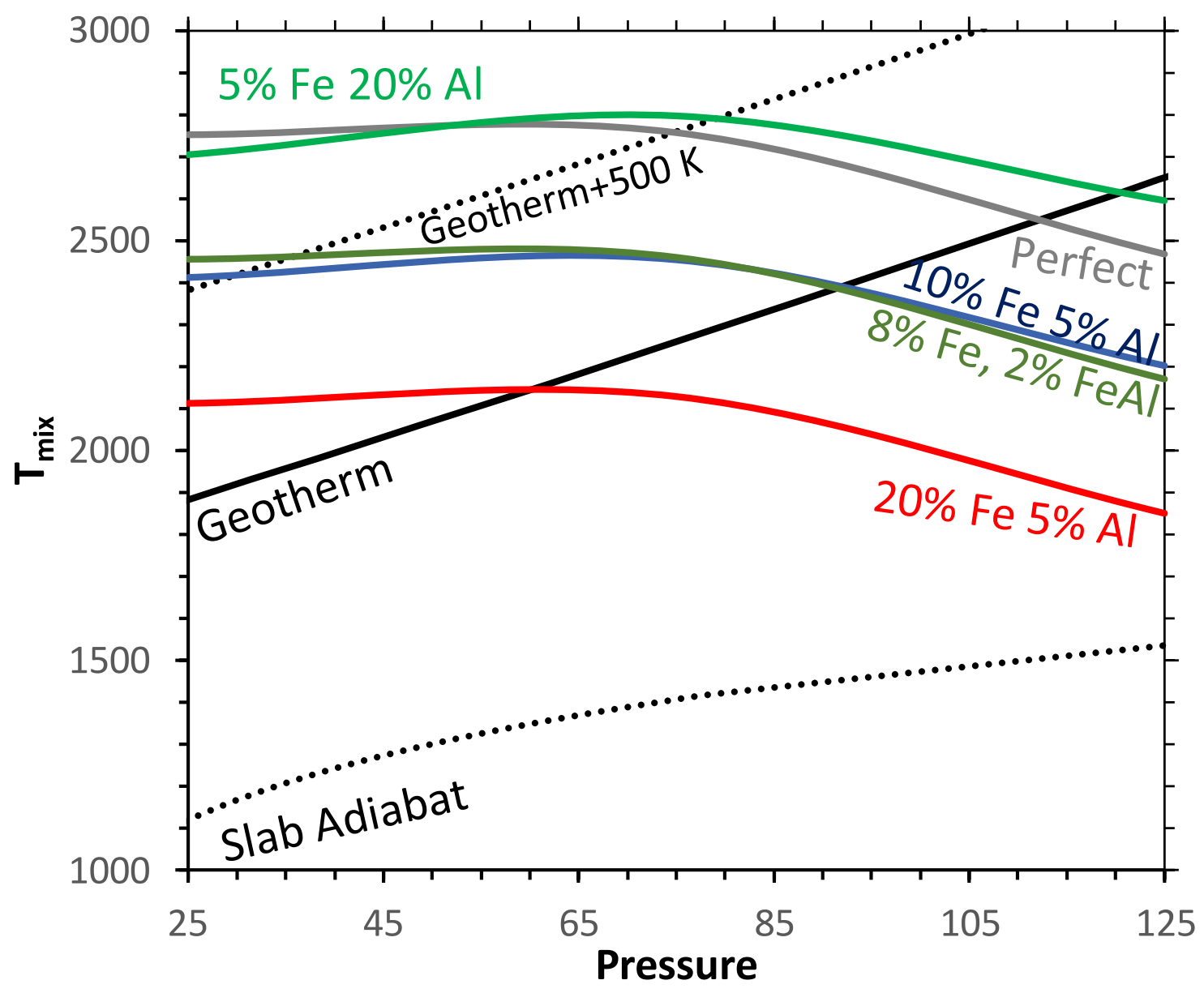

Figure S15 Plot of $\mathrm{T}_{\text {mix }}$ of a sample OIB configuration ( $\mathrm{Ca}=50 \%, \mathrm{Ti}=10 \%$, equilibrated $\mathrm{Ti}$, univariant) as a function of pressure and with different elements added in. These compositions are somewhat arbitrary and illustrate how different ranges of elements can affect the miscibility. In the labels $\mathrm{Fe}=$ ferrous iron, $\mathrm{Al}=\mathrm{Al}-\mathrm{Al}$ pairs and $\mathrm{FeAl}=\mathrm{Fe}-\mathrm{Al}$ pairs, perfect represents a mixture with no added iron or aluminium. The method for constructing this graph is explained in the text. The black lines represent various temperature profiles through the lower mantle- that of standard geotherm (Ono, 2008), that of the coldest possible slab adiabat (Eberle et al., 2002) and an artificial "hot" geotherm which is $500 \mathrm{~K}$ hotter to show how temperature fluctuations could affect things. Even with extremely large amounts of ferrous iron $\mathrm{T}_{\text {mix }}$ for this basalt remains well above the slab adiabat. 


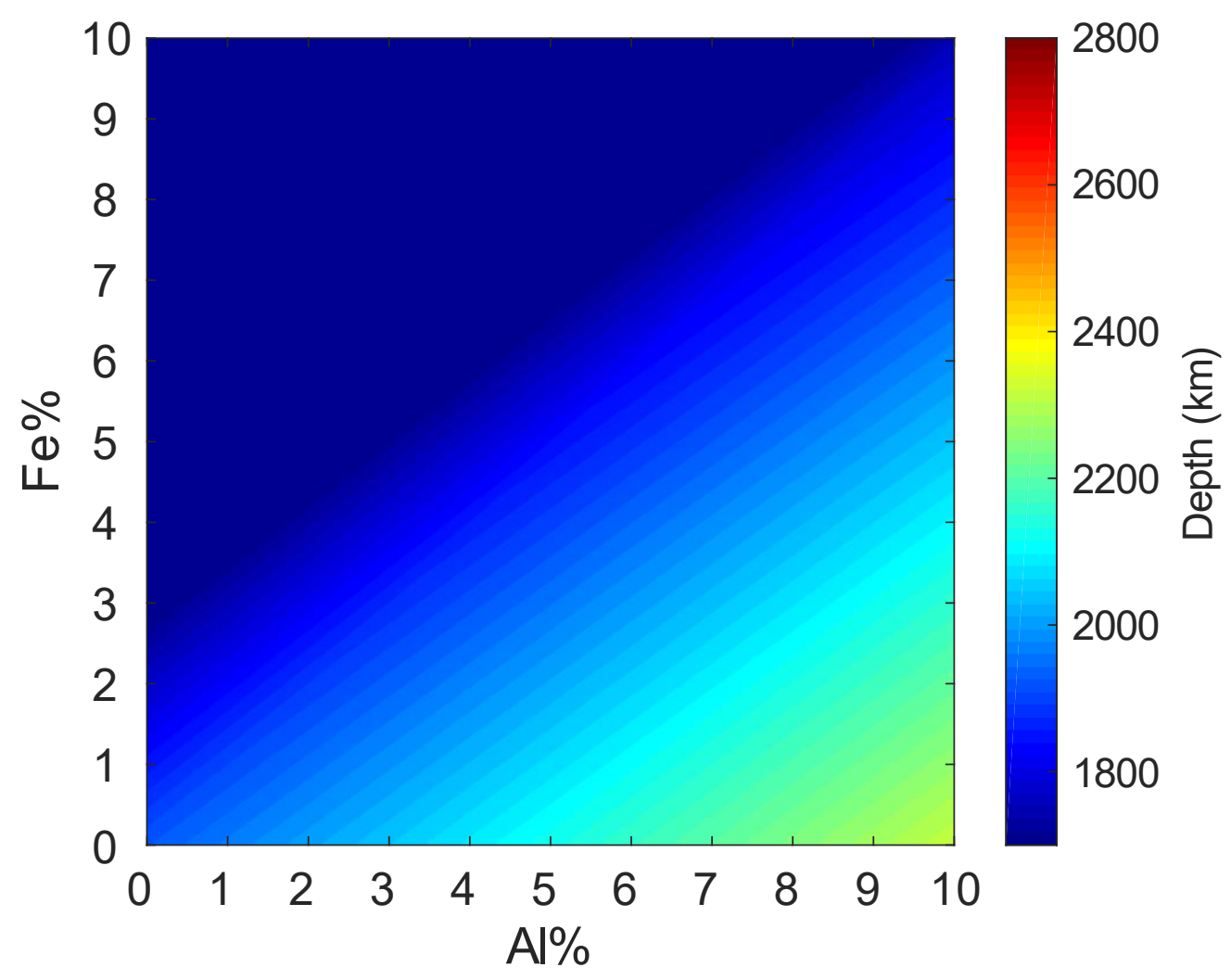

Figure S16 Depth at which $T_{\text {mix }}$ crosses the geotherm for a clinopyroxene ilmenite-megacryst ( $\mathrm{Ca} \%=30$, Ti\%=25, equilibrated $\mathrm{Ti}$, univariant) mixture with various amounts of $\mathrm{Fe}$ and $\mathrm{Al}$ as determined via the model outlined in the text. For this model the formation of Fe-Al was prioritised such that Fe-Al forms first and then leftover Fe or Al forms Ferrous iron or Al-Al pairs. Mixing depths above $1800 \mathrm{~km}$ and below $2800 \mathrm{~km}$ have been truncated to these values to follow the stability field of bdg. 


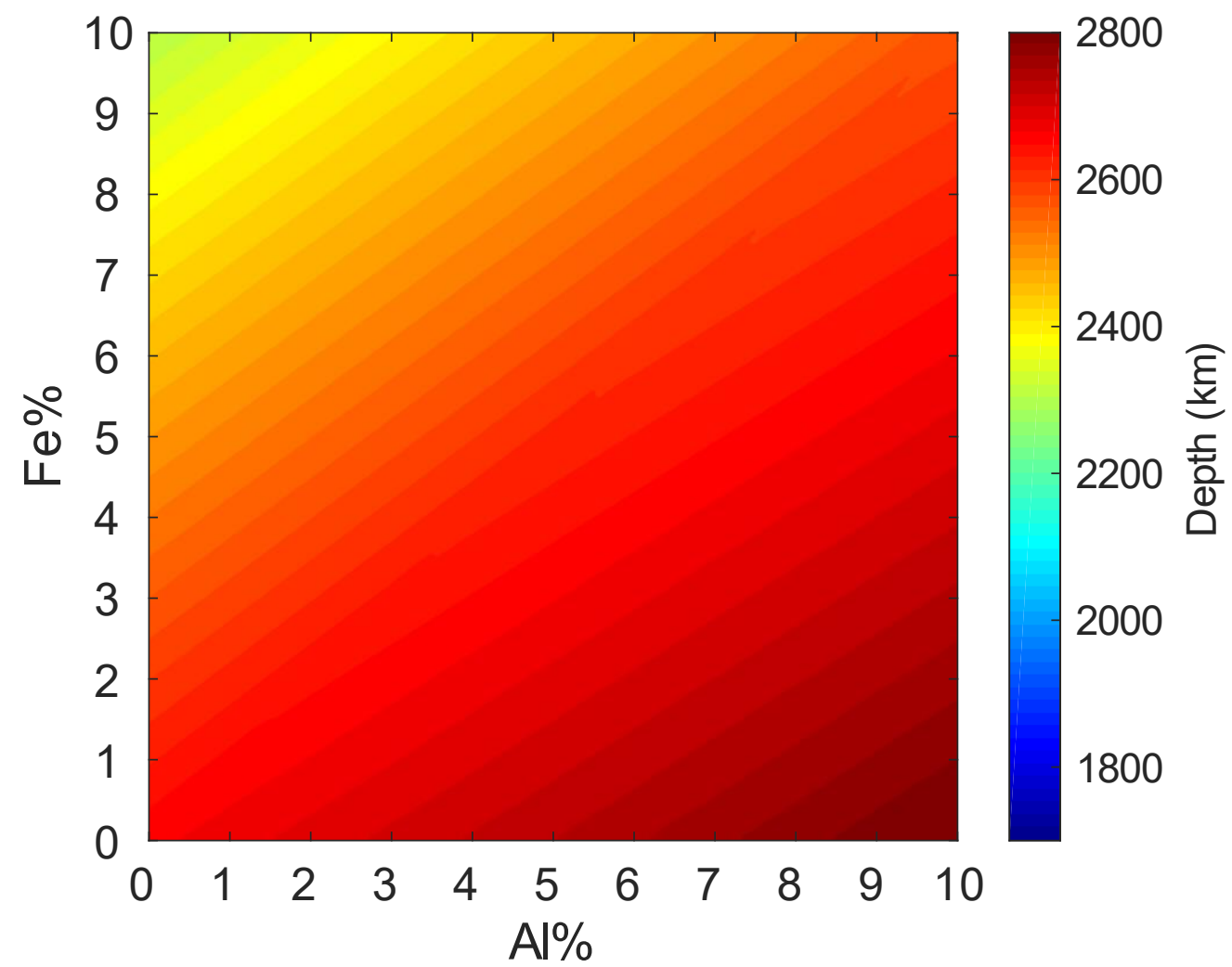

Figure S17: As Figure S16 but for a low Ti basalt mixture more representative of MORB (Ca\%=50, $\mathrm{Ti} \%=1)$. The mixing temperature here is always strongly above a slab adiabat. 


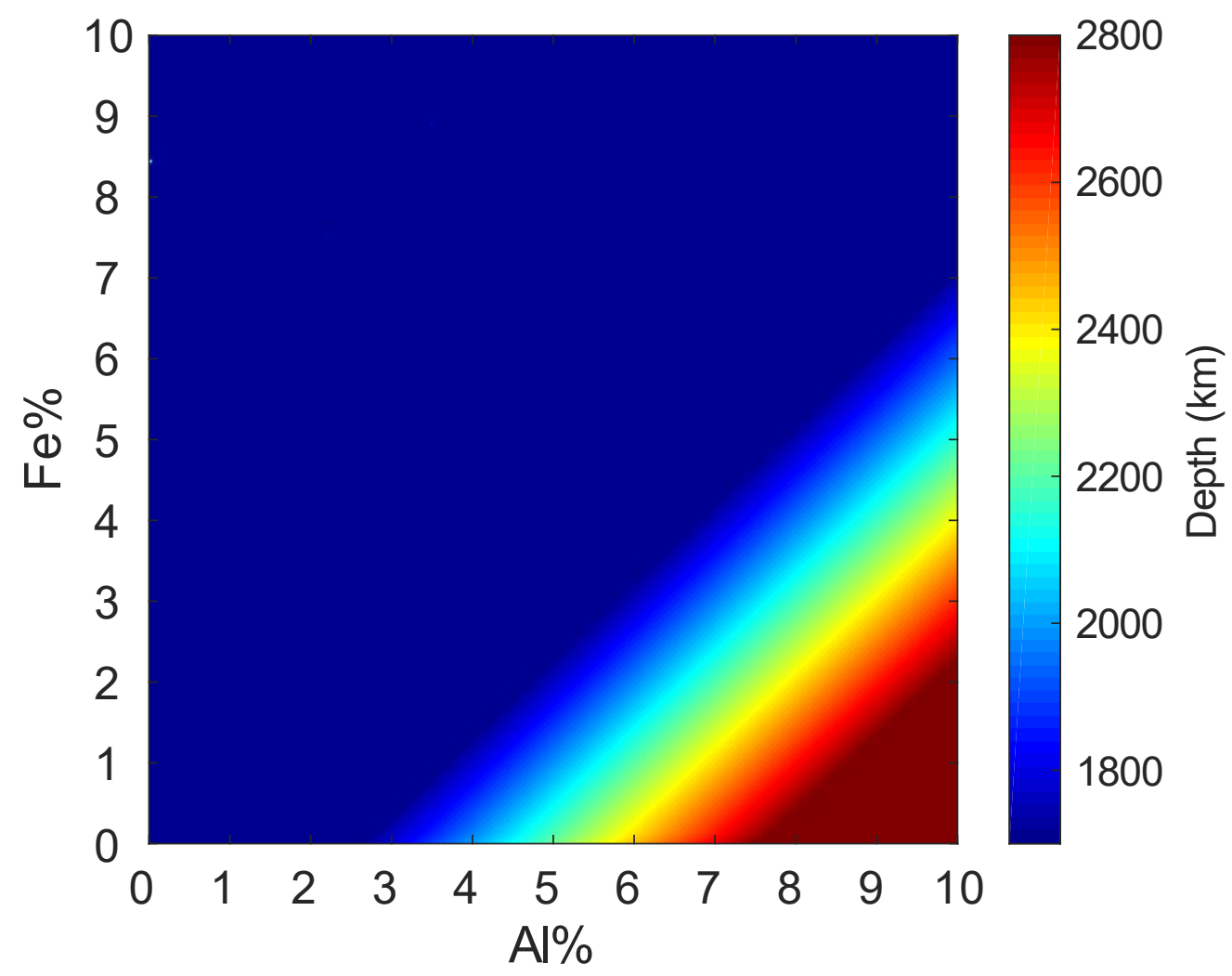

Figure S18- As Figure S16 but for a sample orthopyroxene ilmenite megacryst ( $\mathrm{C} a \%=5 \mathrm{Ti} \%=20$ ). The $20 \% \mathrm{Fe} 5 \% \mathrm{Al}$ case is always below $1000 \mathrm{~K}$. 


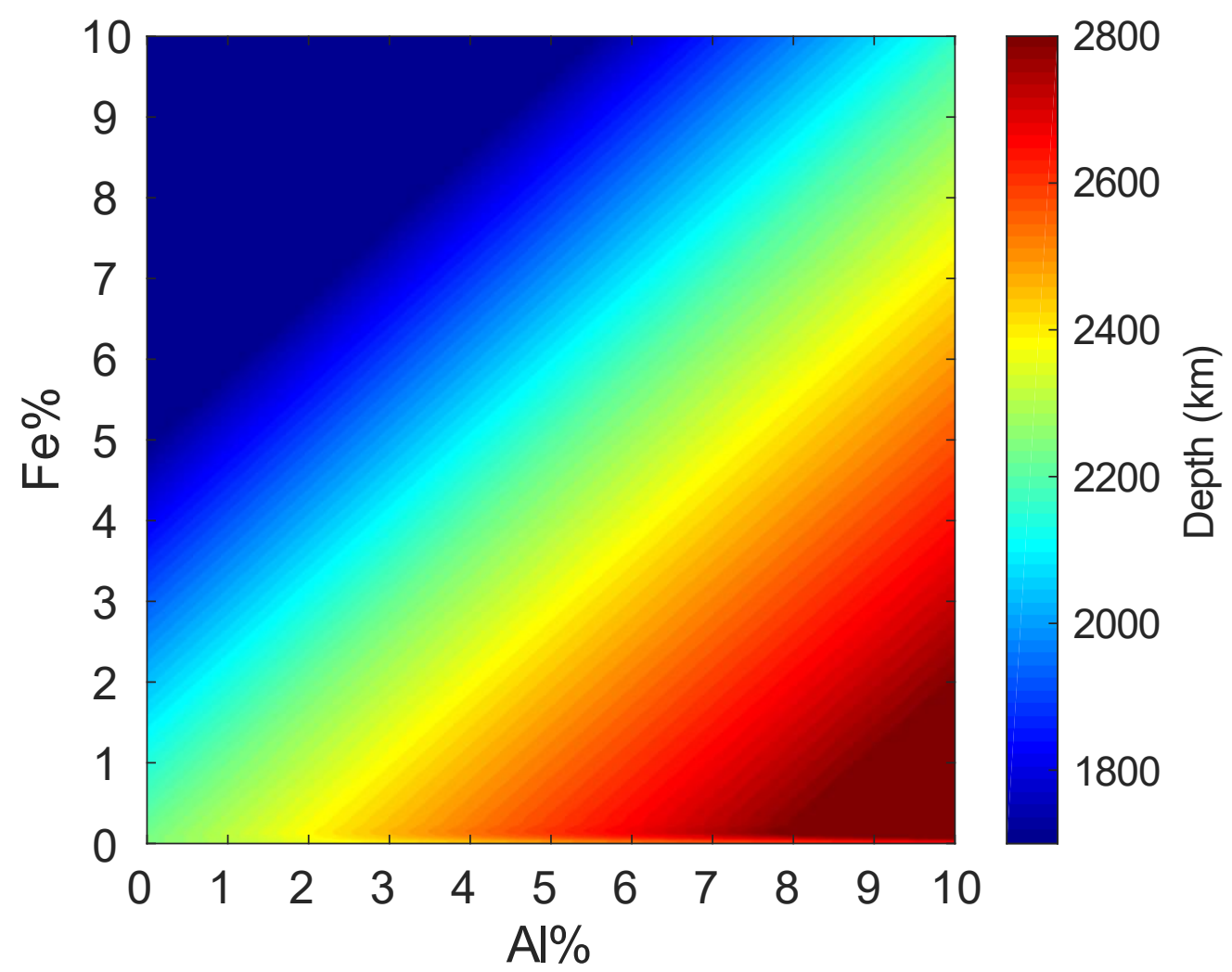

Figure S19: As Figure S16 but for a pyrolytic mixture containining $\mathrm{Ti}(\mathrm{Ca} \%=10, \mathrm{Ti} \%=10)$. 


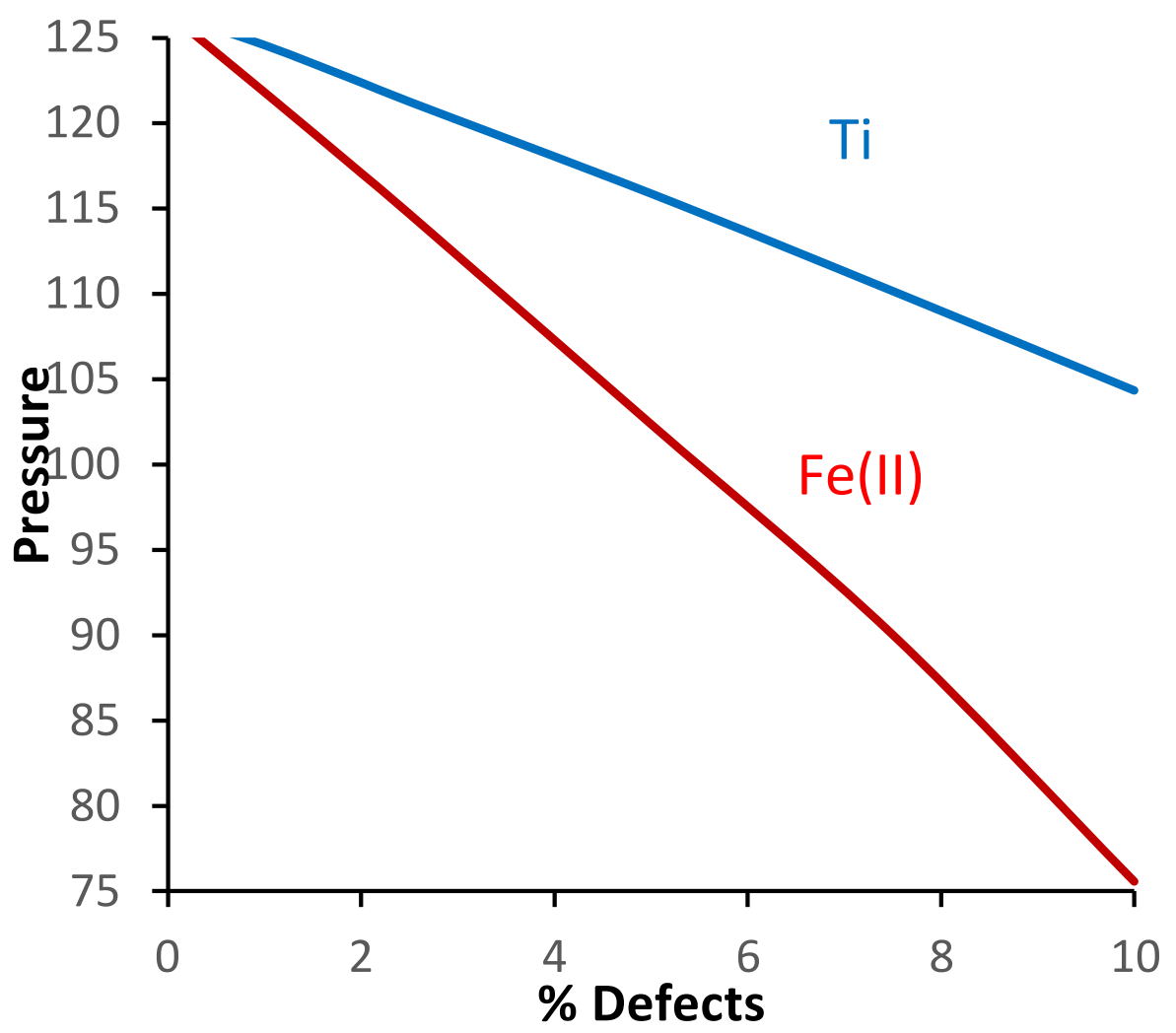

Figure S20: Pressure at which a pyrolytic mixture $(\mathrm{Ca} \%=10)$ with either Fe or Ti reaches the geotherm as a function of Fe or Ti\%. Ti data is projected from our calculations in this paper, Fe data is calculated using our simple model. 


\begin{tabular}{|c|c|c|c|c|c|c|}
\hline & & & $\mathrm{Ti} \%=0$ & 25 & 50 & 100 \\
\hline \multirow{6}{*}{$\mathrm{Ca} \%=50$} & \multirow{3}{*}{$\begin{array}{l}25 \\
\mathrm{GPa}\end{array}$} & $1000 \mathrm{~K}$ & 0.040 & 0.004 & -0.016 & -0.009 \\
\hline & & 2000 & 0.015 & 0.004 & -0.003 & -0.009 \\
\hline & & 3000 & 0.041 & 0.036 & 0.026 & -0.007 \\
\hline & \multirow{3}{*}{$\begin{array}{l}125 \\
\mathrm{GPa}\end{array}$} & 1000 & -0.094 & -0.073 & -0.042 & -0.012 \\
\hline & & 2000 & 0.099 & 0.093 & 0.083 & 0.080 \\
\hline & & 3000 & 0.132 & 0.125 & 0.095 & -0.104 \\
\hline \multirow{6}{*}{$\mathrm{Ca} \%=25$} & & 1000 & -0.033 & -0.032 & -0.032 & -0.033 \\
\hline & 25 & 2000 & 0.011 & 0.003 & -0.002 & -0.007 \\
\hline & & 3000 & 0.031 & 0.027 & 0.020 & -0.005 \\
\hline & & 1000 & -0.033 & -0.022 & -0.023 & -0.018 \\
\hline & 125 & 2000 & 0.074 & 0.070 & 0.063 & 0.060 \\
\hline & & 3000 & 0.099 & 0.094 & 0.071 & -0.078 \\
\hline
\end{tabular}

Table S1 Change in $\mathrm{S}_{\mathrm{Vib}}$ (in meVatom ${ }^{-1} \mathrm{~K}^{-1}$, positive values favour mixing) upon mixing a mixture of Capv and bdg with various values of $\mathrm{Ca} \%$ and $\mathrm{Ti} \%$. 


\begin{tabular}{|c|c|c|c|c|c|c|c|c|c|c|}
\hline & \multicolumn{5}{|c|}{$25 \mathrm{GPa}$} & \multicolumn{5}{|c|}{$125 \mathrm{GPa}$} \\
\hline $\mathrm{Ti} \%=$ & 0 & 12.5 & 25 & 50 & 100 & 0 & 12.5 & 25 & 50 & 100 \\
\hline \multicolumn{11}{|c|}{$1000 \mathrm{~K}$} \\
\hline pbnm & 0.040 & 0.058 & 0.071 & 0.078 & 0.042 & 0.042 & 0.058 & 0.071 & 0.078 & 0.041 \\
\hline pm3m & 0.044 & 0.051 & 0.058 & 0.066 & 0.045 & 0.046 & 0.055 & 0.064 & 0.069 & 0.045 \\
\hline i $4 \mathrm{mcm}$ & 0.037 & 0.057 & 0.069 & 0.076 & 0.035 & 0.037 & 0.052 & 0.066 & 0.071 & 0.042 \\
\hline \multicolumn{11}{|c|}{$2000 \mathrm{~K}$} \\
\hline pbnm & 0.043 & 0.067 & 0.078 & 0.081 & 0.045 & 0.045 & 0.062 & 0.078 & 0.085 & 0.043 \\
\hline pm3m & 0.045 & 0.056 & 0.065 & 0.072 & 0.046 & 0.046 & 0.060 & 0.071 & 0.079 & 0.045 \\
\hline i4mcm & 0.041 & 0.061 & 0.076 & 0.081 & 0.038 & 0.043 & 0.062 & 0.072 & 0.081 & 0.043 \\
\hline \multicolumn{11}{|c|}{$3000 \mathrm{~K}$} \\
\hline pbnm & 0.046 & 0.063 & 0.079 & 0.085 & 0.045 & 0.046 & 0.065 & 0.079 & 0.090 & 0.044 \\
\hline $\mathrm{pm} 3 \mathrm{~m}$ & 0.046 & 0.057 & 0.064 & 0.075 & 0.046 & 0.046 & 0.065 & 0.079 & 0.088 & 0.045 \\
\hline ¡4 $4 \mathrm{mcm}$ & 0.044 & 0.066 & 0.079 & 0.082 & 0.042 & 0.044 & 0.065 & 0.079 & 0.090 & 0.046 \\
\hline Perfect & 0.046 & 0.068 & 0.082 & 0.092 & 0.046 & 0.046 & 0.068 & 0.082 & 0.092 & 0.046 \\
\hline
\end{tabular}

Table S2: List of Sconfig (in meVK ${ }^{-1}$.u..$^{-1}$, positive favours mixing) changes upon mixing Ca-pv and bdg for a $\mathrm{Ca} \%$ of 50 ( $\mathrm{Ca} \%=25$ values are shown in Table S3) and various Ti\% values at different pressures ( 25 and $125 \mathrm{GPa}$ ) and different temperatures $(1000,2000$ and $3000 \mathrm{~K}$ ) as determined by the method presented in the methods section. 3 different phases are presented alongside a hypothetical "perfect" phase where all configurations of Ti:Si and Ca:Mg have the same energy (Boltzmann entropy limit). 


\begin{tabular}{|c|c|c|c|c|c|c|c|c|c|c|}
\hline \multirow[b]{2}{*}{$\mathrm{Ti} \%=$} & \multicolumn{5}{|c|}{$25 \mathrm{GPa}$} & \multicolumn{5}{|c|}{$125 \mathrm{GPa}$} \\
\hline & 0 & 12.5 & 25 & 50 & 100 & 0 & 12.5 & 25 & 50 & 100 \\
\hline \multicolumn{11}{|c|}{$1000 \mathrm{~K}$} \\
\hline pbnm & 0.034 & 0.050 & 0.064 & 0.069 & 0.035 & 0.036 & 0.050 & 0.063 & 0.071 & 0.035 \\
\hline pm3m & 0.035 & 0.046 & 0.054 & 0.059 & 0.036 & 0.034 & 0.046 & 0.053 & 0.060 & 0.032 \\
\hline $\mathrm{i} 4 \mathrm{mcm}$ & 0.032 & 0.050 & 0.063 & 0.067 & 0.032 & 0.028 & 0.046 & 0.058 & 0.066 & 0.034 \\
\hline \multicolumn{11}{|c|}{$2000 \mathrm{~K}$} \\
\hline pbnm & 0.036 & 0.053 & 0.065 & 0.073 & 0.036 & 0.036 & 0.052 & 0.065 & 0.074 & 0.036 \\
\hline pm3m & 0.036 & 0.048 & 0.058 & 0.066 & 0.036 & 0.035 & 0.050 & 0.060 & 0.069 & 0.034 \\
\hline i $4 \mathrm{mcm}$ & 0.034 & 0.053 & 0.068 & 0.072 & 0.034 & 0.032 & 0.052 & 0.063 & 0.072 & 0.036 \\
\hline \multicolumn{11}{|c|}{$3000 \mathrm{~K}$} \\
\hline pbnm & 0.036 & 0.055 & 0.070 & 0.076 & 0.036 & 0.036 & 0.054 & 0.068 & 0.079 & 0.036 \\
\hline pm3m & 0.036 & 0.048 & 0.059 & 0.069 & 0.036 & 0.036 & 0.054 & 0.067 & 0.079 & 0.036 \\
\hline i4mcm & 0.035 & 0.057 & 0.069 & 0.074 & 0.035 & 0.034 & 0.054 & 0.067 & 0.078 & 0.036 \\
\hline Perfect & 0.036 & 0.058 & 0.072 & 0.082 & 0.036 & 0.036 & 0.058 & 0.072 & 0.082 & 0.036 \\
\hline
\end{tabular}

Table S3: As Table S2 but with Ca\%=25 


\begin{tabular}{|l|r|r|r|r|r|r|r|}
\hline & & $\mathrm{Ti} \%=0$ & 5 & 10 & 15 & 20 & 30 \\
\hline \multirow{2}{*}{ Equilibrated } & $25 \mathrm{GPa}$ & 0.2 & 0.9 & 2.2 & 3.6 & 5.4 & 11.2 \\
\cline { 2 - 8 } & 125 & 0.1 & 0.7 & 1.4 & 2.2 & 3.1 & 5.5 \\
\hline $\begin{array}{l}\text { Distributed } \\
\text { (K=1) }\end{array}$ & 25 & 0.2 & 0.9 & 2.2 & 3.8 & 6.1 & 12.2 \\
\cline { 2 - 8 } $\begin{array}{l}\text { CaTiO } \\
\text { source } \\
\text { (K=1000) }\end{array}$ & 125 & 0.1 & 1.5 & 3.8 & 8.3 & 24.6 & 50.0 \\
\cline { 2 - 8 } & 25 & 0.2 & 0.9 & 2.2 & 3.6 & 5.4 & 12.3 \\
\hline $\begin{array}{l}\mathrm{MgTiO}_{3} \\
\text { source } \\
\text { (K=0.00001) }\end{array}$ & 125 & 0.1 & 1.7 & 5.2 & 50.0 & 50.0 & 50.0 \\
\hline \multirow{2}{*}{$\mathrm{K}=2$} & 25 & 0.2 & 8.6 & 19.1 & 32.2 & 49.3 & 50.0 \\
\cline { 2 - 8 } & 125 & 0.1 & 0.7 & 1.4 & 2.2 & 3.1 & 5.5 \\
\hline \multirow{2}{*}{$\mathrm{K}=5$} & 25 & 0.2 & 0.9 & 2.3 & 3.8 & 5.6 & 12.2 \\
\cline { 2 - 8 } & 125 & 0.1 & 1.6 & 4.8 & 50.0 & 50.0 & 50.0 \\
\hline
\end{tabular}

Table S4: Mg solubility (\%) in Ca-pv as a function of pressure, Ti\% and $\mathrm{K}$ at $2000 \mathrm{~K}$. 


\begin{tabular}{|c|c|c|c|c|c|c|c|c|c|c|c|c|c|c|c|}
\hline \multirow[b]{3}{*}{ Element } & \multirow[b]{3}{*}{ Site } & \multirow[b]{3}{*}{$\Delta \mathrm{E}$} & & \multicolumn{6}{|c|}{ Basaltic $\mathrm{Ca} \%=50$} & \multicolumn{6}{|c|}{ Pyrolytic Ca\%=10 } \\
\hline & & & & \multicolumn{3}{|c|}{$1 \mathrm{Ti} \%$} & \multicolumn{3}{|c|}{$10 \mathrm{Ti} \%$} & \multicolumn{3}{|c|}{$1 \mathrm{Ti} \%$} & \multicolumn{3}{|c|}{$10 \mathrm{Ti} \%$} \\
\hline & & & $\mathrm{K}$ & 0.1 & 1 & 10 & 0.1 & 1 & 10 & 0.1 & 1 & 10 & 0.1 & 1 & 10 \\
\hline $2 \mathrm{H}$ & A & 0.11 & 0 & -1 & -7 & -73 & 0 & -5 & -50 & 2 & 16 & 143 & 1 & 14 & 128 \\
\hline $\mathrm{He}$ & Int & -0.27 & 1 & -4 & -44 & -439 & -4 & -40 & -409 & -21 & -214 & -1805 & -15 & -150 & -1598 \\
\hline $\mathrm{Ne}$ & Int & -0.86 & 1 & -10 & -101 & -1072 & -9 & -95 & -1074 & -36 & -362 & -3528 & -26 & -271 & -2775 \\
\hline $\mathrm{Li}(\mathrm{I})$ & A & 0.28 & 0 & 1 & 9 & 80 & 1 & 11 & 96 & 6 & 56 & 508 & 5 & 46 & 402 \\
\hline $\mathrm{Na}(\mathrm{I})$ & A & -0.42 & 0 & -6 & -59 & -596 & -5 & -54 & -567 & -12 & -117 & -1356 & -9 & -90 & -1304 \\
\hline $\mathrm{K}(\mathrm{I})$ & A & -0.10 & 1 & -3 & -27 & -272 & -2 & -24 & -243 & -29 & -279 & -1969 & -19 & -187 & -1655 \\
\hline $\mathrm{Be}(\mathrm{II})$ & A & 0.18 & 0 & 0 & 0 & -10 & 0 & 2 & 10 & 3 & 32 & 296 & 3 & 27 & 244 \\
\hline $\mathrm{Cu}(\mathrm{II})$ & A & -0.14 & 0 & -3 & -32 & -318 & -3 & -29 & -288 & -5 & -48 & -493 & -4 & -36 & -385 \\
\hline $\mathrm{Ni}(\mathrm{II})$ & A & -0.39 & 0 & -6 & -56 & -562 & -5 & -51 & -532 & -11 & -108 & -1237 & -8 & -84 & -1134 \\
\hline $\mathrm{Zn}(\mathrm{II})$ & A & -0.13 & 0 & -3 & -30 & -301 & -3 & -27 & -272 & -4 & -43 & -447 & -3 & -32 & -345 \\
\hline $\mathrm{Co}(\mathrm{II})$ & A & -0.42 & 0 & -6 & -58 & -593 & -5 & -54 & -564 & -11 & -116 & -1344 & -9 & -90 & -1285 \\
\hline $\mathrm{Fe}(\mathrm{II})$ & A & -0.31 & 0 & -5 & -48 & -483 & -4 & -44 & -452 & -9 & -89 & -978 & -7 & -68 & -837 \\
\hline $\mathrm{Fe}(\mathrm{II}) \mathrm{HS}$ & A & -0.20 & 0 & -4 & -37 & -371 & -3 & -34 & -341 & -6 & -61 & -643 & -5 & -46 & -516 \\
\hline $\mathrm{V}(\mathrm{II})$ & $\mathrm{A}$ & -0.26 & 0 & -4 & -43 & -434 & -4 & -40 & -404 & -8 & -77 & -829 & -6 & -59 & -688 \\
\hline $\mathrm{Cr}(\mathrm{II})$ & A & 0.09 & 0 & -1 & -10 & -98 & -1 & -7 & -74 & 1 & 9 & 82 & 1 & 9 & 81 \\
\hline $\mathrm{Mn}(\mathrm{II})$ & A & 0.25 & 0 & 1 & 6 & 54 & 1 & 8 & 71 & 5 & 49 & 447 & 4 & 40 & 357 \\
\hline $\mathrm{Sc}(\mathrm{II})$ & A & -0.22 & 1 & -4 & -39 & -391 & -4 & -36 & -361 & -32 & -309 & -2160 & -21 & -212 & -1905 \\
\hline $\mathrm{Sc}(\mathrm{II}) \mathrm{HS}$ & A & -0.26 & 1 & -4 & -43 & -436 & -4 & -40 & -405 & -33 & -319 & -2230 & -22 & -221 & -2007 \\
\hline $\mathrm{Sr}(\mathrm{II})$ & $\mathrm{A}$ & 0.51 & 1 & 3 & 31 & 280 & 3 & 31 & 284 & -14 & -135 & -1104 & -7 & -71 & -726 \\
\hline $\mathrm{Ba}(\mathrm{II})$ & A & 0.98 & 1 & 8 & 75 & 670 & 8 & 74 & 644 & -2 & -27 & -504 & 2 & 14 & -179 \\
\hline $\mathrm{B}(\mathrm{III})$ & $\mathrm{AB}$ & 0.62 & 1 & 19 & 147 & 968 & 17 & 130 & 844 & 14 & 138 & 1171 & 11 & 108 & 880 \\
\hline $\mathrm{Al}(\mathrm{III})$ & $\mathrm{AB}$ & 0.24 & 0 & 16 & 110 & 614 & 13 & 94 & 522 & 5 & 45 & 416 & 4 & 37 & 333 \\
\hline $\mathrm{Cr}(\mathrm{III})$ & $A B$ & 0.03 & 0 & 14 & 90 & 418 & 12 & 75 & 342 & 0 & -4 & -37 & 0 & -1 & -12 \\
\hline $\mathrm{Cr}(\mathrm{III}) \mathrm{Hs}$ & $A B$ & 0.14 & 1 & 15 & 100 & 523 & 13 & 85 & 438 & 2 & 22 & 209 & 2 & 19 & 178 \\
\hline $\mathrm{Ga}(\mathrm{III})$ & $A B$ & 0.13 & 0 & 15 & 99 & 510 & 12 & 84 & 426 & 2 & 19 & 178 & 2 & 17 & 155 \\
\hline $\mathrm{Fe}(\mathrm{III})$ & $\mathrm{AB}$ & 0.79 & 0 & 21 & 163 & 1112 & 19 & 145 & 973 & 18 & 177 & 1462 & 14 & 138 & 1085 \\
\hline $\mathrm{Fe}(\mathrm{III}) \mathrm{HS}$ & $A B$ & 0.01 & 0 & 13 & 88 & 398 & 11 & 74 & 323 & -1 & -9 & -86 & 0 & -5 & -51 \\
\hline $\mathrm{Sc}(\mathrm{III})$ & $\mathrm{AB}$ & -0.20 & 0 & 11 & 68 & 184 & 9 & 54 & 121 & -6 & -60 & -634 & -5 & -46 & -508 \\
\hline $\ln (I I I)$ & $\mathrm{AB}$ & -0.07 & 0 & 13 & 80 & 312 & 11 & 66 & 242 & -3 & -30 & -300 & -2 & -22 & -223 \\
\hline FeAl & $A B$ & 0.02 & 0 & 14 & 89 & 407 & 11 & 74 & 331 & -1 & -6 & -65 & 0 & -3 & -34 \\
\hline C $4+$ & B & -0.51 & 1 & 7 & 21 & -337 & -202 & -203 & -623 & -14 & -139 & -1702 & -11 & -108 & -1708 \\
\hline
\end{tabular}




\begin{tabular}{|l|l|r|r|r|r|r|r|r|r|r|r|r|r|r|r|}
\hline S 4+ & B & -0.45 & 0 & 7 & 27 & -275 & -202 & -198 & -562 & -12 & -125 & -1474 & -9 & -97 & -1529 \\
\hline Ge4+ & B & -0.17 & 0 & 10 & 55 & 28 & -199 & -171 & -269 & -5 & -53 & -551 & -4 & -40 & -436 \\
\hline Sn4+ & B & -0.51 & 0 & 7 & 21 & -344 & -202 & -204 & -630 & -14 & -141 & -1730 & -11 & -109 & -1733 \\
\hline Ti4+ & B & -0.07 & 1 & 11 & 64 & 122 & -198 & -163 & -181 & -3 & -30 & -306 & -2 & -22 & -228 \\
\hline
\end{tabular}

Table S5: Effect of various elements on $\mathrm{T}_{\text {mix }}$ at $25 \mathrm{GPa}$ with $\mathrm{Ca} \%=50$ or $\mathrm{Ca} \%=10$ and either $\mathrm{Ti} \%=1$ or 10 . Columns are name of the element, site at which that element was placed ( $\mathrm{A}=\mathrm{Mg}$ site, $\mathrm{B}=\mathrm{Si}$ site, $\mathrm{AB}=1$ element at each, Int=interstitial), the change in $\Delta \mathrm{H}_{\text {mix }}$ in $\mathrm{eV}$ from placing one defect element, proportion of this element in the Ca-pv before mixing ( 1 is all in Ca-pv, 0 is all in bdg), change in $\mathrm{T}_{\text {mix }}(\mathrm{K})$ with various amounts of element (in atomic $\%$ of bridgmanite). All elements are non-spin polarised except those labelled HS which were run with their standard high spin configuration. $2 \mathrm{H}$ represents a water molecule where a $\mathrm{Mg}$ has been replaced with 2 Hydrogens in the vacancy. Fe-Al represents a high spin ferric iron replacing a $\mathrm{Mg}$ and an $\mathrm{Al}$ replacing a $\mathrm{Si}$. 


\begin{tabular}{|c|c|c|c|c|c|c|c|c|c|c|c|c|c|c|c|}
\hline \multirow[b]{3}{*}{ Element } & \multirow[b]{3}{*}{ Site } & \multirow[b]{3}{*}{$\Delta \mathrm{E}$} & & \multicolumn{6}{|c|}{ Basaltic $\mathrm{Ca} \%=50$} & \multicolumn{6}{|c|}{ Pyrolytic Ca\%=10 } \\
\hline & & & & \multicolumn{3}{|c|}{$1 \mathrm{Ti} \%$} & \multicolumn{3}{|c|}{10 Ti\% } & \multicolumn{3}{|c|}{$1 \mathrm{Ti} \%$} & \multicolumn{3}{|c|}{10 Ti\% } \\
\hline & & & $\mathrm{K}$ & 0.1 & 1 & 10 & 0.1 & 1 & 10 & 0.1 & 1 & 10 & 0.1 & 1 & \\
\hline $2 \mathrm{H}$ & A & 0.95 & 0 & 4 & 43 & 403 & 5 & 45 & 417 & 14 & 136 & 1240 & 14 & 138 & $12:$ \\
\hline $\mathrm{He}$ & Int & 0.07 & 1 & 0 & -5 & -46 & 0 & -4 & -43 & -7 & -66 & -592 & -6 & -59 & -5 \\
\hline $\mathrm{Ne}$ & Int & -0.90 & 1 & -6 & -58 & -593 & -6 & -60 & -616 & -21 & -211 & -1821 & -21 & -206 & -18 \\
\hline $\mathrm{Li}(\mathrm{I})$ & A & 0.76 & 0 & 3 & 33 & 309 & 3 & 34 & 321 & 11 & 108 & 995 & 11 & 109 & 9 \\
\hline $\mathrm{Na}(\mathrm{I})$ & A & -0.53 & 0 & -4 & -38 & -379 & -4 & -38 & -390 & -9 & -87 & -895 & -9 & -87 & -9 \\
\hline $\mathrm{K}(\mathrm{I})$ & $\mathrm{A}$ & -0.16 & 1 & -2 & -17 & -174 & -2 & -18 & -176 & -16 & -156 & -1242 & -15 & -145 & -11 \\
\hline $\mathrm{Be}(\mathrm{II})$ & $\mathrm{A}$ & 1.17 & 0 & 6 & 55 & 514 & 6 & 58 & 529 & 17 & 169 & 1523 & 17 & 171 & 15 \\
\hline $\mathrm{Cu}(\mathrm{II})$ & $\mathrm{A}$ & -0.38 & 0 & -3 & -29 & -296 & -3 & -30 & -302 & -6 & -64 & -653 & -6 & -64 & -6 \\
\hline $\mathrm{Ni}(\mathrm{II})$ & A & -0.47 & 0 & -3 & -34 & -347 & -4 & -35 & -356 & -8 & -78 & -801 & -8 & -78 & -8 \\
\hline $\mathrm{Zn}(\mathrm{II})$ & A & -0.43 & 0 & -3 & -32 & -322 & -3 & -33 & -330 & -7 & -71 & -731 & -7 & -72 & -7 \\
\hline $\mathrm{Co}(\mathrm{II})$ & $\mathrm{A}$ & -0.55 & 0 & -4 & -39 & -392 & -4 & -40 & -404 & -9 & -90 & -934 & -9 & -91 & -9 \\
\hline $\mathrm{Fe}(\mathrm{II})$ & A & -0.48 & 0 & -4 & -35 & -354 & -4 & -36 & -363 & -8 & -80 & -822 & -8 & -80 & -8 \\
\hline $\mathrm{Fe}(\mathrm{II}) \mathrm{HS}$ & A & -0.47 & 0 & -3 & -34 & -344 & -3 & -35 & -353 & -8 & -77 & -793 & -8 & -78 & -8 \\
\hline $\mathrm{V}(\mathrm{II})$ & A & -0.45 & 0 & -3 & -33 & -336 & -3 & -34 & -345 & -7 & -75 & -771 & -8 & -75 & -7 \\
\hline $\mathrm{Cr}(\mathrm{II})$ & A & -0.23 & 0 & -2 & -21 & -213 & -2 & -22 & -217 & -4 & -42 & -419 & -4 & -41 & -4 \\
\hline $\mathrm{Mn}(\mathrm{II})$ & A & 0.14 & 0 & 0 & -1 & -10 & 0 & 0 & -5 & 2 & 15 & 146 & 2 & 16 & $1:$ \\
\hline $\mathrm{Sc}(\mathrm{II})$ & $\mathrm{A}$ & -0.07 & 1 & -1 & -13 & -127 & -1 & -13 & -127 & -15 & -143 & -1156 & -14 & -132 & -10 \\
\hline $\mathrm{Sc}(\mathrm{II}) \mathrm{HS}$ & A & -0.60 & 1 & -4 & -41 & -419 & -4 & -42 & -432 & -23 & -220 & -1678 & -22 & -210 & -160 \\
\hline $\operatorname{Sr}(I I)$ & $\mathrm{A}$ & 0.70 & 1 & 3 & 30 & 278 & 3 & 31 & 290 & -3 & -31 & -427 & -2 & -19 & -3 \\
\hline $\mathrm{Ba}(\mathrm{II})$ & $\mathrm{A}$ & 1.38 & 1 & 7 & 66 & 612 & 7 & 69 & 629 & 7 & 66 & 182 & 9 & 79 & $2 \varepsilon$ \\
\hline $\mathrm{B}(\mathrm{III})$ & $A B$ & -0.77 & 1 & 2 & -2 & -283 & 2 & -5 & -310 & -12 & -124 & -1317 & -12 & -126 & -13 \\
\hline $\mathrm{Al}(\mathrm{III})$ & $A B$ & 0.43 & 0 & 9 & 65 & 418 & 9 & 64 & 415 & 6 & 59 & 561 & 6 & 60 & 56 \\
\hline $\mathrm{Cr}(\mathrm{III})$ & $A B$ & 0.07 & 0 & 7 & 45 & 219 & 7 & 44 & 212 & 1 & 5 & 48 & 1 & 6 & \\
\hline $\mathrm{Cr}(\mathrm{III}) \mathrm{Hs}$ & $A B$ & -0.15 & 1 & 5 & 32 & 91 & 5 & 31 & 80 & -3 & -29 & -290 & -3 & -29 & $-2 \varepsilon$ \\
\hline $\mathrm{Ga}(\mathrm{III})$ & $A B$ & 0.34 & 0 & 8 & 60 & 366 & 8 & 59 & 362 & 5 & 45 & 428 & 5 & 46 & 4 \\
\hline $\mathrm{Fe}(\mathrm{III})$ & $A B$ & 1.03 & 0 & 12 & 98 & 735 & 12 & 98 & 737 & 15 & 149 & 1353 & 15 & 151 & 13 \\
\hline $\mathrm{Fe}(\mathrm{III}) \mathrm{HS}$ & $A B$ & 0.18 & 0 & 7 & 50 & 276 & 7 & 50 & 270 & 2 & 20 & 195 & 2 & 21 & 20 \\
\hline $\mathrm{Sc}(\mathrm{III})$ & $A B$ & -0.07 & 0 & 6 & 37 & 138 & 6 & 36 & 128 & -2 & -17 & -165 & -2 & -16 & -16 \\
\hline $\ln (I I I)$ & $A B$ & 0.17 & 0 & 7 & 50 & 273 & 7 & 49 & 267 & 2 & 20 & 188 & 2 & 20 & 15 \\
\hline $\mathrm{FeAl}$ & $A B$ & 0.00 & 0 & 6 & 41 & 175 & 6 & 39 & 166 & -1 & -7 & -68 & -1 & -6 & $\pi$ \\
\hline C 4+ & B & -0.08 & 1 & 5 & 29 & 43 & -110 & -91 & -110 & -2 & -19 & -191 & -2 & -19 & -18 \\
\hline
\end{tabular}




\begin{tabular}{|l|l|r|r|r|r|r|r|r|r|r|r|r|r|r|r|}
\hline S 4+ & B & -0.21 & 0 & 4 & 22 & -30 & -111 & -98 & -184 & -4 & -39 & -389 & -4 & -38 & -39 \\
\hline Ge4+ & B & -0.09 & 0 & 5 & 28 & 39 & -110 & -92 & -115 & -2 & -20 & -203 & -2 & -20 & -26 \\
\hline Sn4+ & B & -0.38 & 0 & 4 & 12 & -126 & -112 & -108 & -281 & -6 & -64 & -653 & -6 & -64 & -66 \\
\hline Ti4+ & B & -0.26 & 1 & 4 & 19 & -55 & -111 & -101 & -209 & -5 & -45 & -456 & -4 & -45 & -45 \\
\hline
\end{tabular}

Table S6: As Table S5 but at $125 \mathrm{GPa}$. 


\begin{tabular}{|l|r|r|r|r|r|r|r|r|r|r|r|r|}
\hline & \multicolumn{4}{|c|}{ Pyrolytic Ca\%=10 } & \multicolumn{6}{c|}{ Basaltic Ca\%=50 } \\
\cline { 2 - 14 } & \multicolumn{4}{|c|}{ Ti\%=1 } & \multicolumn{3}{|c|}{ Ti\%=10 } & \multicolumn{3}{c|}{ Ti\%=1 } & \multicolumn{3}{|c|}{ Ti\%=10 } \\
\cline { 2 - 13 } & $0.1 \%$ & 1 & 10 & 0.1 & 1 & 10 & 0.1 & 1 & 10 & 0.1 & 1 & 10 \\
\hline $\mathrm{Fe}^{2+}$ & -6 & -61 & -643 & -5 & -46 & -516 & -4 & -37 & -371 & -3 & -34 & -341 \\
\hline $\mathrm{Fe}^{3+}-\mathrm{Fe}^{3+}$ & -1 & -9 & -86 & 0 & -5 & -51 & 13 & 88 & 398 & 11 & 74 & 323 \\
\hline $\mathrm{Fe}^{3+}-\mathrm{Al}^{3+}$ & -1 & -6 & -65 & 0 & -3 & -34 & 14 & 89 & 407 & 11 & 74 & 331 \\
\hline $\mathrm{Al}^{3+}-\mathrm{Al}^{3+}$ & 5 & 45 & 416 & 4 & 37 & 333 & 16 & 110 & 614 & 13 & 94 & 522 \\
\hline
\end{tabular}

Table S7: As Table 3 but at $25 \mathrm{GPa}$. 